Rodrigo Antonio Faccioli

\title{
Algoritmo Híbrido Multi-Objetivo Para Predição de Estrutura Terciária de Proteínas
}

Dissertação apresentada à Escola de Engenharia de São Carlos da Universidade de São Paulo, como parte dos requisitos para obtenção do título de Mestre em Engenharia Elétrica

Área de Concentração: Sistemas Dinâmicos Orientador: Prof. Dr. Ivan Nunes da Silva 
Epígrafe

Porque dele e por meio dele, e para ele, são todas as coisas. Glória, pois, a ele eternamente. Amém.

Romanos 11, 36 
Dedicatória

À Deus, meus pais, a minha namorada Michelle, meu avô Silvio e meus outros avós: Ana Maria, Maria e Francisco (in memória). 
Gostaria de agradecer a Deus por sempre me presentear com uma família maravilhosa e com pessoas amigas ao meu rendor, as quais contribuiram e muito para a elaboração deste trabalho. Procurarei agradecê-las com singelas palavras.

Agradeço à toda minha família pelo companheirismo, paciência e interesse em saber o andamento da minha pesquisa. À minha irmã, Renata, pela intensa atenção no andamento dos meus estudos. Ressalto meus sinceros agradecimentos a duas pessoas maravilhosas, as quais sinto muito orgulho em poder dizer: meus pais, Cláudio e Terezinha. Tenho que agradecê-los não só pelo apoio financeiro e incentivos em meus estudos, mas principalmente por toda dedicação e atenção que há mais de 25 anos vem apresentando à minha pessoa.

À Michelle, uma mulher encantadora onde posso afirmar, sem sombra de dúvida, que sou uma pessoa felizarda em poder estar compartilhando minha vida com ela. Obrigado por tudo, meu amor.

Ao meu orientador prof. Dr. Ivan Nunes da Silva pelos ensinamentos não só em sistemas inteligentes ou mesmo na escrita deste trabalho, mas também, nas lições de perseverança, amizade e disciplina.

Ao prof. Dr. Alexandre Cláudio Botazzo Delbem, pelos ricos ensinamentos em algoritmos evolutivos e proteínas. Não podendo deixar de agradecê-lo, em especial, pela oportunidade em me permitir trabalhar em parceiria com seu laboratório na investigação do problema de estrutura terciária de proteínas.

À MSc. Telma Woerle de Lima, pela paciência nos ensinamentos, pelo companheirismo nas pesquisas e, acima de tudo, por sua amizade.

Todos meus amigos do ICMC, onde pude compartilhar minhas pesquisas, além de ter amigos pra diversas outras ocasiões. Em especial, quero agradecer toda a ajuda do MSc. Bruno Feres na elaboração deste trabalho, principalmente nos ensinamentos no Latex.

Aos meus amigos do Laips onde tive a oportunidade de vivenciar o significado da palavra equipe. Em especial, gostaria deixar registrado meus agradecimentos ao meu 
grande amigo Marcelo Suetake, o qual ajudou não só na revisão deste trabalho, nas imagens do mesmo, mas também em valiosos ensinamentos e, em hipótese nenhuma posso deixar não evidenciar o seu companheirismo.

Ao meu grande amigo Evandro Alves da Silva onde tenho o prazer de poder contar com seu companheirismo em todas as horas, além da sua paciência em poder dividir o apartamento.

Agradeço a todos meus professores da graduação, os quais pude encontrar uma referência para alavancar conhecimentos em computação, além de ajuda para poder estar cursando o mestrado. Dentre eles, tenho que destacar a contribuição de dois: MSc. Maurício Escarpinati e o MSc. Paulo Eduardo Ambrósio. Além de se tornarem meus amigos, eles merecem um especial agradecimento por tudo que fizeram, fazem e que farão, com certeza, no intuito de colaborar com a minha vida pessoal e profissional.

Tenho também que agradecer a empresa Destinform, a qual trabalhei durante todo o período da minha graduação e no início da pós-graduação. Agradecer pelos incentivos em meus estudos e por confiar em meu trabalho. Não posso deixar de citar meus sinceros votos de agradecimentos a todos que trabalharam comigo, dentre eles: Fabrício, Márcio, Éderson, Daniel, Glauce, Andréa e Antonio Postigo. Em especial, ao Gustavo Postigo, onde pude encontrar além de um chefe, uma pessoa ímpar.

Não posso deixar passar, também, meus agradecimentos a empresa 3WT, a qual pude encontrar pessoas que compartilham conhecimentos e amizades.

Aos funcionários desta instituição, mas em especial a secretaria da pós-graduação da EESC. Não podendo deixar de ressaltar, meus sinceros votos aos segurança em que sempre estão dispostos a nos dar atenção, detre eles: Roberto, Jesus, Tiago e Weber.

Enfim, agradeço todos que contribuíram na elaboração deste trabalho, mas por um esquecimento não constam seus nomes. Mas mesmo assim, sua contribuição foi de igual significância, sendo assim, além dos meus agradecimentos, fica registrado minhas sinceras desculpas. 


\section{Resumo}

Faccioli, R. A. Algoritmo Híbrido Multi-Objetivo Para Predição de Estrutura Terciária de Proteínas. 2007. Dissertação (Mestrado) - Escola de Engenharia de São Carlos, Universidade de São Paulo, São Carlos, 2007.

Muitos problemas de otimização multi-objetivo utilizam os algoritmos evolutivos para encontrar as melhores soluções. Muitos desses algoritmos empregam as fronteiras de $\mathrm{Pa}$ reto como estratégia para obter tais soluções. Entretando, conforme relatado na literatura, há a limitação da fronteira para problemas com até três objetivos, podendo tornar seu emprego insatisfatório para os problemas com quatro ou mais objetivos. Além disso, as propostas apresentadas muitas vezes eliminam o emprego dos algoritmos evolutivos, os quais utilizam tais fronteiras. Entretanto, as características dos algoritmos evolutivos os qualificam para ser empregados em problemas de otimização, como já vem sendo difundido pela literatura, evitando eliminá-lo por causa da limitação das fronteiras de Pareto.

Assim sendo, neste trabalho se buscou eliminar as fronteiras de Pareto e para isso utilizou a lógica Fuzzy, mantendo-se assim o emprego dos algoritmos evolutivos. O problema escolhido para investigar essa substituição foi o problema de predição de estrutura terciária de proteínas, pois além de se encontrar em aberto é de suma relevância para a área de bioinformática.

Palavras-Chave: Bioinformática, Algoritmos Evolutivos, Lógica Fuzzy, folding, Multiobjetivo, fronteiras de Pareto. 


\section{Abstract}

Faccioli, R. A. Multi-objective Approach To Protein Tertiary Structure Prediction. 2007. Thesis (Master) - Sao Carlos Engineering School, Univerty of Sao Paulo, Sao Carlos, 2007.

Several multi-objective optimization problems utilize evolutionary algorithms to find the best solution. Some of these algoritms make use of the Pareto front as a strategy to find these solutions. However, according to the literature, the Pareto front limitation for problems with up to three objectives can make its employment unsatisfactory in problems with four or more objectives. Moreover, many authors, in most cases, propose to remove the evolutionay algorithms because of Pareto front limitation. Nevertheless, characteristics of evolutionay algorithms qualify them to be employed in optmization problems, as it has being spread out by literature, preventing to eliminate it because the Pareto front elimination.

Thus being, this work investigated to remove the Pareto front and for this utilized the Fuzzy logic, remaining itself thus the employ of evolutionary algorithms. The choice problem to investigate this remove was the protein tertiary structure prediction, because it is a open problem and extremely relevance to bioinformatic area.

Keywords: Bioinformatic, Evolutionary Algorithms, Fuzzy Logic, folding, Multiobjetive, Pareto front. 


\section{Lista de Figuras}

2.1 Estrutura básica de um aminoácido. . . . . . . . . . . . . . . . . . . 10

2.2 Classificação dos vinte aminoácidos padrões encontrados em proteínas. . . 12

2.3 Processo de formação de uma ligação peptídica. . . . . . . . . . . . . . . 13

2.4 Representação dos átomos no mesmo plano (de Lima, 2006). . . . . . . . . 14

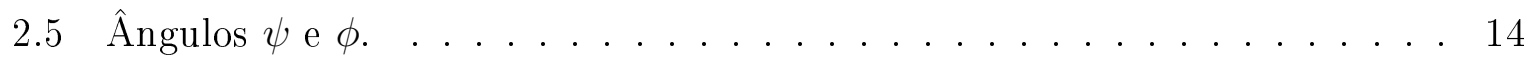

2.6 Mapa de Ramachandran. . . . . . . . . . . . . . . . . . . . . 15

2.7 Estrutura Hélice $\alpha$ (Branden e Tooze, 1991) . . . . . . . . . . . . . . 17

2.8 Estrutura Folhas $\beta$ (Branden e Tooze, 1991) . . . . . . . . . . . . . 17

2.9 Estrutura Voltas (Lodish et al., 2004). . . . . . . . . . . . . . . 18

2.10 Estrutura terciária de uma proteína $(\mathrm{PDB} 1 \mathrm{CCN}) . \ldots \ldots \ldots$

2.11 Gráfico da função de energia potencial de comprimento de ligação. . . . . . 27

2.12 Gráfico da função de energia potencial de torsão. . . . . . . . . . . . . . . . 29

2.13 Gráfico da função de energia eletrostática. . . . . . . . . . . . . . . . 31

2.14 Gráfico da função de van der Waals na forma padrão. . . . . . . . . . . . . 32

3.1 Exemplo do multi-objetivo (Ticona, 2003) . . . . . . . . . . 37

3.2 Esquema do Modelo NSGA-II (Deb, 2001) . . . . . . . . . . . . . 48

3.3 Cálculo da distância de multidão no NSGA-II (Deb, 2001) . . . . . . . . . . 49

3.4 Exemplo do sistema Fuzzy utilizado em Battistella e Cechin (2004) . . . . 51 
4.1 Uma representação dos conjuntos fuzzy. . . . . . . . . . . . . . . . . 63

4.2 Funções fuzzy ativadas pelos fitness. . . . . . . . . . . . . . 63

4.3 Processo da Inferência fuzzy . . . . . . . . . . . . . . . . . . . 64

4.4 Região fuzzy de saída . . . . . . . . . . . . . . . . . . . . . . 64

5.1 Representação dos quatro conjuntos Fuzzy proposto ajustado pelo ANFIS. 72

5.2 Superfície entre os fitness $F_{1} o b j_{3}$ e $F_{3} o b j_{3}$ para o caso com três objetivos. . 74

5.3 Superfície entre os fitness $F_{2} o b j_{3}$ e $F_{3} o b j_{3}$ para o caso com três objetivos. . 74

5.4 Superfície entre os fitness $F_{1} o b j_{4}$ e $F_{2} o b j_{4}$ para o caso com quatro objetivos. 75

5.5 Superfície entre os fitness $F_{2} O b j_{4}$ e $F_{3} o b j_{4}$ para o caso com quatro objetivos. 75

5.6 Superfície entre os fitness $F_{3} o b j_{4}$ e $F_{4} o b j_{4}$ para o caso com quatro objetivos. 76

5.7 Estruturas terciárias da proteína 1JXT com três objetivos. . . . . . . . . . 81

5.8 Estruturas terciárias da proteína 1AB1 com três objetivos. . . . . . . . . . 82

5.9 Estruturas terciárias da proteína 1JXT com quatro objetivos. . . . . . . . 83

5.10 Estruturas terciárias da proteína 1AB1 com quatro objetivos. . . . . . . . . 84

A.1 Esquema dos componentes constituíntes do Toolbox Fuzzy Logic do Matlab. 100 A.2 Tela inicial do editor FIS. . . . . . . . . . . . . . . . . . . . . 101

A.3 Tela inicial do editor das funções de pertinência. . . . . . . . . . . . . . . 102

A.4 Editor de regras ilustrando regras do sistema proposto com quatro entradas. 103

A.5 Visualização das regras do sistema proposto com quatro entradas. . . . . . 104

A.6 Visualizador de superfícies. . . . . . . . . . . . . . . . . . . . . . . 105

A.7 Tela inicial do editor GUI ANFIS. . . . . . . . . . . . . . . 106

A.8 Editor para determinar parâmetros essenciais. . . . . . . . . . . . 107

A.9 Estrutura utilizada pelo ANFIS. . . . . . . . . . . . . . . . 108 


\section{Lista de Tabelas}

2.1 Relação dos vinte aminoácidos padrões e respectivos mnemônicos. . . . . . . 11

3.1 Alguns exemplos de modelos de AEMO. . . . . . . . . . . . . . . . 47

4.1 Valores hipotéticos de Autoridade de Aptidão. . . . . . . . . . . . . . . 65

5.1 Funções de Energia e seu símbolo para representar na Função de Avaliação. 68

5.2 Quantidade de Regras Fuzzy para cada treinamento. . . . . . . . . . . . . 72

5.3 Estrutura primária das proteínas preditas e a utilizada no treinamento. . . 76

$5.4 D M E$ entre as proteínas no teste com três objetivos. . . . . . . . . . . 78

$5.5 D M E$ entre as proteínas no teste com quatro objetivos. . . . . . . . . 78

5.6 Custo computacional entre as proteínas no teste com três objetivos. . . . . 79

5.7 Custo computacional entre as proteínas no teste com quatro objetivos. . . 80 


\section{Lista de Quadros}

3.1 Pseudo-código de um AG típico. . . . . . . . . . . . . . . . . . . . 40

3.2 Cálculo da distância de multidão no NSGA-II. . . . . . . . . . . . . . . . . 49

4.1 Pseudo-código do algoritmo proposto. . . . . . . . . . . . . . 60

4.2 Exemplo das regras fuzzy . . . . . . . . . . . . . . . . 63 


\section{Lista de Abreviaturas e Siglas}

AE Algoritmo Evolutivo

AEMO Algoritmos Evolutivo Multi-objetivo

AG Algoritmo Genético

CE Computação Evolutiva

DEP Determinação da Estrutura da Proteína

GFA General Fuzzy Automata

HMM Hidden Markov Model

PDB Protein Data Bank

PSP Predição de Estrutura de Proteína

POMO Problemas de Otimização Multi-Objetivo

TS Sistema de inferência Takagi-Sugeno 


\title{
Sumário
}

\author{
Epígrafe
}

Dedicatória

Agradecimentos

vii

Resumo

ix

Abstract $\quad$ xi

Lista de Figuras

xiii

Lista de Tabelas $\quad$ xv

Lista de Quadros $\quad$ xvii

Lista de Abreviaturas e Siglas $\quad$ xix

1 Introdução 1

1.1 Motivação e Relevância do Trabalho . . . . . . . . . . . . . . . . . 2

1.2 Objetivos e Contribuições da Pesquisa . . . . . . . . . . . . . 6

1.3 Organização da Dissertação . . . . . . . . . . . . . . . . . . 7

2 Aspectos Relacionados a Predição de Estruturas de Proteínas 9

2.1 Aminoácidos . . . . . . . . . . . . . . . . . . . . . . . . 10

2.2 Ligações Peptídicas e os Polipeptídeos . . . . . . . . . . . . . . . 12

2.3 Estrutura Primária de Proteína . . . . . . . . . . . . . . . . . . . 15

2.4 Estrutura Secundária de Proteína . . . . . . . . . . . . . . . . 16

2.5 Estrutura Terciária de Proteína . . . . . . . . . . . . . . . . . . . 17

2.6 Determinação Experimental da Estrutura Terciária da Proteínas . . . . . . 19 
2.7 Predição de Estrutura Terciária de Proteína . . . . . . . . . . . . . . . 20

2.7.1 Modelagem por Homologia . . . . . . . . . . . . . . . . . 21

2.7.2 Modelagem por "Threading" . . . . . . . . . . . . 23

2.7 .3 Modelagem "Ab initio" . . . . . . . . . . . . . . . . . 24

2.8 Funções de Energia . . . . . . . . . . . . . . . . . . . . . . . 25

2.8.1 Energia de Comprimento de Ligação . . . . . . . . . . . . . 26

2.8.2 Energia de Ângulo de Torsão . . . . . . . . . . . . . . . . . . . 28

2.8 .3 Energia Urey-Bradley . . . . . . . . . . . . . . . . . . . . . . . 29

2.8 .4 Energia Imprópria . . . . . . . . . . . . . . . . . . . . 30

2.8.5 Energia Eletrostática ou de Carga . . . . . . . . . . . . . . . . . 30

2.8.6 Energia de Van der Waals . . . . . . . . . . . . . . . . 31

2.9 Considerações Parciais . . . . . . . . . . . . . . . . . . . . . . . 33

3 Abordagem Evolutiva Multi-objetiva Fuzzy 35

3.1 Otimização Multi-Objetivo . . . . . . . . . . . . . . 36

3.1.1 Soluções de Pareto Ótimas . . . . . . . . . . . . . . . . 36

3.1 .2 Metas em Otimização Multi-Objetivo . . . . . . . . . . . 38

3.2 Teoria da Evolução . . . . . . . . . . . . . . . . . . . . . . 38

3.3 Algoritmos Genéticos . . . . . . . . . . . . . . . . . . . . . . . 39

3.3 .1 Codificação dos Indivíduos . . . . . . . . . . . . . . . . . . . . . 41

3.3 .2 Definição da População Inicial . . . . . . . . . . . . . . . . . . . . . 42

3.3.3 Operadores Genéticos . . . . . . . . . . . . . . . . . . 43

3.3.4 Seleção dos Indivíduos . . . . . . . . . . . . . . . . . . . . . 44

3.4 Algoritmo Evolutivo Multi-objetivo . . . . . . . . . . . . . . . . 45

3.4.1 Algoritmo NSGA-II . . . . . . . . . . . . . . . . . 47

3.4 .2 Distância de Multidão . . . . . . . . . . . . . . . . . . . 48

3.5 Lógica Fuzzy . . . . . . . . . . . . . . . . . . . . . . 50

3.5.1 Universo de Discurso . . . . . . . . . . . . . . . . . . 50

3.5.2 Funções de Pertinência . . . . . . . . . . . . . . . . . . 51

3.5.3 Operações Fuzzy . . . . . . . . . . . . . . . . . . . 52

3.5.4 Inferência Fuzzy . . . . . . . . . . . . . . . . . 53

3.5.5 Processo de Defuzzificação . . . . . . . . . . . . . . . 54

3.5.6 Sistema de Inferência de Takagi-Sugeno . . . . . . . . . . . . . 55

3.6 Método Evolutivo Multi-objetivo Fuzzy . . . . . . . . . . . . . 55 
3.7 Considerações Parciais . . . . . . . . . . . . . . . . . . 56

4 Metodologia Proposta $\quad 59$

4.1 Sistema Fuzzy Proposto . . . . . . . . . . . . . . . . . . . . . 61

4.2 Considerações Parciais . . . . . . . . . . . . . . . . . . 65

5 Resultados da Aplicação do Algoritmo Proposto $\quad 67$

5.1 Função de Avaliação . . . . . . . . . . . . . . . . . . . . . . . 68

5.2 Processo de Treinamento do Algoritmo Proposto . . . . . . . . . . . . . . . 70

5.2 .1 Primeira Etapa . . . . . . . . . . . . . . . 70

5.2 .2 Segunda Etapa . . . . . . . . . . . . . . . . . . . . 73

5.3 Proteínas Alvo . . . . . . . . . . . . . . . . . . . . 76

5.4 Resultados . . . . . . . . . . . . . . . . . . . 77

6 Conclusões e Trabalhos Futuros $\quad 85$

Referências Bibliográficas $\quad 89$

A Toolbox Fuzzy Logic $\quad 99$

A.1 Toolbox Fuzzy Logic do Matlab . . . . . . . . . . . . . . . . . . . . 100

A.2 Técnica ANFIS . . . . . . . . . . . . . . . . . . . . . . . 103

A.2.1 Editor GUI ANFIS . . . . . . . . . . . . . . . . 105

A.2.2 ANFIS por Linha de Comando . . . . . . . . . . . . . . . 108 


\section{Capítulo 1}

\section{Introdução}

A era pós-genômica tem sido caracterizada por dois cenários principais. Primeiro, disponibilização de uma grande quantidade de informações biológicas que necessitam de ferramentas e métodos eficientes para modelar os processos visando posteriormente a análise de seus comportamentos. Segundo, novos modelos e paradigmas computacionais têm sido desenvolvidos muitos deles baseados em sistemas bioinspirados, estão também disponíveis para serem aplicados em problemas complexos e de difícil modelagem perante o contexto da computação. Como exemplo desta complexidade, informações sobre dados biológicos variam de strings simples representados por gráficos em 1D (seqüência de dados) a gráficos 3D, que modelam a estrutura terciária de proteínas (Ezziane, 2006).

Conforme relatos apresentados por Cohen (1994), a utilização de ferramentas eficientes, as quais auxiliam na interpretação desta vasta quantidade de informações oriundas da pesquisa genômica, têm sido cada vez mais essenciais para a comunidade científica que trabalha no assunto. Além disso, relata-se também que um dos mais recentes objetivos da bioinformática é desenvolver modelos in silicio que complementará os experimentos biológicos reais.

Bioinformática e Biologia Computacional estão interessadas no uso de computadores visando o entendimento dos fenômenos biológicos e aquisição e exploração dos seus dados biológicos. Os métodos computacionais de Bioinformática e Biologia Computacional estão sendo cada vez mais usados para aumentar ou alavancar os laboratórios tradicionais e observações baseadas em biologia. Com tais métodos é possível transformar os dados 
brutos em dados úteis, que começaram com o sequenciamento de DNA e que atualmente é aplicado em diversas outras áreas, tais como Predição de Estruturas Terciária de Proteínas (Ezziane, 2006).

Muitos dos desafios da bioinformática podem ser formulados como problemas de otimização, os quais vêm sendo tratados como um problema de otimização mono-objetivo apresentando já resultados satisfatórios. Contudo, para alguns deles não é possível investigálos usando tratamento por otimização mono-objetivo. Sendo assim, os mesmos devem ser mapeados como problemas de otimização multi-objetivos no qual se enquadra o problema de Predição de Estruturas Terciária de Proteínas (Handl et al., 2006).

Mais especificamente, as pesquisas na área de bioinformática estão pautadas no uso de computadores visando auxiliar nos entendimentos dos fenômenos genômicos, bem como na exploração e identificação de padrões e características intrínsecas que permeiam a essência dos dados biológicos (Gusfield, 2004). Paralelamente, os métodos advindos dos sistemas inteligentes, notadamente aqueles baseados em redes neurais artificiais, sistemas de inferência fuzzy e algoritmos evolutivos, estão sendo cada vez mais utilizados na bioinformática.

As características mais atrativas da utilização de sistemas inteligentes em bioinformática consistem em suas elevadas habilidades em mapear sistemas não-lineares e às suas facilidades de serem integrados com outras ferramentas numéricas e computacionais já existentes. A área de sistemas inteligentes é constituída por uma combinação de técnicas de modelagem e computação que podem ser também denominadas como técnicas de "Soft Computing" (Zadeh, 1992), cujo objetivo de destaque desse conjunto de métodos está em alcançar tratabilidade, robustez, baixo custo e altas taxas de eficiência.

\subsection{Motivação e Relevância do Trabalho}

O volumoso conhecimento sobre genes disponível na base de dados do National Center for Biotechnology Information (NCBI) é de aproximadamente 20 milhões de pares, sendo que o conhecimento da maior proteína consiste de 34 mil aminoácidos. Outra base de dados, denominada Protein Data Bank (PDB), tem catalogada cerca de 45 mil proteínas 
especificadas pela sua estrutura terciária (Ezziane, 2006).

Bajic et al. (2003) descreveu as vantagens na integração dos dados e nas tecnologias de data mining que são relevantes para a biologia molecular e ciências biomédicas. Portais Web, como Entez e ExPASy, representam o primeiro nível de integração de dados de bioinformática, metodologias e ferramentas (Bergeron, 2003).

Tan e Gilbert (2003) prepararam uma comparação empírica de vários métodos (SVM, Redes Neurais Artificiais, Árvores de Decisão, entre outros), afirmando que quando trabalhando com combinação de métodos, os resultados obtidos são melhores que aqueles obtidos com a aplicação de somente um método.

Cohen (2004) evidencia a importância do Cientista da Computação para auxiliar os biólogos a interpretar o volumoso dados oriundos da pesquisa genômica e proteômica, além de desenvolver in silicio que serão integrados (utilizados) em experimentos in vivo e in vidro. Sendo assim, por intermédio de data mining é também possível identificar determinados padrões em uma grande quantidade de dados através de algoritmos de aprendizagem. Como exemplo, redes neurais artificiais foram usadas como ferramentas de data mining para predizer a ocorrência de câncer de mama (Pendharkar et al., 1999; Chou et al., 2004). Em Cutello et al. (2005) e de Lima (2006) se utilizaram algoritmos evolutivos multi-objetivos para predizer a estrutura terciária de proteínas. A proposta de Bryson et al. (2000) foi desenvolver o GeneWeaver, um sistema multi-agente que está sendo aplicado para muitos problemas de análises de genes e predição de estruturas de proteínas. O trabalho de Battistella e Cechin (2004) se utilizou uma rede neural artificial e um sistema de inferência fuzzy para a identificação de estruturas de proteínas.

Assim, as informações dispostas nesses bancos de dados são repletas de relações potenciais que requerem um grande esforço computacional para tratá-las. Sendo assim, Tsunoda (2004) investigou a utilização de abordagens evolucionárias (Algoritmos Evolutivos e Programação Evolutiva) e alguns conceitos biológicos com o propósito de descobrir padrões e classificação de proteínas tendo o PDB sua principal base de dados. Além disso, muitos dos métodos tradicionais foram desenvolvidos para dados numéricos homólogos. Entretanto, bancos de dados de bioinformática armazenam cada vez mais seqüência de textos, estruturas de proteínas e outras séries de dados. Por esta razão, a necessidade 
de técnicas de data mining mais sofisticadas e mais inteligentes é fundamental para o desenvolvimento de sistemas eficientes para bioinformática (Ezziane, 2006).

De fato, o campo de biologia molecular é feito sob medida para os métodos baseados em sistemas inteligentes, visto que tais métodos têm uma ótima performance onde há muitos dados quantitativos, mas pouca informação qualitativa disponível (Ezziane, 2006). Desde a introdução de técnicas de sistemas inteligentes nesta área, muitos algoritmos têm sido propostos e aplicados para o estudo de diferentes grupos de dados.

Assim sendo, há a necessidade constante de pesquisar novas abordagens de estimação e otimização, que possam ser efetivamente aplicadas em problemas de identificação de estruturas de proteínas. Torna-se, então, extremanente revelante investigar tais abordagens em problemas de otimização multi-objetivo, pois segundo Handl et al. (2006):

1. Muitos dos critérios e função de validação presentes no cenário do mundo real são conflitantes e suas relações não são conhecidas a priori.

2. Desenvolvimento no campo da computação evolutiva torna-se possível tratar problemas de otimização multi-objetivo complexos (grande números de variáveis, sistemas não-lineares), além de não ser restrito à certos tipos de problemas de otimização.

Dentro desse contexto, uma das tônicas principais das pesquisas da área consiste em investigar a aplicação de diversas abordagens, advindas da área de sistemas inteligentes, nos processos envolvidos com a determinação da estruturas de proteínas.

Mais especificamente, a utilização de sistemas inteligentes, notadamente aqueles baseados em redes neurais artificiais (Haykin, 1999), em sistemas e controladores fuzzy (Pedrycz e Gomide, 1998), e em algoritmos evolutivos (Fogel e Corne, 2003), já têm sido aplicados com sucesso na solução de diversos problemas envolvidos com estimação de estruturas de proteínas. As características mais atrativas desses sistemas consistem em sua elevada habilidade em mapear sistemas não-lineares e à sua facilidade de ser integrado com outras ferramentas numéricas e computacionais já existentes.

Nessa combinação, as redes neurais artificiais se preocupam principalmente com o mapeamento de processos, o qual é feito através da utilização de elementos processadores 
que são especialistas em aprender o comportamento existente entre as variáveis de entradas e saídas dos respectivos processos. Além disso, uma das principais vantagens em se utilizar as abordagens baseadas nas redes neurais artificiais é a não necessidade de conhecimento sobre eventuais modelos matemáticos que descrevem o comportamento dos processos a serem mapeados, pois tais modelos podem ainda ser desconhecidos, ou mesmo ainda, estarem mapeando os processos de forma inapropriada ou particularizada. Esses métodos neurais, tipicamente em ambientes com disponibilização de informações quantitativas, são capazes de descobrir regularidades (padrões) oriundos de grandes bancos de dados, podendo ser identificados através de aprendizado supervisionado (classificação de padrões), ou ainda, não-supervisionado como no caso de clusterização. Como exemplo, em Wiebringhaus et al. (2004), uma aplicação de redes neurais feedforward para classificar as classes referentes às dobras (fold) de proteínas é proposta, tendo como entrada a seqüência de aminoácidos. A conclusão apresentada foi que a rede forneceu um melhor resultado quando comparado com outros métodos de aprendizado de máquinas, como aquele desenvolvido em Markowetz et al. (2003).

Paralelamente, as técnicas associadas aos sistemas e estimadores fuzzy objetivam o mapeamento de processos, cujos valores das variáveis de entrada envolvidas no mesmo possuem diferentes graus de imprecisão e incerteza. Assim sendo, essas técnicas fornecem uma estrutura poderosa para manipular informações aproximadas, em que o processo pode ser controlado/mapeado a partir de um conjunto de regras fuzzy do tipo "Se-Então", as quais são capazes de tratar (coordenar) conhecimentos incompletos, incertos ou mesmo conflitantes. A ocorrência de processos, em situações envoltas de imprecisão e incerteza, é também bastante observada em diversos problemas relacionados com a determinação de estruturas de proteínas. A aplicação de técnicas convencionais em tais processos pode trazer resultados insatisfatórios, pois as mesmas podem não estar aptas para o tratamento de informações incertas. Como exemplo, em Doostfatemeh e Kremer (2005), é proposto um General Fuzzy Automata (GFA) que considera as correlações posicionais dos aminoácidos em uma família de proteína como critérios básicos para a predição e a classificação de seqüências desconhecidas. O GFA apresentou melhores resultados quando comparados com os algoritmos HMM (Hidden Markov Model ${ }^{1}$ ).

\footnotetext{
${ }^{1}$ é um modelo estatístico onde o sistema inicialmente modelado é assumido ser um processo de Markov
} 
Por sua vez, os Algoritmos Evolutivos (AEs) têm já sido também utilizados de forma extensiva como uma ferramenta de otimização na solução de diversos problemas envolvendo determinação de estruturas de proteínas. Mais especificamente, os algoritmos evolutivos são métodos de otimização adaptativos que utilizam operadores, os quais são inspirados em métodos seletivos naturais, que são especialistas na procura de soluções ótimas. Prova-se que os métodos baseados nos algoritmos evolutivos são teoricamente e empiricamente robustos em espaços complexos. Assim, os algoritmos evolutivos (na prática) podem ser definidos como um método de busca de uma solução ótima a partir de uma população de soluções candidatas. Conseqüentemente, as abordagens inspiradas nos algoritmos evolutivos podem ser aplicadas em diversos problemas envolvidos com a determinação de estruturas de proteínas, nas quais requerem a procura de uma solução levando-se em consideração os critérios ótimos associados com os potenciais de energia.

Em resumo, as três principais ferramentas que constituem os sistemas inteligentes permitem o desenvolvimento de metodologias eficientes capazes de modelar diversos tipos de problemas envolvidos com a estimação de estruturas de proteínas. Assim, conforme já testemunhado pelas abordagens citadas acima, a aplicação de forma integrada dessas ferramentas pode produzir resultados promissores para a área de identificação de estruturas de proteínas, os quais poderão contribuir de forma efetiva para a geração de novos conhecimentos que implicarão em ganhos substantivos de eficiência e produtividade.

\subsection{Objetivos e Contribuições da Pesquisa}

Em otimização multi-objetivo, normalmente, não há um único ponto ótimo, mas sim, soluções não dominadas (fronteira de Pareto). Os Algoritmos Evolutivos Multi-objetivo (AEMOs) têm se mostrado como uma técnica poderosa para problemas de otimização multi-objetivo. Alguns AEMOs utilizam a dominância de Pareto, mas quando o problema consiste de muitos objetivos (acima de três), segundo Farina e Amato (2003) há duas razões que o torna insatisfatório, ou sejam:

sem se conhecer os parâmetros, sendo que o desafio é determinar os parâmetros desconhecidos baseando-se nos dados observados. 
1. A visualização da fronteira de Pareto tem que ser realizada de forma cuidadosa.

2. O grupo de solução classificada como Pareto ótimo pode ser uma parte pequena do espaço de busca como um todo. Consequentemente, tem-se pouca contribução no esforço para encontrar a melhor solução.

Em relação aos problemas do mundo real, há um número considerável de problemas de otimização onde há necessidade de considerar mais que três objetivos e assim, na literatura, há trabalhos tais como de Moura (2002) e Farina e Amato (2003) que utilizaram a Lógica Fuzzy com a finalidade de obter um melhor resultado. Nesses trabalhos, com a adição da Lógica Fuzzy, a abordagem atribuída ao sistema necessita de uma modificação considerável nos AEs, caso já esteja pronto, ou até mesmo sem a utilização do mesmo. Em Deb et al. (2006), autor do NSGA-II ${ }^{2}$, afirma que tal algoritmo pode possuir dificuldade em trabalhar em problemas com mais de três objetivos.

Sendo assim, este trabalho de mestrado tem como objetivo propor um algoritmo baseado na Lógica Fuzzy como alternativa à fronteira de Pareto, evitando para tanto que modificações significativas sejam realizadas nos AEs que utilizam a tal fronteira. Como resultado, disponibiliza-se-à um algoritmo híbrido multi-objetivo para aplicar neste problema complexo de otimização, que é intitulado na literatura como predição de estruturas terciárias de proteínas.

\subsection{Organização da Dissertação}

O Capítulo 2 tratará do estudo teórico do problema de predição de estruturas terciárias de proteínas. Contemplar-se-á desde a definição de proteínas, aminoácidos e ligações peptídicas até a determinação da estrutura de proteínas a partir de sua seqüência de aminoácido.

O Capítulo 3 abordará os aspectos teóricos sobre o problema de otimização mutiobjetivo, a computação evolutiva e a lógica fuzzy. Assim, será então possível evidenciar a abordagem Evolutiva Multi-objetiva Fuzzy.

\footnotetext{
${ }^{2}$ Ver seção 3.4.1.
} 
O Capítulo 4 é referente à metodologia proposta, além de ser possível verificar o cenário de aplicação do algoritmo apresentado.

O Capítulo 5 evidenciará os resultados da aplicação do algoritmo proposto no problema de predição da estrutura terciária da proteína.

O Capítulo 6 descreverá as conclusões deste trabalho de mestrado. 


\section{Capítulo 2}

\section{Aspectos Relacionados à Predição de Estruturas de Proteínas em}

\section{Bioinformática}

Proteínas são biopolímeros que possuem como alfabeto um conjunto de 20 aminoácidos. Uma importante propriedade das proteínas é a classificação de suas estruturas hierarquicamente: estrutura primária, estrutura secundária e estrutura terciária (tridimensional).

Uma das relevâncias em investigar as proteínas é devida exercerem diversas funções bioquímicas, sendo as principais atuações: ligação, catálise e atuação como chave molecular e servindo como componente estrutural de células e organismos. Proteínas podem ligar-se a outras macromoléculas, tais como DNA ou outras proteínas. Esta função explica a habilidade das proteínas em apresentar superfícies estruturalmente e quimicamente diversas que podem interagir com outras moléculas com alta especificidade (Petsko e Ringe, 2004).

A responsável por determinar a função da proteína no organismo é a sua estrutura terciária.

Neste capítulo, a Seção 2.1 tratará sobre os aminácidos e propriedades das ligações peptídicas. A hierarquia das proteínas será discutida nas Seções 2.3, 2.4 e 2.5. A Seção 2.6 abordará sobre a determinação da estrutura terciária de proteínas. A Seção 2.7 descreverá 
alguns aspectos relacionados à predição de estrutura terciária de proteínas. A seção de funções de energia utilizadas encontra-se em 2.8 .

\subsection{Aminoácidos}

Aminoácidos são compostos orgânicos que possuem uma estrutura básica comum que consiste de um carbono central denominado carbono $\alpha$, o qual possui quatro ligantes diferentes, um hidrogênio $(\mathrm{H})$, um grupo carboxila $(\mathrm{COOH})$, um grupo amina $\left(\mathrm{NH}_{2}\right)$ e um radical $\mathrm{R}$ também chamado cadeia lateral do aminoácido (que pode consistir de um único átomo de hidrogênio até complexos anéis aromáticos) (Copeland, 1993). A Figura 2.1 representa a estrutura básica de um aminoácido.

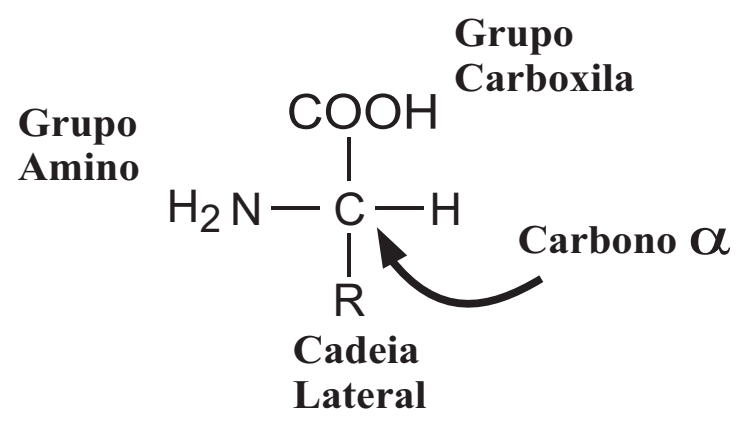

Figura 2.1: Estrutura básica de um aminoácido.

As proteínas são formadas a partir de um conjunto de vinte aminoácidos que se diferenciam pelas suas cadeias laterais. Quando os aminoácidos estão presentes em proteínas são denominados de resíduos, pois no processo de formação da proteína ocorre a perda de átomos (geralmente uma molécula de água - $\mathrm{H}_{2} \mathrm{O}$ ) que compunham a estrutura completa do aminoácido.

Um código de três ou uma letra é utilizado como mnemônico ${ }^{1}$ para representar os aminoácidos. Os vinte aminoácidos estão apresentados na Tabela 2.1, com seus respectivos códigos de três e uma letra, bem como seu peso molecular. A Figura 2.2 apresenta a estrutura química dos vinte aminoácidos presentes nas proteínas.

Dependendo da natureza química da cadeia lateral, os aminoácidos podem ser dividi-

\footnotetext{
${ }^{1} 1$. Que se refere à memória. 2. Que ajuda a memória. 3. Que facilmente se grava na memória.
} 
Tabela 2.1: Relação dos vinte aminoácidos padrões e respectivos mnemônicos.

\begin{tabular}{||c|c|c|c|c||}
\hline \hline Aminoácido & Cód. 3 letras & Cód. 1 letra & $\begin{array}{c}\text { Origem do } \\
\text { Cod. 1 Letra }\end{array}$ & $\begin{array}{c}\text { Peso Molecular } \\
\text { MW }^{2}\end{array}$ \\
\hline \hline Alanina & Ala & A & Alanine & 71 \\
\hline Cisteína & Cys & C & Cysteine & 103 \\
\hline Ácido Aspártico & Asp & D & asparDic acid & 114 \\
\hline Fenilalanina & Phe & F & $F$ enylalanine & 147 \\
\hline Ácido Glutâmico & Glu & E & gluEtamic acid & 128 \\
\hline Glicina & Gly & G & Glycine & 57 \\
\hline Histidina & His & H & Histidine & 137 \\
\hline Isoleucina & Ile & I & Isoleucine & 113 \\
\hline Lisina & Lys & K & letra antes do $L$ & 129 \\
\hline Leucina & Leu & L & Leucine & 113 \\
\hline Metionina & Met & M & $M$ ethionine & 131 \\
\hline Asparagina & Asn & N & asparagi $N$ e & 114 \\
\hline Prolina & Pro & P & Proline & 97 \\
\hline Glutamina & Gln & Q & $Q$-tamine & 128 \\
\hline Arginina & Arg & R & a $R$ ginine & 157 \\
\hline Serina & Ser & S & $S$ erine & 87 \\
\hline Treonina & Thr & T & Theorine & 101 \\
\hline Valina & Val & V & $V$ aline & 99 \\
\hline Triptofano & Trp & W & t $W$ o rings & 186 \\
\hline Tirosina & Tyr & Y & t $Y$ rosine & 163 \\
\hline
\end{tabular}

dos em três diferentes classes. A primeira classe compreende os aminoácidos com cadeia lateral estritamente hidrofóbica, isto é, o composto da cadeia lateral não se dissolve em contato com a água (Alanina, Valina, Leucina, Isoleucina, Fenilalanina e Prolina). Aminoácidos que possuem cadeia lateral estritamente hidrofílica, isto é, o composto da cadeia lateral se dissolve em contato com a água, compõem a segunda classe (Ácido Aspártico, Ácido Glutâmico, Serina, Treonina, Cisteína, Asparagina, Glutamina, Histidina e Argenina). A terceira classe é composta pelos aminoácidos com características polares e apolares que dissolvem no contato com a água, sendo os mesmos também chamados anfipáticos (Lisina, Tirosina, Metionina, e Triptofano) (Petsko e Ringe, 2004). 

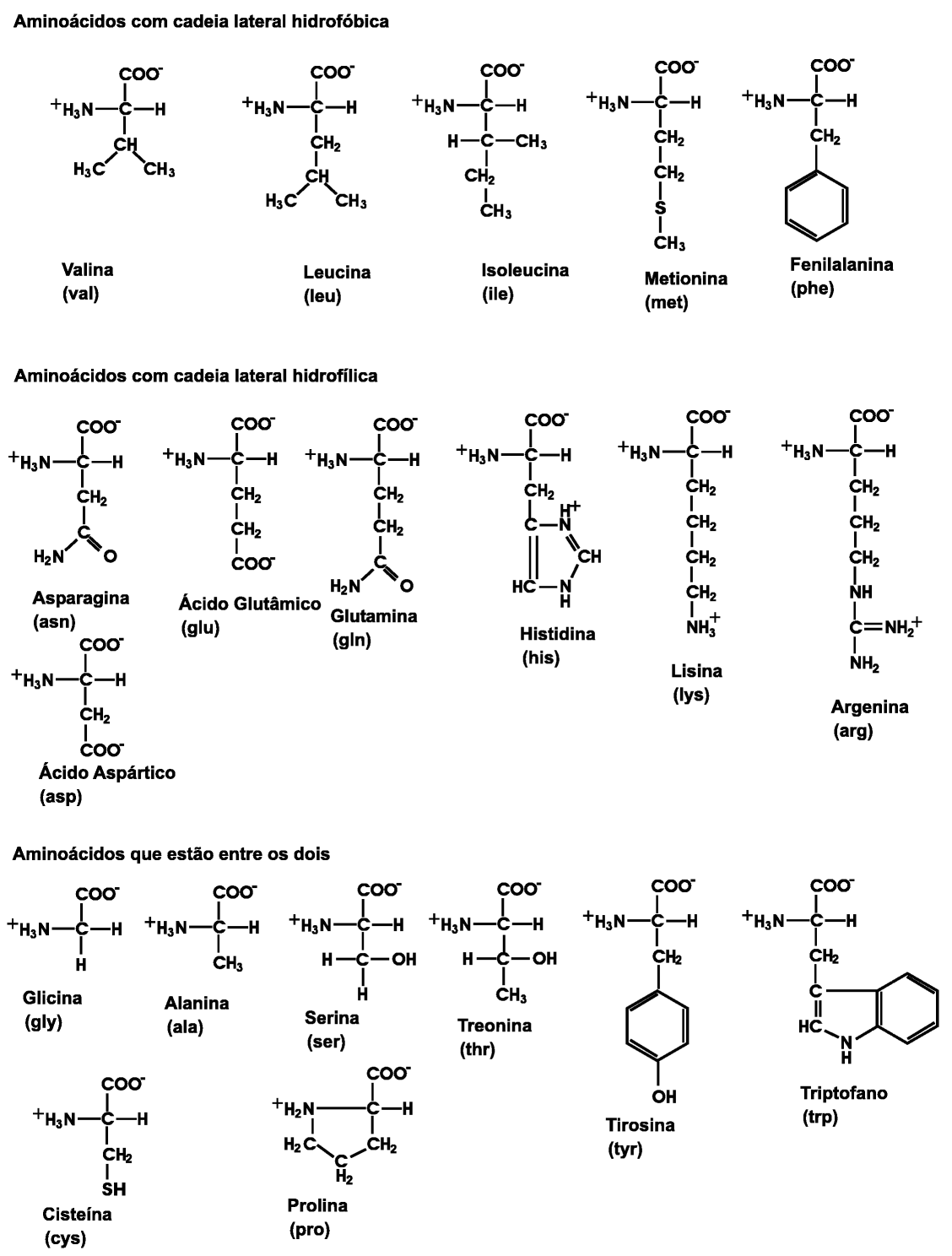

Figura 2.2: Classificação dos vinte aminoácidos padrões encontrados em proteínas.

\subsection{Ligações Peptídicas e os Polipeptídeos}

Os aminoácidos formam polímeros ${ }^{3}$ (cadeias polipeptídicas) por meio de ligações covalentes denominadas ligações peptídicas, sendo que este processo de polimerização ocorre no ribossomo da célula (Schulz e Schirmer, 1979). Essas ligações ocorrem entre o grupo carboxila de um aminoácido e o grupo amina do outro (Copeland, 1993). Durante o processo de ligação ocorre a perda de uma molécula de água, a Figura 2.3 representa o resultado de uma ligação peptídica.

\footnotetext{
${ }^{3}$ Macromoléculas constitídas pela repetição de pequenas moléculas idênticas ou praticamente idênticas, os monômeros, ligadas covalentemente (Lodish et al., 2004).
} 


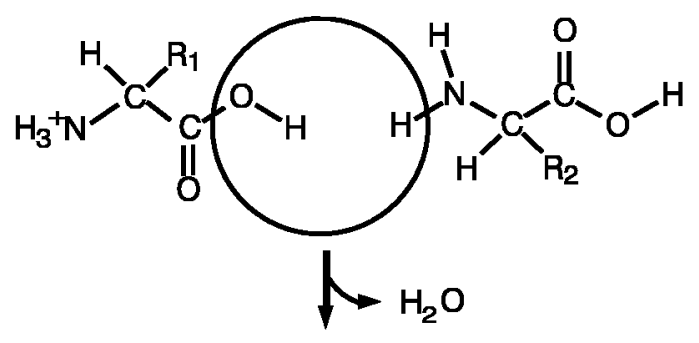<smiles>[R2]C([2H])C(=O)NC(=O)C([R2])[NH3+]</smiles>

+aminoácido 3

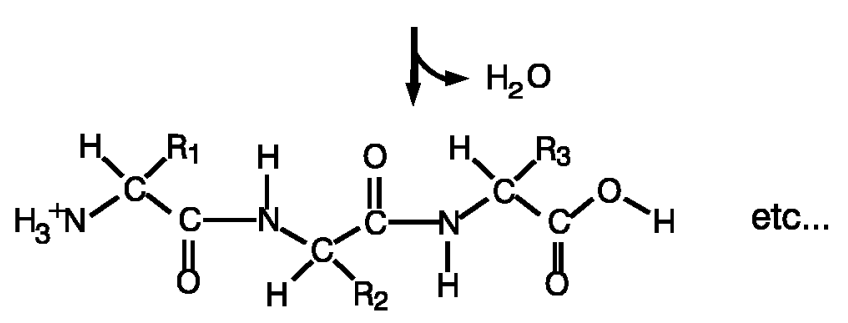

Figura 2.3: Processo de formação de uma ligação peptídica.

Quando vários aminoácidos estão conectados, o polímero resultante é denominado polipeptídeo. A diferença entre proteínas e polipeptídeos é basicamente semântica, por definição todas as proteínas são polipeptídeos, porém costuma-se chamar de polipeptídeo apenas pequenas sequências de aminoácidos.

As ligações Peptídicas possuem algumas propriedades. A primeira, é o comprimento da ligação peptídica não pode ser medido como uma típica dupla ligacão carboxílica $(\mathrm{C}=\mathrm{O})$ e uma ligação simples carbono-nitrogênio. Pelo contrário, ambas as distâncias das ligações carboxílica e carbono-nitrogênio estão nos valores intermediários entre as distâncias conhecidas para compostos deste tipo já relatados. A explicação para esses valores resulta da nuvem de elétrons observada na molécula triatômica O-C-N, na qual a dupla ligação fica alternando desta forma $\mathrm{O}=\mathrm{C}-\mathrm{N}$ e O-C $=\mathrm{N}$ (Copeland, 1993). Observa-se que estas ligações ocorrem em uma estrutura planar, assim, os seguintes seis átomos fazem parte de um mesmo plano (Figura 2.4), $\mathrm{C}_{i}^{\alpha}, \mathrm{C}_{i}, \mathrm{O}_{i}, \mathrm{~N}_{i+1}, \mathrm{H}_{i+1}, \mathrm{C}_{i+1}^{\alpha}$, ou seja, carbonos $\alpha$ de aminoácidos adjacentes estão no mesmo plano (Schulz e Schirmer, 1979).

Outra propriedade observada é que, embora a rotação sobre a ligação C-N seja res- 


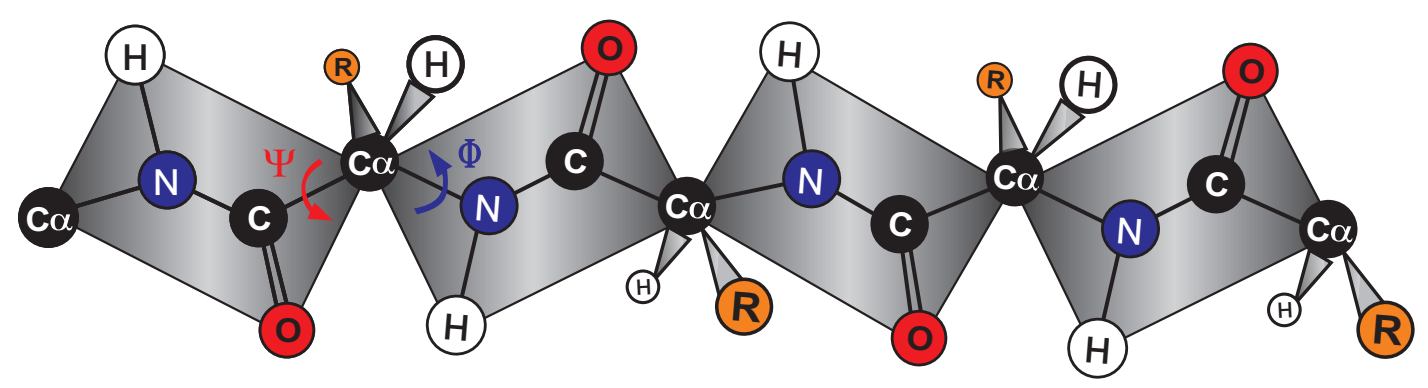

Figura 2.4: Representação dos átomos no mesmo plano (de Lima, 2006).

trita ${ }^{4}$, rotações sobre o $\mathrm{C}_{\alpha}-\mathrm{N}$ e $\mathrm{C}_{\alpha}$-C podem ocorrer livremente podendo ser descritas por dois ângulos $\phi$ e $\psi$, associados respectivamente a cada uma das ligações (Figura 2.5) (Ramachandran e Sasiskharan, 1968).

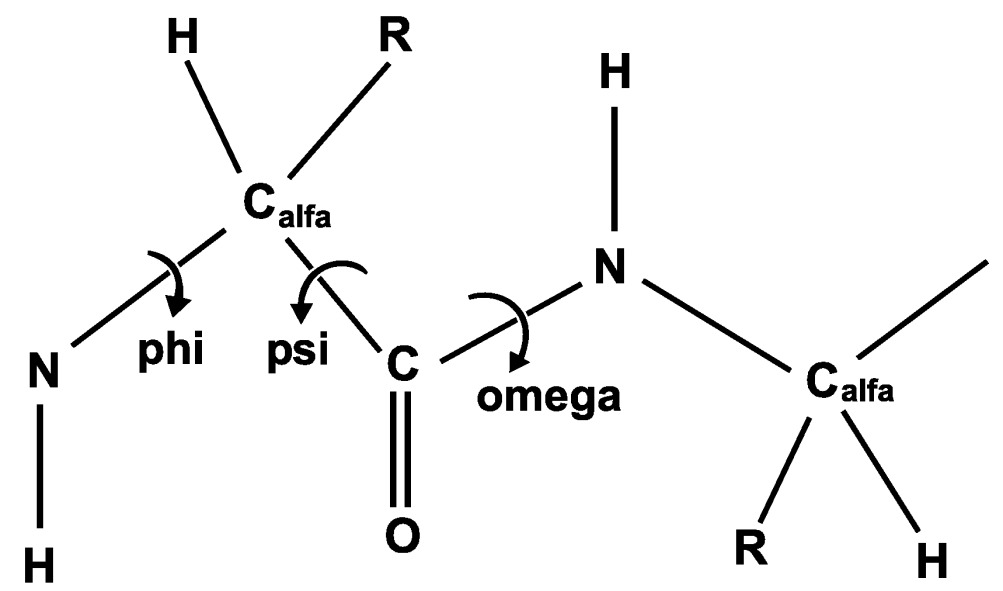

Figura 2.5: Ângulos $\psi$ e $\phi$.

Através de experimentos laboratoriais, Ramachandran e seus colaboradores, observaram que os pares $\phi$ e $\psi$ concentram-se em duas regiões do mapa (Figura 2.6 ) para todos os aminoácidos exceto a glicina que, por apresentar uma cadeia lateral muito simples, possui menos restrições espaciais conformacionais. Pode-se observar também que cada um dos dois quadrantes de concentração pode ser associado a um tipo de estrutura secundária, a qual será discutida na Seção 2.4 (Copeland, 1993). Os ângulos $\phi$ e $\psi$ são chamados de ângulos diedrais e são responsáveis por definir a forma da cadeia principal do polipeptídeo, o ângulo $\omega$ pode assumir os valores de $180^{\circ}$ graus ou $0^{\circ}$ graus. Os valores assumidos pelo ângulos diedrais respeitam a propriedade de que os carbonos $\alpha$ de dois aminoácidos adjacentes devem estar no mesmo plano.

\footnotetext{
${ }^{4}$ onde $\mathrm{C}$ não é o carbono $\alpha$.
} 


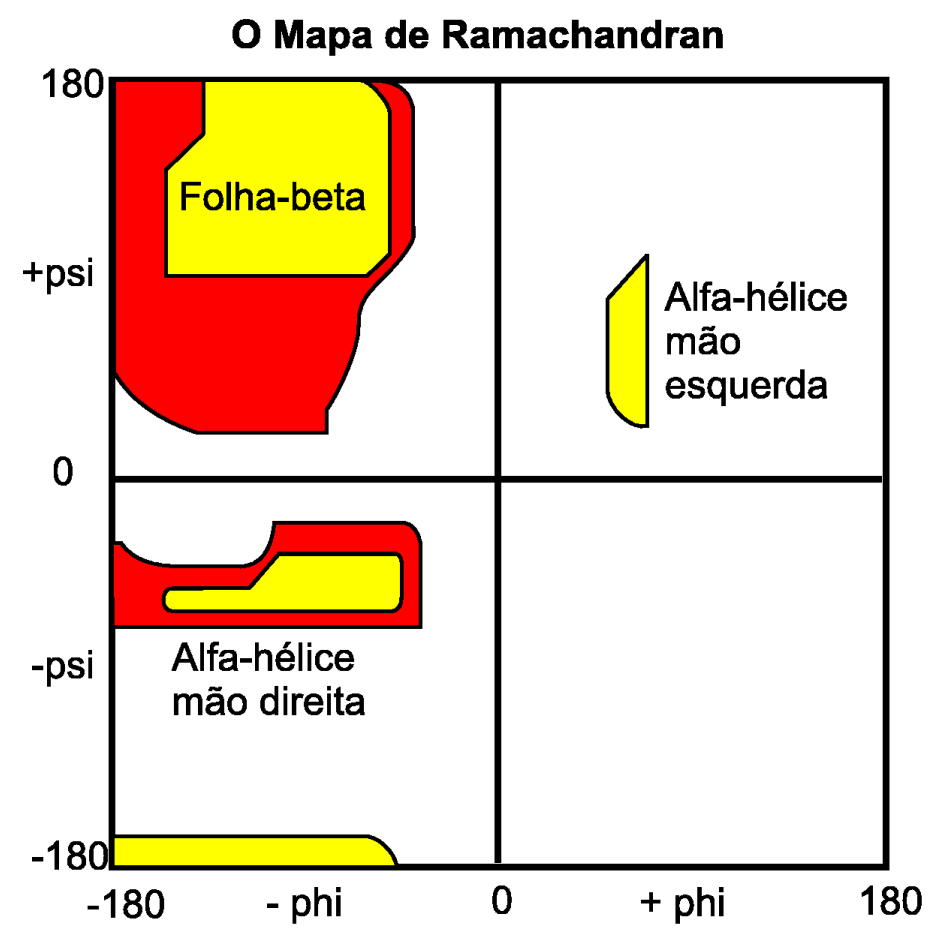

Figura 2.6: Mapa de Ramachandran.

\subsection{Estrutura Primária de Proteína}

A sequência dos aminoácidos que compõem a proteína representa a estrutura primária da mesma. Com esta informação, pode-se apenas afirmar o número de resíduos e como estão ligados (Ligação Peptídica). Uma outra característica da estrutura primária é poder identificar as proteínas similares (repetição de sequências) e agrupá-las em famílias.

Segundo Lodish et al. (2004), muitos termos são usados para designar as cadeias formadas pela polimerização dos aminoácidos. Uma cadeia curta de aminoácidos, unidos por ligação peptídica em uma sequência, é chamada de peptídeo; já as cadeias mais longas são denominadas polipeptídeos. Os peptídeos normalmente contêm menos de 30 resíduos de aminoácidos enquanto os polipeptídeos podem conter 4 mil resíduos.

A string TTCCPSIVARSNFNVCRLPGTPEALCATYTGCIIIPGATCPGDYAN foi obtida no Protein Data Bank (PDB), ${ }^{5}$ sendo esta a estrutura primária da proteína $1 \mathrm{CCN}$. Tendo tal informação e observando a Tabela 2.1, pode-se concluir que a proteína em questão é formada pelos aminoácidos: Treonina, Cisteína, Prolina, Serina, Isoleucina, Valina,

\footnotetext{
${ }^{5} \mathrm{O}$ PDB é uma das principais bases de dados de proteínas com estrutura terciária determinada por meio dos métodos experimentais.
} 
Alanina, Asparagina, Arginina, Fenilalanina, Leucina, Glicina, Ácido Glutâmico e Tirosina.

\subsection{Estrutura Secundária de Proteína}

Embora as proteínas sejam polímeros lineares, suas estruturas não são cordões aleatórios (Lodish et al., 2004). A grande parte das proteínas solúveis tem um centro ligeiramente empacotado consistindo primariamente de aminoácidos hidrofóbicos. Esta observação pode ser explicada pela tendência que grupos hidrofóbicos possuem de evitar o contato com a água e de interagir com outros. Outra característica interessante de cadeias polipeptídicas dobradas é que os segmentos da cadeia em aproximadamente todas as proteínas adotam conformações nas quais os ângulos de torção $\phi$ e $\psi$ da cadeia principal repetem-se em padrões regulares. Esses padrões regulares formam os elementos da estrutura secundária da proteína.

Segundo Lodish et al. (2004), pode-se definir três tipos de elementos de estrutura secundária:

1. Hélice $\alpha$,

2. Folhas $\beta$,

3. Voltas.

A seguir, será ilustrado, respectivamente, cada estrutura secundária de proteínas. Nota-se na Figura 2.7 uma forma de hélice, sendo assim, tal figura representa a estrutura Hélice $\alpha$.

Já a Figura 2.8 representa a estrutura Folhas $\beta$ a qual é apresentada por flechas em razão de poder assumir direções na cadeia de polipepitídica (Branden e Tooze, 1991).

Enfim, a estrutura Voltas é ilustrada na Figura 2.9. É importante o formato U a qual qualifica como uma estrutura volta.

Estes são os tipos de estrutura secundária considerados estáveis estruturalmente, devido principalmente, à formação de pontes de hidrogênio entre os grupos carboxila e amino 


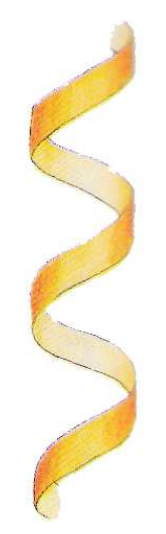

Figura 2.7: Estrutura Hélice $\alpha$ (Branden e Tooze, 1991).

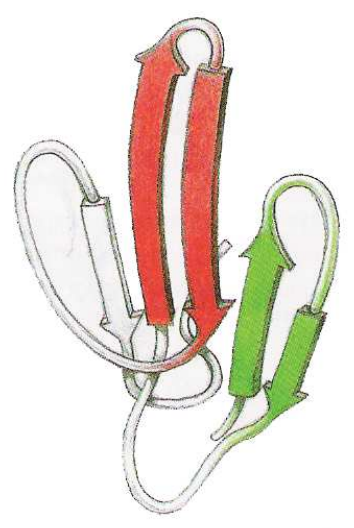

Figura 2.8: Estrutura Folhas $\beta$ (Branden e Tooze, 1991).

de aminoácidos não diretamente ligados e que em função da estrutura tridimensional da proteína, encontram-se próximos (Copeland, 1993).

A relevância da estrutura secundária é contribuir significativamente para a estabilização da dobra total da proteína.

\subsection{Estrutura Terciária de Proteína}

A estrutura terciária das proteínas refere-se à conformação total (arranjo tridimencional) de todos os resíduos de aminoácidos e é estabilizada, principalmente, por interações hidrofóbicas entre as cadeias não polares, pontes de hidrogênio entre as cadeias polares 


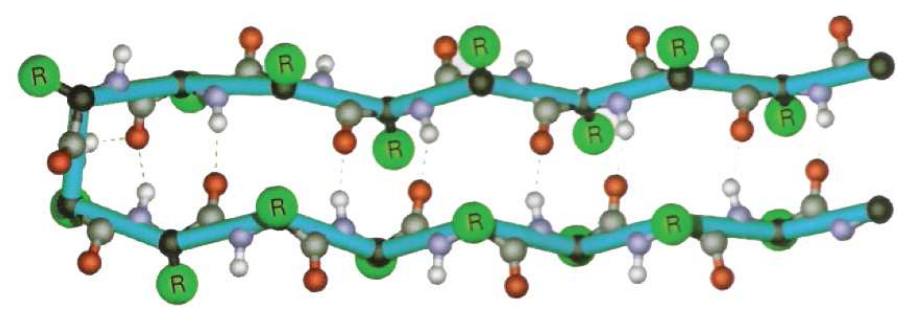

Figura 2.9: Estrutura Voltas (Lodish et al., 2004).

e ligações peptídicas. Essas forças mantêm os elementos da estrutura secundária unidos e compacta (Lodish et al., 2004). A Figura 2.10 é um exemplo da estrutura terciária de uma proteína.

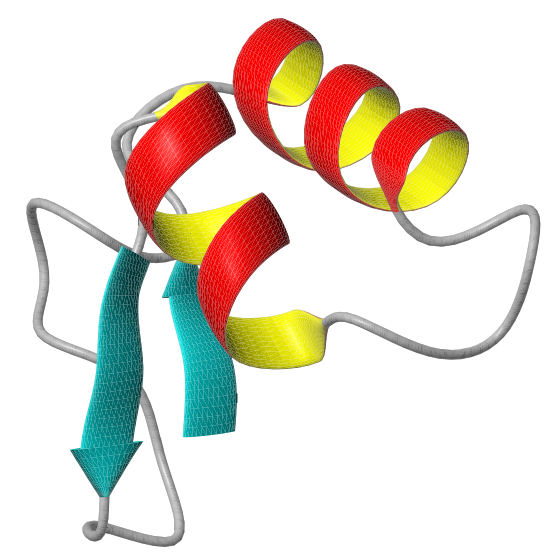

Figura 2.10: Estrutura terciária de uma proteína (PDB 1CCN).

A forma tridimensional assumida pela proteína é conhecida por dobra nativa (ou enovelamento nativo) e deve-se principalmente à variação de fatores termodinâmicos. Em sua estrutura nativa, as proteínas, estão no formato que lhes permite ter a mínima energia livre, favorável na solução em que se encontram. Alguns fatores termodinâmicos influenciam o processo de dobramento das proteínas, sendo um dos mais importantes a necessidade de resguardar os aminoácidos não polares do meio aquoso, o que forma o conhecido centro hidrofóbico da proteína. De forma similar, o processo de dobramento também procura favorecer as interações entre os aminoácidos polares e moléculas do solvente na superfície hidrofílica da proteína. Assim, proteínas em seu estado natural sempre dobram-se espontaneamente em estruturas tridimensionais, quando em condições de soluções favoráveis (Copeland, 1993).

A caracterização da estrutura terciária é muito difícil. Uma das possibilidades é por 
meio do arranjo topológico dos vários elementos da estrutura secundária. Um efeito da estrutura terciária é criar uma superfície topográfica complexa que permite a proteína interagir especificamente com pequenas moléculas que podem ligar-se em fendas, ou com outras macromoléculas, com as quais a proteína pode ter regiões de topologia complementar e carga (positiva ou negativa). Esses locais reconhecidos são freqüentemente formados de extensões de aminoácidos unindo elementos de estrutura secundária (Petsko e Ringe, 2004).

As relevâncias em investigar a estrutura terciária são as seguintes:

- É através dela que é definida a forma e a dimensão da proteína.

- Permite definir o conceito de proximidades espaciais entre aminoácidos que estão distantes na cadeia linear (estrutura primária ${ }^{6}$ ) da proteína, mas que precisam estar próximos para formar locais de catálise de uma enzima, locais ativos (ou sítio ativo) para a ligação de um receptor, ou um local de recombinação para a ação de outra proteína (Copeland, 1993).

Em suma, pode-se afirmar que a estrutura terciária é a responsável pela determinação da função da proteína no organismo.

A estrutura terciária das proteínas com peso molecular maior que 15 mil, possui uma unidade fundamental conhecida como Domínio. Geralmente, um domínio é caracterizado por alguma característica interessante: uma abundância incomum de um derterminado aminoácido (domínios ricos em prolina é um domínio ácido) (Lodish et al., 2004).

\subsection{Determinação Experimental da Estrutura Terciária da Proteínas}

Pode ser determinada experimentalmente a estrutura terciária da proteína por meio de dois métodos diferentes: cristalografia de raio-X e Ressonância Nuclear Magnética (RNM). A interação dos raios-X com os elétrons em moléculas arranjadas em um cristal é utilizada

\footnotetext{
${ }^{6}$ Ver seção 2.3 .
} 
para obter um mapa de densidade de elétrons da molécula, o qual pode ser interpretado em termos de um modelo atômico. Atuais avanços técnicos, tais como computadores poderosos, incluindo sistemas gráficos, detectores de áreas eletrônicas e muitas fontes fortes de raios-X de radiação síncrona, têm facilitado extremamente o uso de cristalografia de raio-X (de Lima, 2006).

Pode ser difícil de obter a cristalização de proteínas e, geralmente, requer muitos experimentos diferentes variando um número de parâmetros, tais como $\mathrm{pH}$, temperatura, concentração da proteína e a natureza do solvente. Cristais de proteínas contêm vários canais e furos preenchidos com solventes, os quais podem ser utilizados para difusão de metais pesados no cristal. A adição de metais pesados é necessária para a fase da difração de raios (Branden e Tooze, 1991).

Estruturas de raio-X são determinadas em diferentes níveis de resolução. Na resolução mais baixa somente a forma da molécula é obtida, enquanto que na alta resolução a maioria das posições atômicas pode ser determinada com alto grau de exatidão. Na resolução intermediária a dobra da cadeia polipeptídica é, geralmente, corretamente revelada, bem como as posições aproximadas das cadeias laterais, incluindo seus sítios ativos. A qualidade do modelo tridimensional final da proteína depende da resolução dos dados do raio-X e do grau de refinamento (Branden e Tooze, 1991).

No método de RNM as propriedades de spin magnético do núcleo atômico da molécula são utilizadas para obter uma lista das restrições de distância entre os átomos na molécula, a partir da qual a estrutura tridimensional da molécula da proteína pode ser obtida. Este método não requer cristais de proteína e pode ser utilizado em moléculas protéicas em soluções concentradas. No entanto, sua utilização é restrita a pequenas moléculas de proteína (Branden e Tooze, 1991).

\subsection{Predição de Estrutura Terciária de Proteína}

Os métodos experimentais para determinação da estrutura terciária das proteínas possuem uma série de condições para que estes possam ser utilizados (Seção 2.6), o que torna extremamente relevante a investigação de métodos computacionais eficientes para 
a determinação da estrutura terciária, na qual qualifica-se como predição de estrutura terciária de proteínas.

O processo de formação da estrutura terciária é denominado dobramento e existem algumas propriedades físicas que determinam este processo (Karplus e Shakhnovich, 1992):

- rigidez da cadeia principal (cadeia que contém todos os carbonos $\alpha$, Seção 2.1);

- interações entre os aminoácidos, incluindo interações eletrostáticas;

- forças de Van der Waals;

- restrições de volume;

- pontes de hidrogênio e dissulfeto;

- interações dos aminoácidos com o meio aquoso.

Por ainda não haver uma teoria que explique adequadamente o processo de dobramento de uma proteína em sua estrutura terciária, a qual é necessária para a determinação da sua função, uma alternativa tem sido as abordagens que visam a Determinação da Estrutura da Proteína (DEP) sendo que a mesma pode ser vista como um problema de otimização. Vários métodos de otimização têm sido investigados para esse problema, destacando-se aqueles baseados em threading (Baxevanis e Ouellette, 2001), homologia (Doolittle, 1986; Hilbert et al., 1993), Ab initio (Cui et al., 1998; Vullo, 2002) e semi Ab initio (Inbar et al., 2003, 2005).

\subsubsection{Modelagem por Homologia}

A modelagem por homologia significa predizer a estrutura terciária de uma proteína desconhecida com base em uma estrutura conhecida de uma outra proteína (homóloga ${ }^{7}$ ). Neste contexto, é importante descobrir a quantidade de similaridade com a seqüência conhecida necessária para predizer a estrutura com exatidão. Para determinar essa similaridade, Hilbert et al. (1993) estudaram superposições de alinhamento de um largo

\footnotetext{
${ }^{7}$ São proteínas que possuem um ancestral comum (Doolittle, 1986).
} 
número de estruturas conhecidas de diferentes formas e classes funcionais com diferentes graus de homologia. Com base neste estudo, Hilbert et al. sugeriram as seguintes relações entre seqüências homólogas e diferenças estruturais:

- O tamanho do núcleo da região comum diminui conforme diminui a identidade na seqüência. Alinhamentos com mais de $50 \%$ de similaridade possuem acima de 90\% de seus resíduos em regiões estruturalmente conservadas. Se a identidade na seqüência fica abaixo de $20 \%$, o núcleo da região comum contém cerca de $65 \%$ dos aminoácidos.

- Regiões estruturalmente divergentes com mais de $50 \%$ de similaridade na seqüência possuem conformação estrutural parecida. Grandes desvios estruturais podem acontecer se a similaridade for baixa.

- A diminuição da correlação de similaridade na seqüencia implica em aumento no número de inserções e/ou remoções em uma das seqüências para que se tornem iguais. Identificou-se que para um número máximo de 16 inserções e remoções, em geral, a similaridade é abaixo de 20\%. Por outro lado, praticamente nenhuma inserção e remoção é verificada com mais de $60 \%$ de similaridade.

Os estudos de Hilbert et al. não se esgotam o assunto de similaridade de proteínas.

Kabsch e Sander (1983) demonstraram que até mesmo uma similaridade exata, em pequenos segmentos, não fornece indicação de estrutura, apresentando exemplos de pentapeptídeos idênticos que participam de diferentes estruturas em diferentes proteínas. Em Wilson et al. (1985), extendeu-se essa idéia para hexapeptídeos. Mas, em Cohen et al. (1993), examinando os hexapeptídeos conclui que, dentro de uma classe estrutural de proteína ou domínio, a similaridade na estrutura de um hexapeptídeo seqüencialmente idêntico é preservada. Foi com esse estudo que inspirou a possibilidade de desenvolver algoritmos para predizer as estruturas terciárias de proteínas com domínio conhecido (Barton et al., 1993; Peitsch, 2002).

Em suma, as técnicas de modelagem por homologia investiga um dobramento desconhecido, modelando-o por intermédio da estrutura homóloga conhecida. Entretanto, 
sabe-se que, e não muito incomum, encontrar duas proteínas tendo baixa identidade na seqüência com estrutura terciária, mas com função similares entretanto.

\subsubsection{Modelagem por "Threading"}

As abordagens de threading e modelagem por homologia ${ }^{8}$ são baseadas na observação de que muitas proteínas no PDB são muito similares. Sendo assim, muitos cientistas estão investigando que há somente um limitado número de dobramentos de proteínas diferentes na natureza. As estimativas variam consideravelmente, mas prevê-se que existam menos de 1000 dobras de proteínas. Isso propicia uma abordagem para a predição de estrutura terciária de proteínas, determinando a estrutura de uma nova proteína pela busca (match) de seu melhor ajuste para alguma estrutura particular na biblioteca de estruturas. A diferença entre threading e modelagem por homologia é que na primeira, aplica-se quando a proteína não tem nenhuma proteína homóloga, mas pode ter uma estrutura tridimensional similar; na segunda, há a necessidade de possuir uma proteína homóloga.

O processo de determinação dos métodos de threading pode ser descrito da seguinte forma: obtém uma seqüência de busca e tenta alinha-la em um modelo de estrutura escolhido aleatoriamente do conjunto das principais estruturas tridimensionais determinadas de proteínas. A seqüência de busca é a estrutura primária de uma proteína que tem estrutura tridimensional desconhecida. As estruturas tridimensionais que compõem a biblioteca de estruturas foram obtidas por cristalografia de raio-X ou por ressonância nuclear magnética. O alinhamento da seqüência de busca com o modelo de estrutura pode ocorrer das seguintes formas:

- Alinhamento seqüência-seqüência: busca encontrar o melhor alinhamento entre a seqüência de busca e a seqüência de aminoácidos do modelo de estrutura por meio de inserções e remoções.

- Alinhamento seqüência-estrutura: a seqüência de busca é movimentada sobre a estrutura tridimensional sujeita à pré-determinadas restrições físicas referentes ao

\footnotetext{
${ }^{8}$ Ver seção 2.7.1.
} 
tamanho dos elementos da estrutura secundária, às regiões de loop que podem ser fixas ou variáveis dentro de um intervalo, entre outras restrições.

Para cada posicionamento da seqüência contra a estrutura, interações de pareamento e hidrofóbicas entre resíduos não locais são determinadas. Esses cálculos (termodinâmicos) são usados para determinar o alinhamento mais favorável da seqüência questionada contra o modelo de estrutura selecionado (Baxevanis e Ouellette, 2001).

\subsubsection{Modelagem "Ab initio"}

Em abordagens $A b$ initio, nenhuma homologia na seqüência é necessária em relação às proteínas de estrutura conhecida. O processo de determinação não depende da proteína ter uma dobra similar conhecida. As abordagens computacionais Ab initio típicas computam a estrutura tridimensional realizando buscas no espaço de conformações adequado (Vullo, 2002). Alguns modelos computacionais são baseados em métodos de otimização. Este problema envolve dois aspectos: primeiro, a especificação da função de minimização e, segundo, a escolha do algoritmo de busca (Khimasia e Coveney, 1997).

As funções de minimização são baseadas em leis físicas de movimentação em campos potenciais cuidadosamente planejados (dinâmicas moleculares) (Vullo, 2002). Na maioria dos casos a função procura minimizar a energia livre da molécula, pois sabe-se que a estrutura nativa das proteínas tem sua energia mínima (Khimasia e Coveney, 1997).

Avaliar a função de minimização para proteínas grandes e o fato de que o espaço de busca cresce exponencialmente conforme aumenta o número de resíduos da proteína são alguns dos desafios deste método. Em Cui et al. (1998), observou-se algumas outras informações referentes à estrutura de proteínas que podem ser utilizadas no processo de determinação de estrutura terciária, ou sejam:

1. Estruturas nativas de proteínas são compactas e têm um centro bem acondicionado que é altamente enriquecido com resíduos hidrofóbicos.

2. A força de interação hidrofóbica dirige o processo de dobra; dificilmente resíduos não-polares são encontrados na superfície externa da proteína. 
3. Proteínas globulares são organizadas com uma estrutura hierárquica; isto é, estrutura secundária, estrutura terciária e estrutura quaternária ${ }^{9}$.

4. As proteínas empregam caminhos de dobra evitando extensivas buscas no espaço conformacional.

\subsection{Funções de Energia}

As funções de energia utilizadas foram baseadas nas implementações disponíveis no sistema de modelagem molecular TINKER. O TINKER é um programa de modelagem molecular consistido de um pacote geral e completo para dinâmicas e mecânicas moleculares com algumas características especiais para biopolímeros (Ponder, 2001).

Por intermédio do TINKER, tem-se a possibilidade de se trabalhar em vários sistemas operacionais, por exemplo, Windows, Unix/Linux, Mac; ou seja, TINKER é um programa multiplaforma. É possível também, analisar seu código e, inclusive, até mesmo modificálo uma vez que é open-source. Referindo-se ao código do TINKER, este foi implementado em Fortran77 com algumas extensões escritas na linguagem C.

Assim sendo, o TINKER atualmente é bem difundido perante a comunidade científica. Vale ressaltar que o mesmo utiliza diversos conjuntos de parâmetros comuns a outros programas de pacotes de energia como, por exemplo: AMBER, CHARMM, OPLS entre outros (Ponder, 2001).

Com relação ao formato de arquivos e suas respectivas conversões, o TINKER reconhece tais formatos em:

- Coordenadas internas, onde são apresentados os ângulos de ligação, torsão e comprimentos das ligações dos átomos.

- Formato XYZ, contendo as coordenadas cartesianas da cada átomo.

\footnotetext{
${ }^{9}$ Refere-se à relação espacial (ligadas por ligações não-covalentes) entre duas ou mais cadeias polipeptídicas para compor uma proteína.
} 
- Formato PDB, amplamente utilizado para representar as estruturas de proteínas, ácidos nucleicos e nucleotídeos.

As funções de energia dividem-se em dois grupos: O grupo das ligações Covalentes e não-Covalentes. Pertencem ao primeiro grupo as energias Comprimento de Ligação, Ângulo de Torsão, Urey-Bradley e Imprópria. Já as energias de van der Waals e Eletrostática englobam o segundo grupo. Segundo Lodish et al. (2004) embora as energias do segundo grupo possuem uma força atrativa menor em relaçãs às primeiras, têm a mesma importância para a estabilização de uma biomolécula na qual se tem a proteína como exemplo. A seguir, estas energias serão apresentadas em seus detalhes.

\subsubsection{Energia de Comprimento de Ligação}

As interações de comprimento de ligação são melhor compreendidas de forma funcional analisando como a energia de ligação muda de acordo com o comprimento da ligação. A energia de ligação é menor em um particular comprimento natural ou de referência $\left(r_{0}\right)$. Se a ligação é comprimida, então a nuvem de elétrons dos dois átomos será gradualmente sobreposta. Se a ligação é afastada do equilíbrio a energia começa a aumentar. Eventualmente, no entanto, a ligação é disassociada, ou seja, deixa de existir. A Figura 2.11 mostra o comportamento da energia em relação ao comprimento da ligação. A linha cheia mostra a aproximação harmônica por uma expansão de Taylor para pequenas variações no comprimento da ligação em relação ao valor de referência. A linha pontilhada mostra o comportamento da energia utilizando o potencial de Morse (Morse, 1929) que mais se aproxima do comportamento real da energia potencial de ligação, havendo a disassociação da ligação após um certo afastamento do comprimento de ligação ideal. Embora tal potencial seja o que mais se aproxima do comportamento real, o seu emprego não é comum em virtude de sua complexidade, sendo que, para cada ligação, o mesmo exige três parâmetros (Leach, 2001).

A expansão de Taylor é aplicado em $\left(r-r_{0}\right)$, onde, como mencionado, $r_{0}$ é a distância de referência e $r$ é a distância real. A Equação (2.1) apresenta a expansão de Taylor utilizada para o cálculo da energia potencial de ligação. 


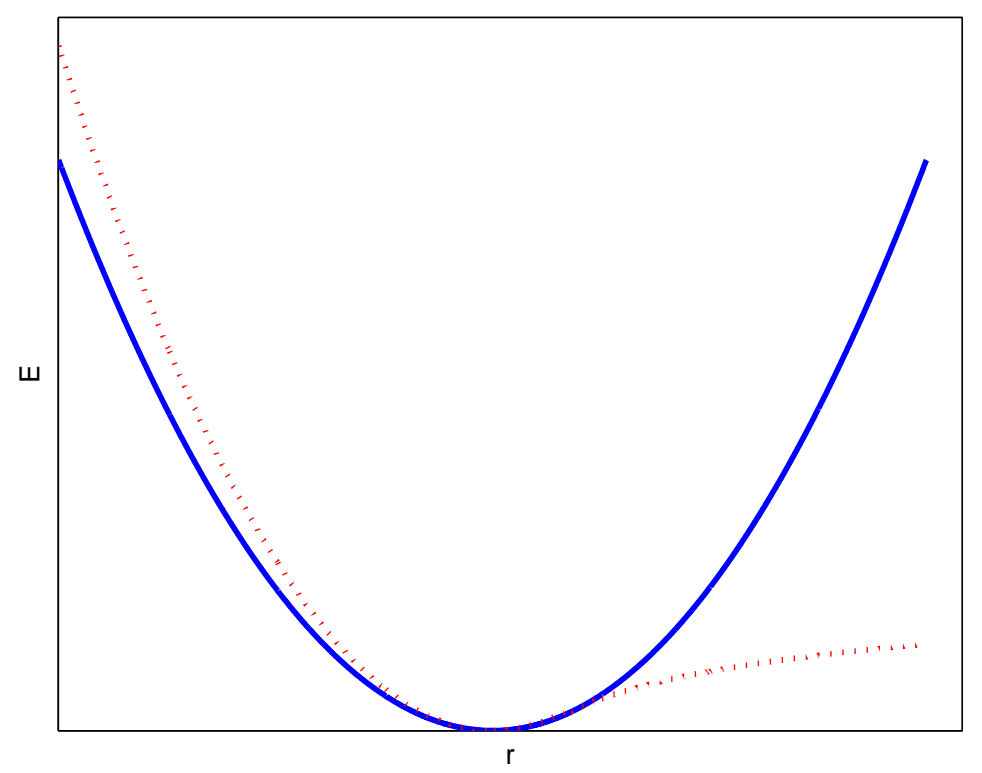

Figura 2.11: Gráfico da função de energia potencial de comprimento de ligação.

$$
E(r)=E\left(r_{0}\right)+\left.\frac{d E}{d r}\right|_{r=r_{0}}\left(r-r_{0}\right)+\left.\frac{1}{2} \frac{d^{2} E}{d r^{2}}\right|_{r=r_{0}}\left(r-r_{0}\right)^{2}+\left.\frac{1}{6} \frac{d^{3} E}{d r^{3}}\right|_{r=r_{0}}\left(r-r_{0}\right)^{3}+\ldots
$$

Em sua forma simplificada, a Equação (2.1) é resumida ao termo $\left(r-r_{0}\right)^{2}$, sendo conhecida como aproximação harmônica. Considerando $E\left(r_{0}\right)=0$ e que em $r=r_{0}$ a energia é nula, então a primeira derivada da energia é zero, e assumindo $k_{r}=\left.\frac{d^{2} E}{d r^{2}}\right|_{r=r_{0}}$, tem-se:

$$
E_{\text {bond }}(r)=\frac{1}{2} k_{r}\left(r-r_{0}\right)^{2}
$$

O comprimento de ligação de referência $r_{0}$ é freqüentemente denominado de comprimento de ligação de equilíbrio.

As forças entre átomos (covalentes) ligados são muito fortes em comparação com outras forças relativas às interações entre os átomos. Esta é uma justificativa para utilizar uma aproximação harmônica. É importante lembrar que esta é uma aproximação para o potencial de comprimento de ligação real e que, para grandes desvios de $r_{0}$, a aproximação harmônica não reflete o comportamento verdadeiro do potencial de comprimento de 
ligação. Para situações onde o comprimento de ligação pode desviar para longe de $r_{0}$, ou ainda, em casos onde se deseja calcular de forma precisa, há a necessidade de se utilizar o potencial de Morse.

\subsubsection{Energia de Ângulo de Torsão}

Interações de ângulo de torsão são diferentes das interações de comprimento de ligação em dois aspectos: O primeiro é que as barreiras de rotação internas são baixas comparadas às outras interações, significando que mudanças nos ângulos diedrais podem ser grandes; e segundo, o potencial de torsão, $E_{\text {tors }}$, é periódico por meio de uma rotação de $360^{\circ}$. O primeiro aspecto implica que seria inapropriado aproximar $E_{\text {tors }}$ por uma série de Taylor.

Além disso, $E_{\text {tors }}$ pode ser utilizada em muitas diferentes formas, dependendo dos átomos envolvidos. Assim, a forma funcional escolhida deve ser capaz de modelar amplamente diferentes potenciais.

Os termos Comprimento de Ligação e Ângulos de Torsão são consideradas medidas "hard" de liberdade, em que há a necessidade de uma quantidade substancial de energia para causar deformações significativas advindos dos seus valores de referência. Muitas das variações na estrutura da molécula se deve à complexa interação entre as contribuições torsionais (torções) e das ligações não-covalente (Leach, 2001).

Para as interações de torsão é comum sua modelagem utilizar uma série de Fourier, ou seja:

$$
E_{\text {tors }}(\phi)=\sum_{n} \frac{1}{2} V_{n} \cos (n \phi)
$$

onde $n$ é o número de fases utilizadas, $V_{n}$ são as constantes de força de rotação de torsão e $\phi$ é o ângulo de torsão atual. É costume mover a origem do potencial e incluir fatores de fase ficando a Equação (2.4) como se segue:

$$
E_{\text {tors }}(\phi)=\sum_{n} \frac{1}{2} V_{n}\left(1+\cos \left(n \phi-\gamma_{n}\right)\right)
$$

onde os ângulos de fase $\gamma_{n}$ são geralmente escolhidos de forma que os termos com $V_{n}$ 
positivo tenham energia mínima em $180^{\circ}$.

Na Figura 2.12 podem ser vistas as três primeiras fases da Equação (2.4). A linha cheia apresenta o gráfico da Equação (2.4) para $n=1$, a linha pontilhada para $n=2$ e a linha tracejada ilustra o gráfico da Equação (2.4) para $n=3$.

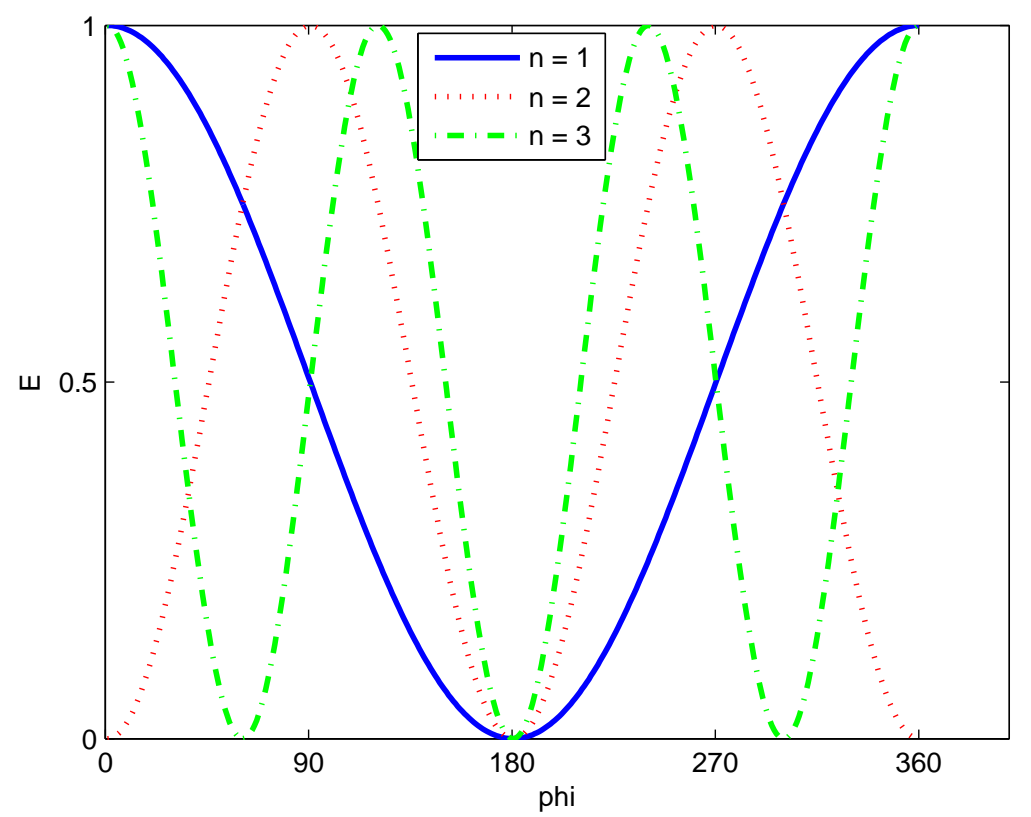

Figura 2.12: Gráfico da função de energia potencial de torsão.

\subsubsection{Energia Urey-Bradley}

O termo de energia Urey-Bradley refere-se às interações entre pares de átomos $i \mathrm{e}$ $j$ separados por duas ligações atômicas, conhecida como interação $1: 3$ átomos e são calculados utilizando um termo de aproximação harmônica da distância entre os àtomos $i$ e $j$, como o utilizado para energia de comprimento de ligação e energia de ângulo de ligação.

A expressão utilizada para a energia de interação Urey-Bradley é dada pela sequinte equação:

$$
E_{\text {urey }}(s)=\frac{1}{2} k_{\text {urey }}\left(s-s_{0}\right)^{2}
$$

onde $k_{\text {urey }}$ é a constante de força da interação Urey-Bradley e $s_{0}$ é a distância ideal entre 
os átomos $i$ e $j$.

\subsubsection{Energia Imprópria}

Energia imprópria está associada com deformações dos ângulos de torsão impróprios. Estes ângulos de torsão referem-se a átomos com hibridização $s p 2$, que geram deformações fora do plano.

Para o cálculo da energia referente às interações de ângulos de torsão impróprios é utilizada uma aproximação harmônica dada pela equação seguinte:

$$
E_{\text {improper }}(\omega)=\frac{1}{2} k_{\text {improper }}\left(\omega-\omega_{0}\right)^{2}
$$

onde $k_{\text {improper }}$ é a constante de força imprópria e $\omega_{0}$ é o ângulo de torsão impróprio ideal. Para o cálculo da energia imprópria da estrutura que está sendo avaliada é utilizado o somatório de todas as interações de impróprias da molécula.

\subsubsection{Energia Eletrostática ou de Carga}

A interação eletrostática entre um par de átomos é representada pelo potencial de Coulomb apresentado na Equação (2.7), onde $D$ é a função dielétrica efetiva para a média entre os átomos e $r$ é a distância entre dois átomos tendo cargas $q_{i}$ e $q_{j}$.

$$
E_{\text {charge }}=\sum i, j \frac{q_{i} q_{j}}{D r_{i, j}}
$$

Considerando que as cargas $\left(q_{i}\right.$ e $\left.q_{j}\right)$ dos átomos não variam, tem-se que a energia eletrostática então varia de acordo com a distância entre os átomos. Assim, tendo-se o produto das cargas $q_{i}$ e $q_{j}$ como positivo, e variando o tamanho da distância entre os átomos, obtem-se o gráfico apresentado na Figura 2.13. Neste gráfico, observa-se que conforme a distância entre os átomos diminui a energia tende a infinito e que quando a distância aumenta a energia tende a zero.

Como no caso da energia de van der Waals (Seção 2.8.6), tendo também como obje- 


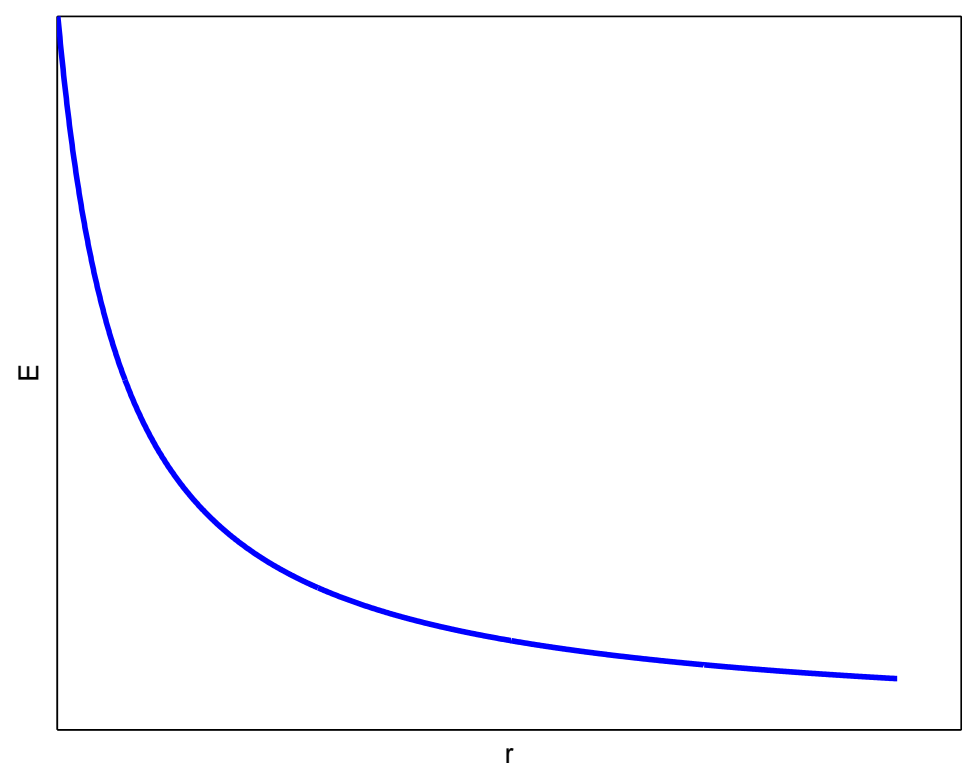

Figura 2.13: Gráfico da função de energia eletrostática.

tivo aumentar a velocidade computacional, é interessante estabelecer um valor de corte determinando a maior distância em que a interação eletrostática será considerada. Caso sejam consideradas todas as interações, tem-se um crescimento de acordo com o quadrado do número de átomos da molécula.

\subsubsection{Energia de Van der Waals}

A interação de van der Waals ocorre quando dois átomos aproximam-se muito um do outro criando uma força de atração fraca e inespecífica. Entende-se como uma interação inespecífica o caso em que dois átomos ligados não-covalentemente (não compartilham um par de elétrons) estiverem sufientemente próximos ${ }^{10}$ a ponto dos elétrons de um dos átomos pertubarem os elétrons do outro, sendo que esta pertubação gera um dipolo temporário no segundo átomo e atrair-se-ão fracamente (Lodish et al., 2004).

A interação de van der Waals é freqüêntemente modelada utilizando o potencial de Leonnard-Jones 6-12 que expressa a energia de interação utilizando constantes $A$ e $C$

\footnotetext{
${ }^{10}$ Quando muito próximos os átomos se repelirão devido as cargas negativas dos seus elétrons (Lodish et al., 2004).
} 
dependentes do tipo do átomo. Os valores de $A$ e $C$ podem ser determinados por uma variedade de métodos, como distância dos não ligados em cristais e medidas de dispersão na fase gasosa. A Equação (2.8) é a forma geral do potencial de Leonnard-Jones, onde $r=\frac{r_{i, j}}{R_{i}+R_{j}}$.

$$
E_{v d w}=\sum_{i, j} \frac{A_{i, j}}{r^{12}}-\frac{C_{i, j}}{r^{6}}
$$

As interações de van der Waals são uma das mais importantes para a estabilidade de macromoléculas biológicas. Estas interações são calculadas sobre pares de átomos. Em princípio, todas as interações de todos os pares de átomos deveriam ser avaliados, mas isto elevaria significativamente o custo computacional. Sendo assim, define-se previamente a máxima distância que eviderenciará uma interação de van der Waals. Em de Lima (2006) esta distância foi de $r_{i, j}>8$. Outro valor de corte estabelecido é quando a distância entre os átomos se torna menor que uma distância pré-definida, conhecido como corte de diminuição, pois neste caso $E_{v d w} \rightarrow \infty$, como pode ser observado na Figura 2.14 que mostra o gráfico da função de van der Waals em sua forma padrão.

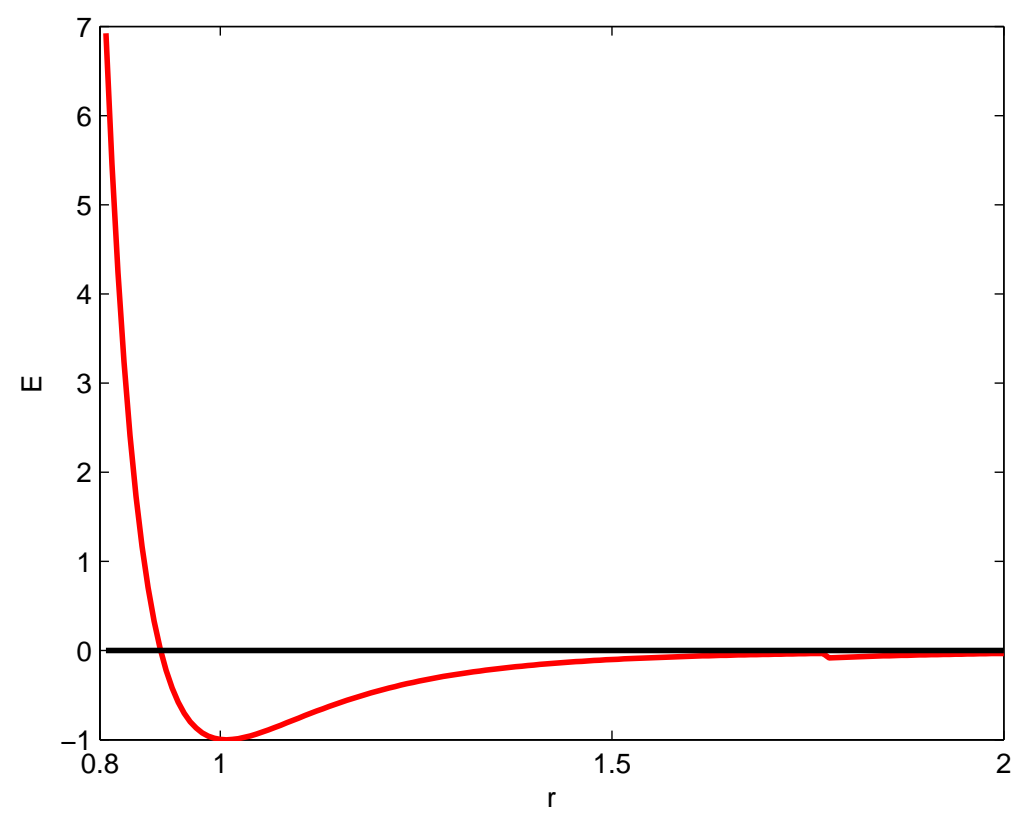

Figura 2.14: Gráfico da função de van der Waals na forma padrão. 


\subsection{Considerações Parciais}

Neste capítulo foi possível obter informações sobre as protéinas e elucidar os desafios, devido sua complexidade, para o problema de predição de estruturas terciárias de proteínas in silicio. Podemos enfatizar algumas informações sobre as proteínas, ou sejam:

- As proteínas são compostos orgânicos, constituído por compostos mais simples, denominados aminoácidos, os quais possuem um carbono central, $C_{\alpha}$, que possui quatro ligantes diferentes: um grupo amino, um grupo carboxila, um hidrogênio e um radical ou cadeia lateral. Os aminoácidos são diferenciados por mudanças no radical. Pequenas seqüencias de aminoácidos são chamados polipeptídeos.

- As proteínas são moléculas hierarquicamente estruturadas, ou seja, possuem uma estrutura primária (seqüência linear dos aminoácidos), estrutura secundária (conformações locais repetidas em quase todas as proteínas) e a estrutura terciária (arranjo tridimensional da molécula protéica).

- A relevância em investigar a estrutura terciária da proteína está em virtude de ser possível determinar qual a função da proteína no organismo. Este conhecimento contribui para o desenvolvimento de novos fármacos, pois conhecendo a estrutura tridimensional, torna-se possível determinar quais os melhores compostos podem ligar-se ao sítio ativo da proteína.

Foi também descrito as funções de energia que serão utilizadas na função de avaliação ${ }^{11}$ do algoritmo proposto.

\footnotetext{
${ }^{11}$ Ver na Seção 5.1.
} 


\section{Capítulo 3}

\section{Abordagem Evolutiva Multi-objetiva}

\section{Fuzzy}

A abordagem Evolutiva ou Computação Evolutiva (CE) trata de inspirar-se nos fenômenos que ocorrem na natureza para solucionar problemas, principalmente na área de otimização. Uma das motivações de aplicar CE é sua capacidade de lidar com problemas complexos para os quais não é possível, ou é difícil, obter uma descrição detalhada dos mesmos ou não se consegue impor restrições rígidas ao escopo do problema de otimização. Outra motivação é capacitar o computador a tomar decisões, antes restritas a especialistas humanos, possuindo como informação somente as conseqüências das ações tomadas anteriormente, constiuindo assim a evolução do processo de aprendizagem (Michalewicz, 1996).

A abordagem Fuzzy possibilita ao computador a proficiência de intepretar características subjetivas, ou até mesmo, quando suas fronteiras ${ }^{1}$ não são possíveis definir com segurança.

Neste capítulo, a Seção 3.1 trata da otimização multi-objetivo no que diz respeito ao conceito e definições. A Seção 3.2 referencia sobre a base fundamental dos algoritmos genéticos (Seção 3.3) que é a teoria da evolução. A Seção 3.4 refere-se aos algoritmos evolutivos aplicados nos problemas de otimização multi-objetivo. A Seção 3.5 abordará a

\footnotetext{
${ }^{1}$ Ver a Seção 3.1 .
} 
lógica Fuzzy e na Seção 3.6 será apresentada a abordagem evolutiva multi-objetiva Fuzzy que é a metodologia computacional que será investigada e aplicada.

\subsection{Otimização Multi-Objetivo}

Os Problemas de Otimização Multi-Objetivo (POMO) abordam os problemas onde a quantidade de objetivos não seja único e que há a necessidade de serem tratados simultaneamente. Neste tipo de problema, há um grupo de soluções que atenda um "equilíbrio" de situações (soluções).

Um POMO possui um conjunto de funções objetivos a serem otimizadas e restrições que devem ser satisfeitas por qualquer solução factível ${ }^{2}$ (Deb, 2001). O conjunto de todas as soluções factíveis é conhecido como espaço de busca ou região factível.

Para os algoritmos de otimização, todas as funções objetivos devem ser maximizadas ou minimizadas.

O espaço de objetivos $\mathbf{Z}$ é um espaço multi-dimensional, composto pelo vetor funções objetivos $\mathbf{f}(\mathbf{x})$. A diferença entre multi-objetivo e mono-objetivo é o espaço de busca: no multi-objetivo é multidimensional, cada solução $\mathbf{x}$, no espaço de decisão, possui f(x) em Z; e no mono-objetivo, é unidimensional.

\subsubsection{Soluções de Pareto Ótimas}

Apresentar uma decisão implica em considerar vários aspectos visando encontrar a melhor solução. Pode haver situações que, considerando somente as características quantitativas, não se consegue determinar uma solução melhor que a outra. Toma-se como exemplo Ticona (2003): para a decisão da compra de um carro, pode-se considerar que se está procurando o carro com melhores preço e conforto. A Figura 3.1 ilustra essas opções.

O objetivo é minimizar preço e maximizar conforto. Neste caso, tem-se cinco possíveis alternativas de compra. As soluções 1 e 2, são descartadas, pois a solução 5 fornece mais

\footnotetext{
${ }^{2}$ Uma solução x é factível se, e somente se, satisfazer todas as restrições. Caso contrário, a solução será não factível.
} 


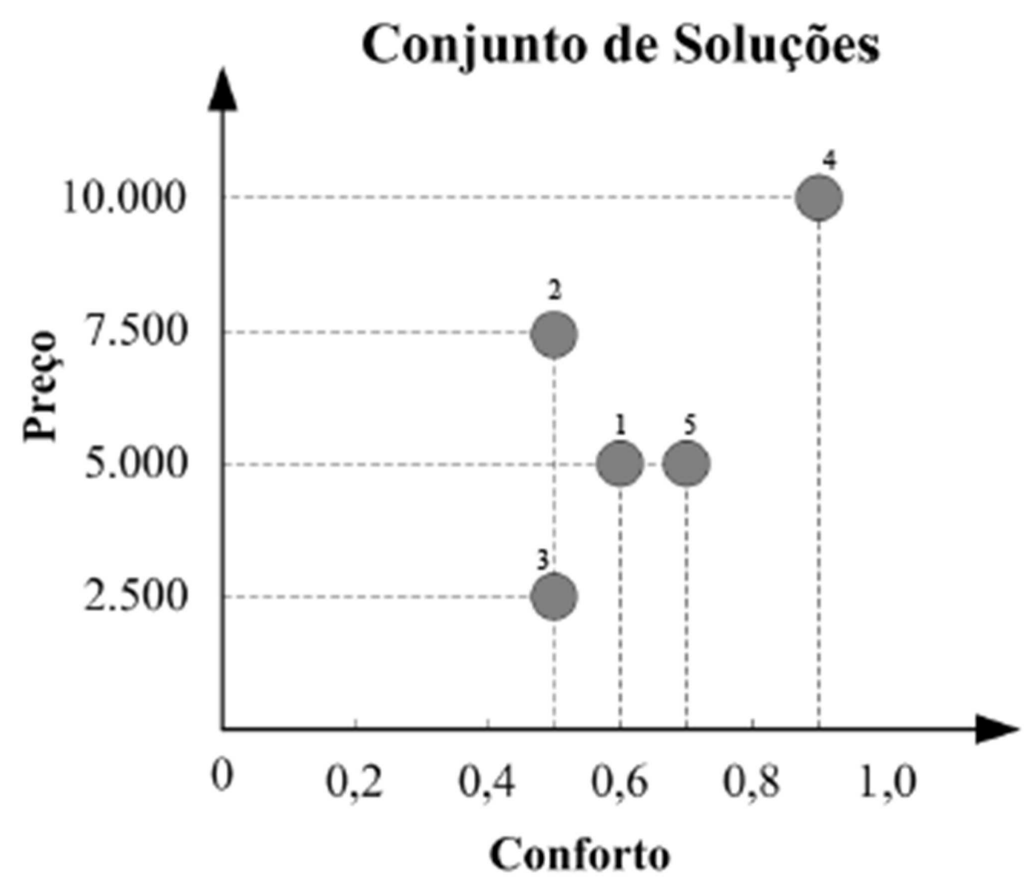

Figura 3.1: Exemplo do multi-objetivo (Ticona, 2003).

conforto por um igual preço e preço inferior, respectivamente. As soluções 3, 4 e 5 são as melhores alternativas de compra, mas em termos quantitativos, não se pode afirmar quem é a melhor. Pode-se atribuir um "compromisso" entre os objetivos. Quanto maior o conforto, maior o preço e vice-versa (Ticona, 2003).

Uma solução domina uma outra solução se, e somente se, em todos seus objetivos, possuir valores melhores. No exemplo de Ticona (2003), a solução 5 domina a solução 1 e não é dominada por nenhuma outra. Aplica-se o mesmo, para as soluções 3 e 4 .

Não tendo mais informações a respeito das soluções, pode-se afirmar que o conjunto das soluções 3, 4 e 5 são as melhores soluções, o qual é também conhecido como conjunto não dominado. Logo, as soluções 1 e 2 constituem o conjunto dominado.

O conjunto das soluções não dominadas pode ser representado no espaço cartesiano e formam a chamada frente de Pareto $^{3}$ ou fronteira de Pareto. As soluções Pareto ótimas ou conjunto Pareto ótimo, ou ainda, fronteira ótima de Pareto, formam o conjunto de

\footnotetext{
${ }^{3}$ Vilfredo Pareto, economista e sociólogo italiano. Graduou-se na universidade de Turin em 1869 e trabalhou como engenheiro em uma grande companhia ferroviária. Em 1893 foi lecionar na universidade de Lausanne, França (Encyclopédia Britannica, 2007).
} 
soluções não dominadas em relação a todas as soluções possíveis.

\subsubsection{Metas em Otimização Multi-Objetivo}

Em Deb (2001) é assinalada duas importantes metas em otimização multi-objetivo:

1. Encontrar um conjunto de soluções que esteja o mais próximo possível do conjunto Pareto ótimo.

2. Encontrar um conjunto de soluções com maior diversidade possível.

A primeira meta é comum para todos os problemas de otimização, porque soluções muito distantes da fronteira ótima de Pareto são indesejáveis. No entanto, a segunda meta, encontrar a maior divesidade, é uma meta específica para a otimização multi-objetivo. Em POMO, trabalha-se com o espaço de decisões e o espaço de objetivos, sendo imprescindível que as soluções tenham uma boa diversidade nestes espaços.

\subsection{Teoria da Evolução}

A teoria da evolução foi proposta por Charles Darwin (Darwin, 1859) na década de 1850 e até nos dias atuais é o principal conceito unificador das diversas áreas da biologia. Tal teoria começou a ser desenvolvida a partir das observações de Darwin durante sua viagem a bordo do navio Beagle. Esta teoria tem como um de seus princípios o conceito de seleção natural, o qual afirma que o meio atua sobre os indivíduos selecionando os mais adaptados ao ambiente para sobreviver, pois as populações não podem crescer demais. São considerados indivíduos adaptados ao ambiente aqueles que conseguem sobreviver e deixar descendentes.

Darwin não conseguia explicar, geneticamente, como a variabilidade dos indivíduos surgia e era transmitida para os descendentes. Só em 1900, nos estudos de Gregor Mendel, torna-se possível explicar a ligação entre os mecanismos de herança e o cromossomo, dando origem a genética (Silva Junior e Sasson, 2003). 
Em 1940, pesquisadores com o auxílio da teoria genética chegaram à Teoria Sintética da Evolução ou Neodarwinismo (Silva Junior e Sasson, 2003) baseada nos conceitos de recombinação gênica e mutação. A recombinação gênica é responsável pela transmissão das características dos pais para os filhos. A mutação é responsável pelo surgimento da diversidade nos indivíduos da população, com o surgimento de novas características que, se forem benéficas, tornam os indivíduos mais aptos e adaptados, facilitando a geração de descendentes com tais características; caso contrário, essas características tendem a ser eliminadas. Esse processo é denominado de seleção natural.

\subsection{Algoritmos Genéticos}

Holland (1975) introduziu os Algoritmos Genéticos (AGs) com a motivação de estudar, formalmente, os conceitos de adaptação que ocorrem na natureza, formalizá-los matematicamente e desenvolver sistemas artificiais ${ }^{4}$ que imitassem os mecanismos originais encontrados em sistemas naturais.

O AG proposto por Holland é um método que consiste em modificar uma população ${ }^{5}$ inicial em uma nova população utilizando a seleção natural e os operadores genéticos: recombinação gênica (ou crossover) e mutação. Os AGs utilizam uma terminologia originada da teoria da evolução natural (Seção 3.2 ) e da genética. Um indivíduo da população é representado por um único cromossomo, que contém a codificação (genótipo) de uma possível solução do problema (fenótipo). Cromossomos são geralmente implementados na forma de listas de atributos, vetores ou strings, onde cada atributo é conhecido como gene e os possíveis valores que um determinado gene pode assumir são denominados alelos. No AG proposto por Holland um cromossomo é geralmente representado por uma string binária, ou seja, uma string de zeros e uns.

Segundo Michalewicz (1996), um AG busca um espaço de soluções potenciais para o problema e para isso requer um equilíbrio entre dois objetivos aparentemente conflitantes: o aproveitamento das melhores soluções e a exploração do espaço de busca. AGs cons-

\footnotetext{
${ }^{4}$ Simulados em computador.

${ }^{5}$ Conjunto de indivíduos representando as soluções candidatas codificadas de forma similar a cromossomos em genética.
} 
tituem, assim, uma classe de métodos de busca de propósito geral que apresentam um balanço considerável entre aproveitamento de melhores soluções e exploração do espaço de busca.

Mesmo apresentando etapas não-determinísticas em seu desenvolvimento, os AGs, não são métodos de busca puramente aleatórios em conseqüência à combinação de variações aleatórias com seleção pelos valores de adequação (fitness) atribuído a cada indivíduo. Uma propriedade importante dos AGs é que esses mantêm uma população de soluções candidatas enquanto que outros métodos alternativos, como simulated annealing (Aarts e Korst, 1989), analisam um único ponto no espaço de busca a cada instante. Além disso, os AGs possuem um paralelismo implícito decorrente da avaliação independente de cada uma das cadeias de bits (cromossomo) que compõem os indivíduos. O processo de busca é multi-direcional, com a manutenção de soluções candidatas que representam a busca em várias partes do domínio e com troca de informações entre essas soluções. A cada geração, soluções relativamente "boas" geram mais descendentes, enquanto que soluções relativamente "ruins" tendem a ser eliminadas. Para fazer a distinção entre diferentes soluções, é empregada a função de avaliação (fitness) que simula o papel da pressão exercida pelo ambiente sobre o indivíduo. O Quadro 3.1 descreve um AG típico:

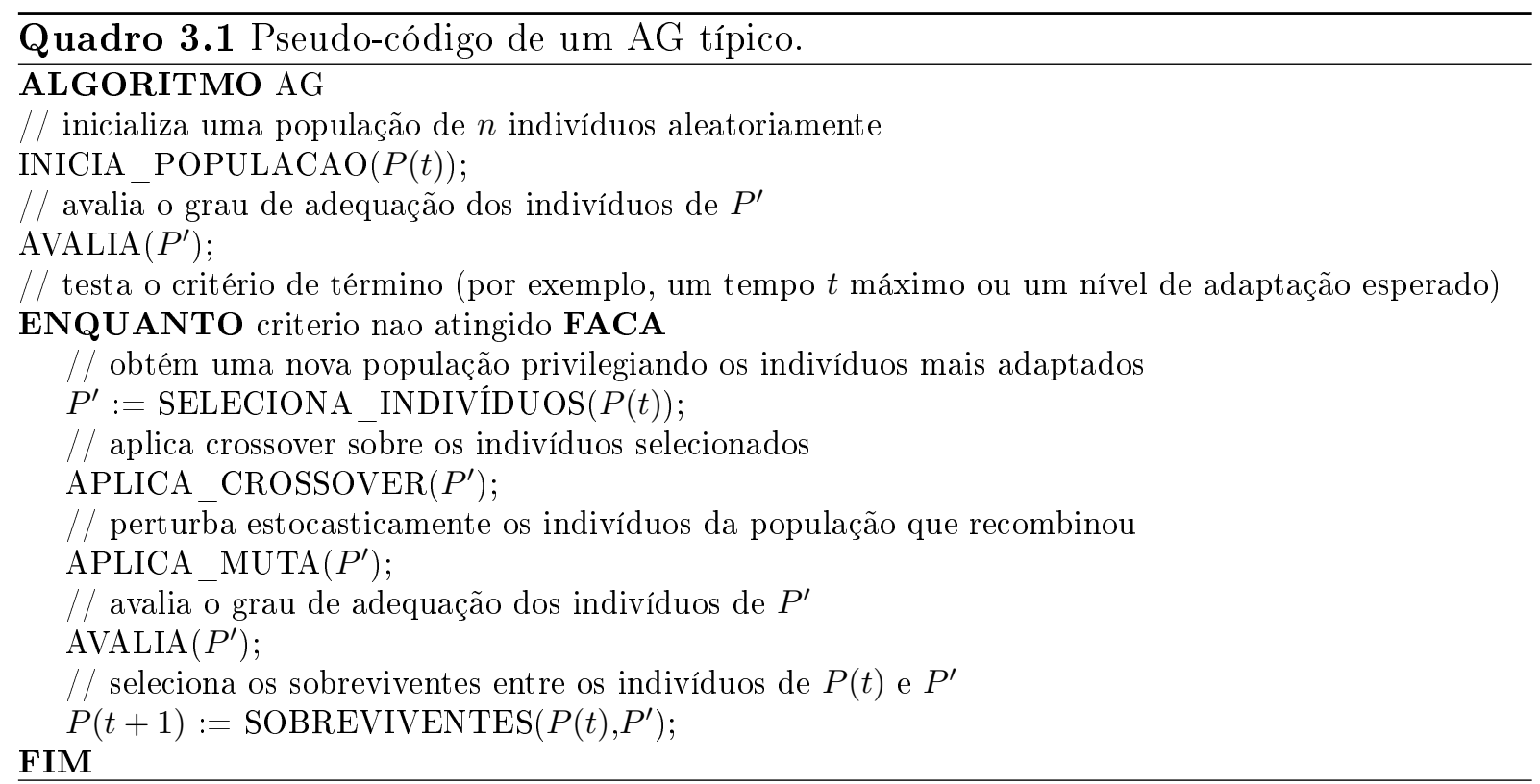

Para desenvolver um AG, em um problema particular, deve-se considerar os seguintes componentes: 
- representação genética para soluções potenciais (etapa de codificação);

- procedimento para criar uma população inicial;

- função de avaliação para classificar as soluções em termos de sua adaptação ao ambiente (sua capacidade de resolver o problema);

- definir os operadores genéticos ${ }^{6}$ com base na codificação (representação dos dados referentes ao indivíduo) utilizada;

- valores para os diversos parâmetros do AG, tais como: tamanho da população, probabilidades de aplicação dos operadores genéticos e outros.

\subsubsection{Codificação dos Indivíduos}

A codificação é uma das etapas mais críticas na definição de um AG. No AG clássico7 os indivíduos da população são codificados em strings binárias de tamanho fixo. A grande motivação para o emprego da codificação binária está na Teoria de Esquemas (Holland, 1992) utilizada para justificar a eficiência dos AGs e, concluindo, a representação binária maximiza o paralelismo implícito inerente ao AG. Entretanto, tanto Michalewicz (1996) como Deb (2001) apresentam resultados de comparações do desempenho de AGs com codificação binária e com ponto flutuante. Os resultados apresentados revelam superioridade da codificação em ponto flutuante quando comparada com a codificação binária.

Michalewicz (1996) argumenta que a representação binária não é adequada quando o espaço de busca é de alta dimensão. Porém, esta argumentação não é muito aceita na literatura sobre AGs. Espaços de busca de alta dimensão podem às vezes ser explorados eficientemente, enquanto que espaços de busca de dimensão reduzida podem apresentar dificuldades significativas. Outro problema encontrado com a codificação binária ocorre quando o espaço de busca do problema é contínuo, podendo ocorrer Hamming cliffs com certas strings, por exemplo 01111 e 10000, onde a transição para uma solução vizinha no espaço de números de ponto flutuante requer a alteração de muitos bits da string (Deb,

\footnotetext{
${ }^{6}$ Ver na Seção 3.3.3.

${ }^{7}$ Proposto por Holland.
} 
2001). Os Hamming cliffs presentes na codificação binária causam o atraso para uma busca gradual nos espaços de busca contínuos.

Outra dificuldade no caso de problemas com espaços de busca contínuos é a incapacidade de armazenar qualquer precisão arbitrária na solução ótima, sendo necessário quando a codificação binária é utilizada escolher a priori o tamanho da string para que o AG seja capaz de armazenar uma certa precisão na solução. Quanto mais precisão for requerida, então maior será o tamanho da string. Para grandes strings, requer-se uma população grande, aumentando assim a complexibilidade do algoritmo, tornando-o então inviável (Deb, 2001). Deb (2001) apresenta um operador de crossover para AGs com codificação de ponto flutuante que simula o princípio do operador de crossover de um ponto para AGs utilizando a codificação binária.

A definição inadequada da codificação pode acarretar problemas de convergência prematura $^{8}$ do AG. A estrutura de um cromossomo deve representar uma solução como um todo e deve ser a mais simples possível.

Em Michalewicz (1996) são referenciados que nos problemas de otimização com restrição há a possiblidade de que os indivíduos modificados por crossover/mutação sejam inválidos. Nesses casos, cuidados especiais devem ser tomados na definição da codificação e/ou dos operadores.

\subsubsection{Definição da População Inicial}

Quando não há algum conhecimento do problema, o método para inicializar a população é aleatória. Deve atentar-se para os problemas com restrições visando não gerar indivíduos inválidos na etapa de inicialização. Conforme mencionado em de Lima (2006), no caso de codificação binária, se é sabido que a solução final vai apresentar mais $0^{\prime}$ s do que $1^{\prime}$ s, então esta informação pode ser utilizada, mesmo que não se saiba exatamente a proporção.

\footnotetext{
${ }^{8} \mathrm{~A}$ convergência prematura ocorre quando indivíduos relativamente adaptados, contudo não ótimos, rapidamente dominam a população fazendo com que o AG convirja para um máximo ou mínimo local. Este problema pode ocorrer devido a uma formulação inadequada do problema.
} 


\subsubsection{Operadores Genéticos}

Os operadores genéticos mais freqüentemente utilizados em AGs são o crossover e a mutação.

\section{Operador de Crossover}

O operador de crossover ou recombinação cria novos indivíduos utilizando a combinação de dois ou mais indivíduos. Estes indivíduos são chamados pais. No operador de crossover, há a troca de informação entre diferentes soluções candidatas. No AG clássico é atribuída uma probabilidade fixa de ocorrer crossover aos indivíduos da população.

O tipo de crossover mais difundido é o crossover de um ponto. Para a aplicação deste, são selecionados dois indivíduos (pais) e, a partir de seus cromossomos, são gerados dois novos indivíduos (filhos). Para gerar os filhos, seleciona-se um mesmo ponto de corte aleatoriamente nos cromossomos dos pais, então, os segmentos de cromossomo criados a partir do ponto de corte são trocados.

Muitos outros tipos de crossover têm sido propostos na literatura. Alguns, exclusivos, quando utiliza-se codificação em ponto flutuante. Um exemplo é o crossover de mistura $($ BLX- $\alpha)$ (Eshelman e Schaffer, 1993). Considere $x^{1}$ e $x^{2}$ dois indivíduos selecionados para crossover e assume-se que $x_{i}^{1}<x_{i}^{2}$ onde $i$ representa o $i$-ésimo gene. O BLX- $\alpha$ escolhe aleatoriamente uma solução no intervalo $\left[x_{i}^{1}-\alpha\left(x_{i}^{2}-x_{i}^{1}\right), x_{i}^{2}+\alpha\left(x_{i}^{2}-x_{i}^{1}\right)\right]$. A literatura tem reportado que o melhor valor para $\alpha$ é 0.5 sobre qualquer outro valor escolhido. Se a diferença entre os pais for pequena, então a diferença entre os pais e os filhos também será pequena e vice versa. Esta propriedade permite que este operador execute uma busca pelo espaço inteiro, no início, e também execute uma busca localizada quando a população tende a convergir para uma região do espaço de busca.

\section{Operador de Mutação}

O operador de mutação altera aleatoriamente um ou mais genes de um cromossomo. A taxa de mutação é a probabilidade de ocorrência de mutação em um gene. A finalidade do operador de mutação é criar uma variabilidade extra na população, mas sem destruir 
o progresso já obtido com a busca.

Para elucidar, toma-se a exemplo, a codificação binária. O operador de mutação padrão simplesmente troca o valor de um gene em um cromossomo (Holland, 1992). Assim, se um gene selecionado para mutação tem valor um, o seu valor passará a ser zero após a aplicação da mutação, e vice versa.

Nos problemas com codificação em ponto flutuante, os operadores de mutação mais populares são a mutação uniforme e a mutação gaussiana (Michalewicz e Schoenauer, 1996). O operador para mutação uniforme seleciona aleatoriamente um componente $k \in$ $\{1,2, \ldots, n\}$ do cromossomo $x=\left[x_{1}, \ldots, x_{k}, \ldots, x_{n}\right]$ e gera um indivíduo $x^{\prime}=\left[x_{1}, \ldots, x_{k}^{\prime}, \ldots, x_{n}\right]$, onde $x_{k}^{\prime}$ é um número aleatório (com distribuição de probabilidade uniforme) amostrado no intervalo $[L B, U B]$, onde $L B$ e $U B$ são, respectivamente, os limites inferior e superior para o valor do alelo $x_{k}$. No caso da mutação gaussiana, todos os componentes de um cromossomo $x=\left[x_{1}, \ldots, x_{k}, \ldots, x_{n}\right]$ são modificados na forma:

$$
x^{\prime}=x+N(0, \sigma)
$$

onde $N(0, \sigma)$ é um vetor de variáveis aleatórias gaussianas independentes, com média zero e desvio padrão $\sigma$. Outro operador de mutação, especialmente desenvolvido para problemas de otimização com restrições e codificação em ponto flutuante, é a chamada mutação não-uniforme, destinada a realizar pequenos ajustes necessários para atingir a solução ótima junto aos indivíduos da população. Este e outros exemplos de operadores de mutação para problemas de otimização numérica podem ser encontrados em Michalewicz (1996) e em Michalewicz e Schoenauer (1996).

\subsubsection{Seleção dos Indivíduos}

O AG proposto por Holland utiliza um método de seleção de indivíduos para a próxima geração chamado técnica da roleta (Michalewicz, 1996). A técnica da roleta atribui a cada indivíduo de uma população uma probabilidade de passar para a próxima geração que é proporcional ao fitness do indivíduo e à somatória do fitness de todos os indivíduos da população. Assim, quanto maior o fitness de um indivíduo, maior a probabilidade 
deste passar para a próxima geração. Sendo assim, a seleção de indivíduos pela técnica da roleta pode fazer com que o melhor indivíduo da população seja perdido, ou seja, não passe para a próxima geração. Uma alternativa é escolher como solução o melhor indivíduo encontrado em todas as gerações do algoritmo. Pode-se, também, manter sempre o melhor indivíduo da geração atual na geração seguinte, estratégia essa conhecida como seleção elitista (Fogel, 1994; Michalewicz, 1996).

A literatura relata outros mecanismo de seleção, dentre essas destacam-se a baseada em rank (Bäck et al., 1997) e seleção por Torneio. A primeira estratégia utiliza as posições dos indivíduos ordenados de acordo com o fitness para determinar a probabilidade de seleção. Podem ser usados mapeamentos lineares ou não-lineares para determinar a probabilidade de seleção. Já a segunda, um número $m$ de indivíduos da população é escolhido aleatoriamente para formar uma sub-população temporária. Deste grupo, o melhor indivíduo é selecionado. Assim, escolhe-se cada indivíduo que irá compor o grupo de $N$ indivíduos selecionados.

Os mecanismos de seleção têm sidos empregados, também, para determinar os indivíduos que irão sofrer crossover e mutação. O número de indivíduos selecionados para crossover pode ser bem menor que o total de indivíduos da população, indicando que só alguns terão maior probabilidade de gerar descendentes em grande número.

\subsection{Algoritmo Evolutivo Multi-objetivo}

Os Algoritmos Evolutivo Multi-Objetivo (AEMO) têm sido aplicados para problemas de otimização multi-objetivo (Seção 3.1). O primeiro AEMO implementado foi proposto por Schaffer (1985) e foi denominado VEGA (Vector Evaluated Genetic Algorithm). Nesta proposta Schaffer propõe uma modificação no AGs para avaliar cada objetivo separadamente. Um dos problemas do algoritmo proposto por Schaffer é que este não obtém boa diversidade nas soluções da fronteira de Pareto (Seção 3.1.1).

Goldberg (1989) cita um procedimento que ordena as soluções baseado no conceito de dominância que fornece um valor de aptidão para uma solução proporcional ao número de soluções que esta domina. Com isto, as soluções não dominadas possuem maior 
aptidão e assim terão maior quantidade de cópias na lista de soluções. Com o objetivo de manter a diversidade das soluções, Goldberg sugeriu a utilização de um método de compartilhamento que calcula o nicho de cada solução dentro da fronteira que a solução pertence. Com base nas idéias iniciais de Goldberg foram então propostos vários modelos de AEMOs.

O operador de seleção é a principal diferença entre os AEs tradicionais e os AEMOs, quando a comparação entre duas soluções deve se realizar de acordo com o conceito de dominância de Pareto. A Tabela 3.1 sintetiza os principais modelos de AEMOs encontrados na literatura. Em algumas proposta, como MOGA e SPEA, o valor de aptidão é proporcional à dominância da solução. Em outros métodos, como NPGA, utilizam a dominância Pareto e não calculam um valor de aptidão.

Os modelos de AEMO são classificados por Deb (Deb, 2001) em dois tipos:

1. Não elitistas: compreende os modelos que como o próprio nome indica, não utilizam alguma forma de elitismo nas suas interações.

2. Elitistas: compreende os modelos que empregam alguma forma de elitismo. Alguns modelos, como SPEA-2 e PESA (Tabela 3.1), utilizam uma população externa para armazenar as soluções não dominadas encontradas até o momento. Métodos como NSGA-II combinam a população atual com a população gerada e preserva as melhores soluções de ambas. Estudo realizado por Zitzler et al. (2000) conclui que o elitismo melhora as soluções encontradas por um modelo de AEMO.

A Tabela 3.1 apresenta os principais modelos de AEMO e seus autores.

Dentre os AEMOs, detalhar-se-á na Seção 3.4.1 o modelo proposto para o NSGA-II, em virtude da utilização do mesmo neste trabalho. A escolha do NSGA-II se baseia em dois aspectos:

1. Como relatado pela literatura, O NSGA-II é o AEMO mais utilizado atualmente em virtude de suas características.

2. O NSGA-II utiliza as fronteiras de Pareto, podendo se tornar então insatisfatório seu emprego para problemas acima de três objetivos. 
Tabela 3.1: Alguns exemplos de modelos de AEMO.

\begin{tabular}{|c|c|c|}
\hline Sigla & Nome do Modelo & Autores \\
\hline VEGA & Vector Evaluated Genetic Algorithm & (Schaffer, 1985) \\
\hline WBGA & Weight Based Genetic Algorithm & (Hajela e Lin, 1992) \\
\hline MOGA & Multiple Objective Genetic Algorithm & (Fonseca e Fleming, 1993) \\
\hline NSGA & Non-Dominated Sorting Genetic Algorithm & (Srinivas e Deb, 1994) \\
\hline NPGA & Niched-Pareto Genetic Algorithm & (Horn et al., 1994) \\
\hline PPES & Predator-Prey Evolution Strategy & (Laumanns et al., 1998) \\
\hline REMOEA & $\begin{array}{l}\text { Rudoph's Elitist Multi-Objective } \\
\text { Evolutionay Algorithm }\end{array}$ & (Rudolph, 2001) \\
\hline NSGA-II & $\begin{array}{c}\text { Elitist Non-Dominated Sorting Genetic } \\
\text { Algorithm }\end{array}$ & (Deb et al., 2000) \\
\hline $\begin{array}{l}\text { SPEA, } \\
\text { SPEA-2 }\end{array}$ & Strenght Pareto Evolutionary Algorithm 1 e 2 & $\begin{array}{l}\text { (Zitzler e Thiele, 1998), } \\
\text { (Zitzler et al., 2001) }\end{array}$ \\
\hline$\overline{\text { TGA }}$ & Thermodynamical Genetic Algorithm & (Kita et al., 1996) \\
\hline PAES & Pareto-Archived Evolutionary Strategy & (Knowles e Corne, 1999) \\
\hline $\begin{array}{l}\text { MONGA-I, } \\
\text { MONGA-II }\end{array}$ & Multi-Objective Messy Genetic Algorithm & (Veldhuizen, 1999) \\
\hline Micro-GA & Multi-Objective Micro-Genetic Algorithm & (Coello e Pulido, 2001) \\
\hline PESA-I, PESA-II & Pareto Envelope-Base Selection Algorithm & $\begin{array}{l}\text { (Corne et al., 2000), } \\
\text { (Corne et al., 2001) }\end{array}$ \\
\hline RDGA & Rank-Density-based Genetic Algorithm & (Haiming e Gary, 2003) \\
\hline GENMOP & General Multi-objective Parallel Genetic Algorithm & (Kleeman e Lamont, 2005) \\
\hline SDMOGA & $\begin{array}{l}\text { Multi-Objective Genetic Algorithm } \\
\text { based on Objective Space Divided }\end{array}$ & (Wangshu et al., 2006) \\
\hline RJGGA & Real-coding Jumping Gene Genetic Algorithm & (Ripon et al., 2007) \\
\hline
\end{tabular}

\subsubsection{Algoritmo NSGA-II}

O algoritmo NSGA-II é baseado em uma ordenação elitista por não-dominância (Deb et al., 2000). O NSGA-II, com a população de indivíduos pais $P$, gera a população de indivíduos filhos $Q$ como nos AEs convencionais. Na primeira iteração, gera-se uma população $P_{t}$, que é ordenada por não-dominância (Seção 3.1.1). Depois, aplicando os operadores de seleção por torneio (Seção 3.3.4), cruzamento e mutação, obtém-se a população de indivíduos filhos $Q_{t}$. Tanto $P$ como $Q$ são de tamanho $N$.

Para o próximo passo, ambas as populações são unidas em uma nova população $R_{t}=$ $P_{t} \bigcup Q_{t}$, com $|R|=2 N$. Para as seguintes gerações, $n=1,2, \ldots$, o algoritmo NSGA-II trabalha com a população $R_{t}$ (Figura 3.2).

Obtida a população $R_{t}$, realiza-se então a ordenação por não-dominância da mesma, obtendo as fronteiras $F_{1}, F_{2}, \ldots$ e todos estes conjuntos são inseridos na nova população 
$P_{t+1}$. Considerando que apenas $N$ soluções podem ser inseridas na população $P_{t+1}, N$ soluções de $R_{t}$ são descartadas. Para preencher as $P_{t+1}$, começa-se com as soluções em $F_{1}$; se não forem completadas as $N$ soluções, prossegue-se com $F_{2}$ e, assim por diante. Cada conjunto $F_{i}$ deve ser inserido na sua totalidade em $P_{t+1}$, isto ocorre quando $\left|P_{t+1}\right|+\left|F_{i}\right| \leq$ $N$. Quando ocorre o caso de ao inserir $F_{j}$ a $\left|F_{j}\right|>N-\left|P_{t+1}\right|$, o algoritmo NSGA-II seleciona as soluções de $F_{j}$ que estejam melhor diversificadas. A Figura 3.2 ilustra uma iteração do algoritmo NSGA-II.

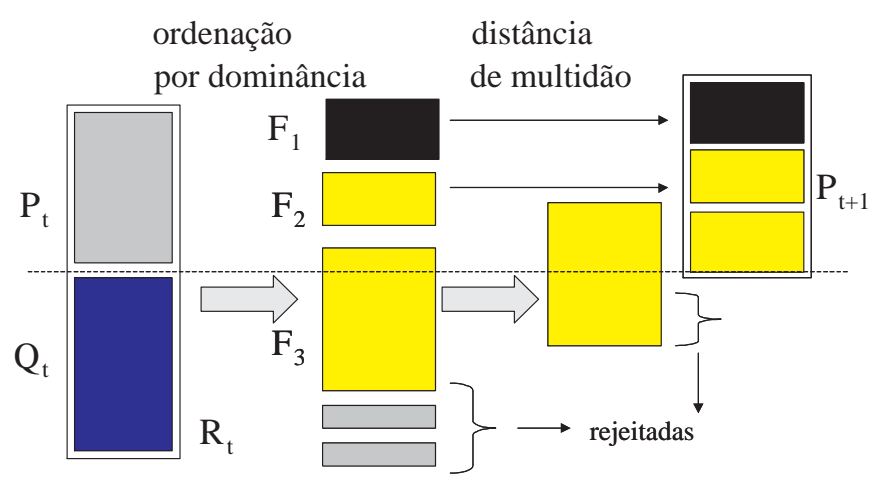

Figura 3.2: Esquema do Modelo NSGA-II (Deb, 2001).

O algoritmo NSGA-II emprega um método chamado de distância de multidão (Ver Seção 3.4.2) (crowding distance). Tendo obtidas as distâncias, os conjuntos de soluções $F_{j}$ são ordenados decrescentemente em relação às suas distâncias, e copia-se as primeiras $N-\left|P_{t+1}\right|$ soluções de $F_{j}$ para $P_{t+1}$. Finalmente, obtém-se $Q_{t+1}$ a partir de $P_{t+1}$ usando os operadores de seleção por torneio, crossover e mutação.

\subsubsection{Distância de Multidão}

A distância de multidão $d_{i}$ de uma solução $i$ representa uma estimativa do perímetro formado pelo cubóide cujos vértices são os seus vizinhos. A Figura 3.3 apresenta a distância de multidão para a solução $i$. Quanto maior o cubóide de $i$, mais afastada se encontra a solução $i$ dos seus vizinhos. As soluções extremas em cada objetivo, ou seja, a melhor e a pior solução em cada objetivo, terão um cubóide infinito. O procedimento para encontrar a distância de multidão está descrito no Quadro, 3.2 onde $I_{i}^{m}$ representa a $i$-ésima solução na lista ordenada pelo objetivo $m . I_{1}^{m}$ e $I_{l}^{m}$ são os elementos da lista com o menor e o 
maior valor para um objetivo $m . f_{m}^{I_{i+1}^{m}}$ e $f_{m}^{I_{i-1}^{m}}$ são os valores dos vizinhos de $i$ na $m$-ésima função objetivo. Os $f_{m}^{\max }$ e $f_{m}^{\min }$ são parâmetros dos limites máximo e mínimo em cada objetivo. A Equação (3.1) garante que as soluções mais afastadas tenham $d_{i}$ maior do que as mais próximas.

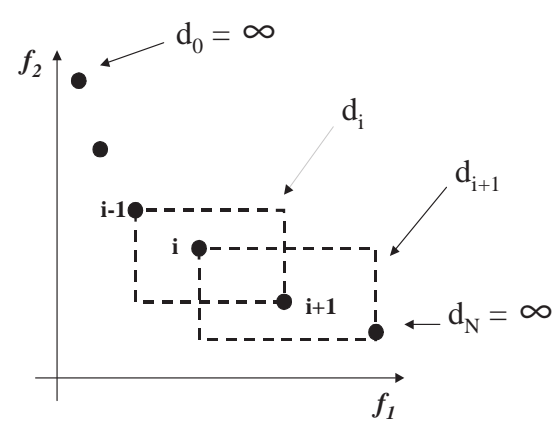

Figura 3.3: Cálculo da distância de multidão no NSGA-II (Deb, 2001).

Quadro 3.2 Cálculo da distância de multidão no NSGA-II.

ALGORITMO Distância Multidão

$/ / F_{j}$ : conjunto de soluções na fronteira $i$

1. $l$ denota o número de soluções em $F_{j}$

2. Para cada solução em $F j$ atribui-se $d_{i}=0$

3. Para cada função objetivo $m=1,2, \ldots, M$

Ordenar decrescentemente as soluções por $f_{m}$ na lista $I^{m}$

4. Para cada solução extrema (mínimo e máximo) em cada um dos $M$ objetivos

Fazer $d_{I_{1}^{m}}=d_{I_{l}^{m}}=\infty$

5. Para as soluções $i=2, \ldots, l-1$ calcular:

$$
d_{I_{i}^{m}}=d_{I_{i}^{m}}+\frac{f_{m}^{I_{i+1}^{m}}-f_{m}^{I_{i-1}^{m}}}{f_{m}^{\max }-f_{m}^{m i n}}
$$

A forma como é mantida a diversidade entre as soluções não dominadas é a principal vantagem do NSGA-II. O método de comparação por multidão é utilizado para a seleção por torneio e para escolher os elementos da fronteira $F_{j}$ (Deb, 2001). Se o conjunto $F_{1}$ tem um tamanho maior que $N$, será executado o processo de escolher apenas $N$ soluções, pois utilizando a distância de multidão faz com que sejam perdidas algumas soluções. Seja um $F_{1}$ onde existam várias soluções Pareto-ótimas muito próximas e alguma solução distante não Pareto-ótima, mas não dominada no momento. Considerando que o cubóide da solução não dominada é maior, esta solução será copiada em $P_{t+1}$ enquanto que uma solução Pareto-ótima é eliminada. Esta situação faz com que o NSGA-II possa cair em 
um ciclo de gerar soluções Pareto-ótimas e não Pareto-ótimas até convergir finalmente a um conjunto de soluções Pareto-ótimas (Deb, 2001).

\subsection{Lógica Fuzzy}

Os sistemas Fuzzy (nebulosos), introduzido por Zadeh (1973), consistem em aproximar o processo de decisão computacional da decisão humana. Ou seja, a decisão de uma máquina não se resuma apenas um "sim" ou "não", mas também tenham decisões abstratas do tipo "próximo de", "em torno de", "muito boa", etc (Pedrycz e Gomide, 1998).

As características de um sistema Fuzzy são as seguintes:

- Expressa imprecisões e incertezas.

- Sistemas baseados em regras lingüisticas.

- Raciocínio é executado de modo aproximado.

- Conclusões são obtidas de forma paralela.

- Capacidade de aproximar sistemas não lineares complexos.

A grande diferença entre os conjuntos Fuzzy e os conjuntos Clássicos está na definição da Função de Inclusão. Nos conjuntos Clássicos, ela indica se um determinado elemento pertence ou não a determinado conjunto. Já em conjuntos Fuzzy, ela é flexibilizada, ou seja, os elementos podem pertencer parcialmente ao conjunto (Função Pertinência ${ }^{9}$ ).

\subsubsection{Universo de Discurso}

Universo de Discurso é o conjunto de valores que definem o domínio das variáveis de Entrada e Saída. Como exemplo, na Figura 3.4 (Battistella e Cechin, 2004), ilustra-se um sistema Fuzzy, tendo o universo de discurso $X$ no intervalo $[-5,5]$, sendo que $F 1, F 2$ e $F 3$ são os respectivos conjuntos fuzzy.

\footnotetext{
${ }^{9}$ Ver Seção 3.5.2.
} 


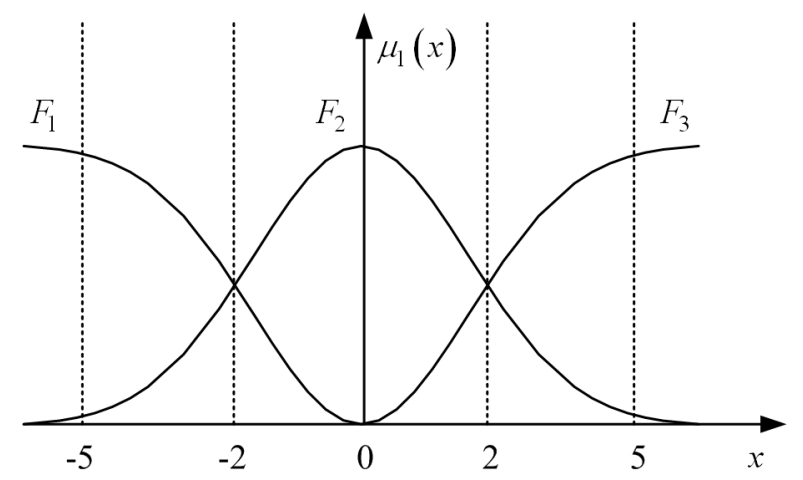

Figura 3.4: Exemplo do sistema Fuzzy utilizado em Battistella e Cechin (2004)

\subsubsection{Funções de Pertinência}

A Função de Pertinência é a função que define o grau de inclusão de um determinado elemento em um conjunto Fuzzy, considerando seu universo de discurso (Seção 3.5.1). Formalmente, tem-se este mapeamento descrito em (3.2).

$$
\mu_{A(x)}=x \rightarrow[0,1] ; x \in X
$$

onde $\mu_{A(x)}$ retorna o grau de pertinência do elemento $x$, referente ao universo de discurso $X$, em relação ao conjunto fuzzy $A$. O grau de pertinência é um valor normalizado entre 0 e 1 , ou seja, $\mu_{A(x)} \in[0,1]$ (Pedrycz e Gomide, 1998).

Como exemplo, considera-se a Figura 3.4 que denota três conjuntos fuzzy: $F_{1}, F_{2}$ e $F_{3}$. Neste exemplo, verifica-se que para $\mathrm{x}=0$, as funções $F_{1}, F_{2}$ e $F_{3}$ possui graus de pertinência 0,1 e 0 , respectivamente.

Os principais tipos de funções de pertinência são: Funções Triangulares, Funções Trapezoidais, Funções Gaussianas e Funções Sigmóides.

Uma informação importante quando trabalhando com conjuntos fuzzy é que mesmo um elemento possuindo grau de pertinência 1.0, não significa que este estará excluso dos outros conjuntos fuzzy. 


\subsubsection{Operações Fuzzy}

As operações básicas em conjuntos fuzzy são as seguintes: União, Intersecção e Complemento. Estas operações são geralmente definidas em função dos operadores $\max (\vee)$ e $\min (\wedge)$, os quais são análogos aos operadores produto(.) e soma $(+)$ da álgebra elementar.

A União entre dois conjuntos fuzzy $A$ e $B$, pertencentes a um mesmo universo de discurso $X$, é formada pelos valores máximos entre $\mu_{A(x)}$ e $\mu_{B(x)}$. Formalmente, tem-se:

$$
\mu_{A(x)} \cup \mu_{B(x)}=\max \left(\mu_{A(x)}, \mu_{B(x)}\right) ; x \in X
$$

A Intersecção entre dois conjuntos fuzzy $A$ e $B$, pertencentes a um mesmo universo de discurso $X$, é formada pelos valores mínimos entre $\mu_{A(x)}$ e $\mu_{B(x)}$. Formalmente, tem-se:

$$
\mu_{A(x)} \cap \mu_{B(x)}=\min \left(\mu_{A(x)}, \mu_{B(x)}\right) ; x \in X
$$

O complemento de um conjunto fuzzy $A$ normalizado, pertencente a um universo de discurso $X$, é formado pela subtração de $\mu_{A(x)}$ do valor unitário $\{1\}$. Formalmente, tem-se:

$$
\mu_{\bar{A}(x)}=1-\mu_{A(x)} ; x \in X
$$

Há a operação de agregação que consiste em combinar um ou mais conjuntos fuzzy visando a obtenção de um único conjunto fuzzy. Uma das aplicações da agregação é no processo de defuzzificação que será abordado na Seção 3.5.5.

Admitindo-se então $N$ conjuntos $F u z z y$ dados por $\{A 1, A 2, \ldots, A n\}$ definidos em um mesmo universo de discurso $X$, então a função de pertinência $\mu_{B(x)}$ representando o conjunto fuzzy $B$, o qual é resultante da aplicação da agregação $A G G R($.$) sobre os elementos$ de $\{A 1, A 2, \ldots, A n\}$, é dada por:

$$
\mu_{B(x)}=A G G R\left(\mu_{A 1(x)}, \mu_{A 2(x)}, \ldots, \mu_{A n(x)}\right) ; x \in X
$$

As condições necessárias para que uma função seja classificada como função de agre- 
gação são:

1. A função deve obedecer as condições de contorno definidas por:

- $A G G R(0,0,0,0, \ldots, 0)=0$

- $A G G R(1,1,1,1, \ldots, 1)=1$

2. A função deve obedecer a condição de monotonicidade, ou seja:

- $A G G R\left(a 1, a 2, a 3, a_{4}, \ldots, a n\right) \geq A G G R(b 1, b 2, b 3, b 4, \ldots, b n)$

Assim, verifica-se que os operadores min e max são também classificados como funções de agregação.

\subsubsection{Inferência Fuzzy}

Os sistemas de inferência fuzzy permite o tratamento de informações incertas e imprecisas, as quais são representadas por uma família de conjuntos fuzzy, possibilitando modelar o sistema quando as informações advindas são qualitativas. O processo de inferência fuzzy, ou raciocínio aproximado, permite o mapeamento do conhecimento a respeito de um sistema utilizando regras fuzzy do tipo "se-então". Tendo um conjunto finito dessas regras se pode determinar, por intermédio da inferência, o comportamento de variáveis de saída do sistema.

Considera-se que $x$ e $y$ são variáveis lingüisticas compostas, respectivamente, por um conjunto de termos $\{A 1, A 2, \ldots, A n\}$ e $\{B 1, B 2, \ldots, B n\}$, então o objetivo do processo de inferência é encontrar uma função de pertinência $B^{\prime}$ que representa a consequência da aplicação simultânea de regras da forma "se (condição) então (ação)". Assim, considerando um fato observável A', tem-se: 
FATO: $X$ é $A$ '

Regra 1 : Se $X$ é $A_{1}$ ENTÃO $Y$ é $B_{1}$

Regra 2 : Se $X$ é $A_{2}$ ENTÃO $Y$ é $B_{2}$

(...)

$\operatorname{Regra}_{N}$ : Se $X$ é $A_{N}$ ENTÃO $Y$ é $B_{N}$

CONSEQÜENCIA: $\quad Y$ é $B$

Para duas variáveis linguísticas $x$ e $y$ com valores $A$ e $B$, respectivamente, a função de pertinência $\mu_{A \rightarrow B(x, y)}$ indicando o resultado da inferência pode ser obtida através dos seguintes operadores:

1. Mandani $\mu_{A \rightarrow B(x, y)}=\min \left(\mu_{A(x)}, \mu_{B(y)}\right)$

2. Zadeh $\mu_{A \rightarrow B(x, y)}=\max \left(1-\mu_{A(x)}, \min \left(\mu_{A(x)}, \mu_{B(y)}\right)\right.$

3. Larsen $\left.\mu_{A \rightarrow B(x, y)}=\mu_{A(x)} \cdot \mu_{B(y)}\right)$

4. Aritmético $\mu_{A \rightarrow B(x, y)}=\min \left(1,1-\mu_{A(x)}+\mu_{B(y)}\right)$

5. Booleano $\mu_{A \rightarrow B(x, y)}=\min \left(1-\mu_{A(x)}, \mu_{B(y)}\right)$

O resultado final da inferência é uma região fuzzy representativa da saída do processo. Os passos para determinar tal região fuzzy de saída são constituídos por:

1. Encontrar todas as regras fuzzy que estejam ativadas.

2. Determinar a saída fuzzy de cada uma das regras ativadas.

3. Combinar (Agregar) todas as saídas fuzzy calculadas no passo (2).

\subsubsection{Processo de Defuzzificação}

Para determinar uma região fuzzy $B^{\prime}$ advinda de todas as regras ativadas se deve aplicar o operador de agregação (Seção 3.5.3) e, após, usando um método de defuzzificação, obtem-se uma resposta não-fuzzy (crisp). Os principais métodos de defuzzificação são os seguintes: 
1. Centro de Área: $\frac{\sum_{k=1}^{N} \mu_{B^{\prime}\left(V_{k}\right)} \cdot V_{k}}{\sum_{k=1}^{N} \mu_{B^{\prime}\left(V_{k}\right)}}$, onde $V_{k}$ é a discretização do universo de discurso.

2. Média dos Máximos: $\sum_{k=1}^{M} \frac{V_{k}}{M}$, onde $M$ é a quantidade de elementos que contêm graus de pertinência máximos.

Assim, a resposta final defuzzificada será um valor numérico pertecente ao universo de discurso da respectiva saída.

\subsubsection{Sistema de Inferência de Takagi-Sugeno}

Desenvolvido por Takagi e Sugeno (1985), sendo que o principal diferenciador está no fato de que a sua função de pertinência de saída pode ser tanto uma função linear quanto uma função constante.

Uma regra típica do sistema de inferência de Takagi-Sugeno pode ser descrito como:

Se $x$ é $A$ e $y$ é $B$ então $C$ é $a x+a y+c$

A metodologia de Takagi-Sugeno é mais apropriada quando há disponibilidade de informações quantitativas sobre o processo (Cheng-Jian e Yong-Ji, 2005), sendo esse o caso da aplicação abordada nesta dissertação.

\subsection{Método Evolutivo Multi-objetivo Fuzzy}

A integração de lógica Fuzzy e AE proporcionam a modelagem de problemas de otimização que possuem incertezas e informações imprecisas. Segundo Alcalá et al. (2004) o grande sucesso dos sistemas Fuzzy deve-se a sua capacidade de incorporar a experiência do conhecimento especialista, tendo por objetivo inferir na procura das melhores soluções, e o emprego de algoritmos evolutivos está em sua ampla utilização, inclusive em problemas de otimização, incluindo-se o multi-objetivo.

Bonissone et al. (2002) aplicou técnicas evolutivas para ajustar um sistema de decisão Fuzzy, onde o mesmo automaticamente computa o risco de uma aplicação de seguros. Já 
em Voget e Kolonko (1998) é apresentado um esquema de otimização multi-objetivo em que um sistema Fuzzy controla a regulação do processo de seleção e função de fitness. O sistema gerencia, por exemplo, a taxa de mutação e o tamanho da população.

O algoritmo FDD-GA (Fuzzy-Dominance-Driven GA), proposto em Koppen et al. (2005), investigou a relação da fuzzificação da dominância de Pareto e sua aplicação no design dos AEMOs para os problemas de otimização. Em tal estudo, utilizou o chamado problema da Caixa de Pareto $^{10}$, o qual permitiu comprovar uma melhor performance do algoritmo FDD-GA quando havia uma diminuição dos pontos dominados, sendo isto em virtude do aumento da dimensão da referida caixa quando o mesmo comparado com outros AEMOs inclusive o NSGA-II.

É importante ressaltar a diferença entre a proposta apresentada em Koppen et al. (2005) e esta dissertação. Neste trabalho, investiga-se a substituição das fronteiras de Pareto por um sistema Fuzzy, enquanto que a outra abordagem, busca encontrar a melhor solução perante todas as outras, ou seja, encontrar o Pareto Ótimo.

Já em González et al. (2006) é proposto um AEMO para contribuir na redução do erro aproximado global de um sistema Fuzzy. Tal algoritmo é uma modificação do NSGA-II com novos operadores de mutação. Sendo assim, segundo a proposta de González, torna-se possível modelar um sistema Fuzzy perante alguns dados de treinamento.

Um estudo de caso de uma companhia de exportação/importação, do sul da Espanha, foi apresentado em Jiménez et al. (2006). Nesta pesquisa evidenciou o uso de AEMO Fuzzy em virtude de sua complexidade.

\subsection{Considerações Parciais}

Neste capítulo foi abordado, teoricamente, as abordagens computacionais que serão investigadas, além de tratar sobre o problema de otimização multi-objetivo como um todo.

Foi possível evidenciar os aspectos do método evolutivo multi-objetivo fuzzy, a qual é a metodologia proposta neste trabalho. Além de uma breve revisão bibliográfica do

\footnotetext{
${ }^{10}$ Do inglês, Pareto-Box problem.
} 
assunto.

Além disso, este capítulo abordou a utilização da metologia proposta por TakagiSugeno, onde se evidencia uma melhor performace do sistema quando este possui informações quantitativas, sendo esta a situação apresentada nesta dissertação. 


\section{Capítulo 4}

\section{Formulação do Algoritmo Híbrido}

\section{Multi-objetivo}

A metodologia proposta consiste em desenvolver um algoritmo Híbrido multi-objetivo e aplicar o mesmo no problema de predição de estruturas terciárias de proteínas.

O algoritmo consistirá de duas abordagens inteligentes: Evolutivo e Lógica Fuzzy. A justificativa da utilização da técnica Evolutiva é porque esta já vem sendo aplicada nos problemas multi-objetivo onde o espaço de busca é complexo por possuir vários objetivos. Entretanto, a maioria dos algoritmos evolutivos multi-objetivo trabalham utilizando a fronteira de Pareto, sendo que o uso da mesma pode se tornar insatisfatória quando o problema possui mais que três objetivos (Deb et al., 2006). A Lógica Fuzzy é trabalhada como um sistema de inferência e adotada para contornar o problema da fronteira de Pareto.

A maioria dos algoritmos evolutivos multi-objetivo que trabalham com fronteira de Pareto, para melhorar a seleção dos indivíduos da fronteira, tem que recorrer a alguma outra informação (dado) para decidir quem são os melhores daquela fronteira. Com isso, há um aumento de esforço computacional. Para trabalhar com esta informação adicional, utilizam-se várias abordagens, inclusive Fuzzy.

Tendo em vista este cenário, espera-se do algoritmo proposto um esforço computacional menor, além de mapear intrinsecamente a informação que decide os melhores indivíduos 
sem a necessidade de trabalhar com a fronteira de Pareto, mas tendo o espaço de busca percorrido.

O procedimento de execução do algoritmo proposto consiste de dois passos principais, ou sejam:

1. Um AE é executado com todos seus fitness e operadores genéticos.

2. Um sistema de inferência contendo quatro conjuntos Fuzzy \{ MUITO BOA, BOA, RUIM, MUITO RUIM \} tem a missão de computar os indivíduos mais adaptados.

O Quadro 4.1 descreve o algoritmo proposto:

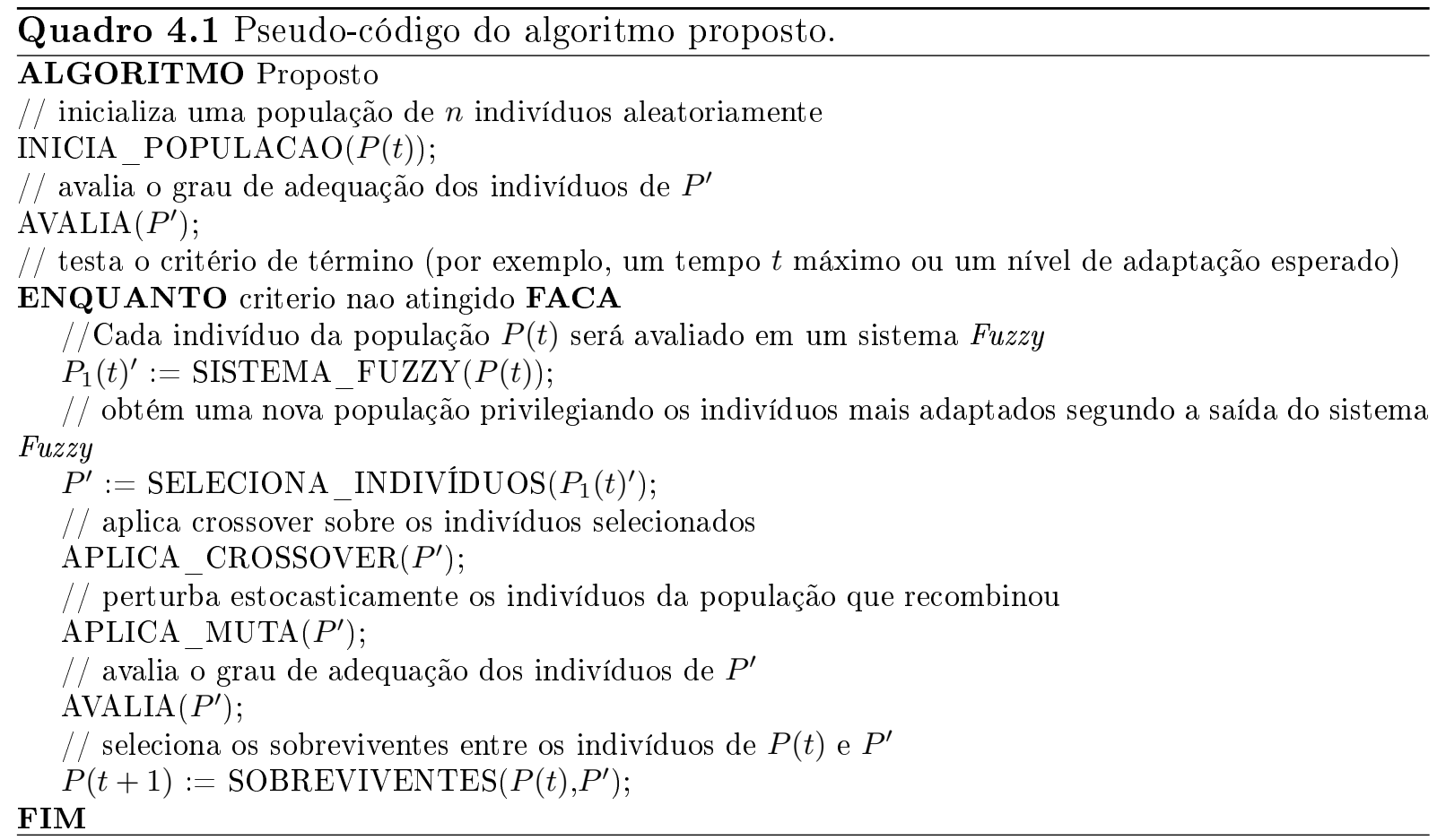

Analisando o Quadro 4.1, observa-se que o mesmo se assemelha com o AG típico, exceto pela inclusão do procedimento SISTEMA_FUZZY(). Esta exceção será detalhada na próxima seção.

Como o algoritmo proposto contribuirá para a seleção dos indivíduos mais adaptados do AE, os operadores genéticos dependerão do AE utilizado.

Assumindo as metas de otimização multi-objetivo assinalada por Deb (2001), no que diz respeito à diversidade, o algoritmo, após ordenar os indivíduos por ordem crescente 
de acordo com a defuzzificação, utilizará um epsilon $(\epsilon)$ que terá a finalidade de filtrar valores muito próximos, ou seja, se a diferença entre dois indivíduos for menor que $\epsilon$, então apenas o indivíduo que apresentar maior valor será selecionado. Assim, espera-se, mapear melhor o espaço de busca, pois valores muito próximos, tendem, não garantir boa diversidade.

\subsection{Sistema Fuzzy Proposto}

Conforme mencionado anteriormente, o sistema Fuzzy proposto visa substituir a fronteira de Pareto para os problemas multi-objetivo.

Para cada indivíduo será calculado seus fitness. Com estes valores, o sistema fuzzy será capaz de ordenar as melhores soluções em ordem crescente, como ocorre no NSGA-II, por exemplo. Mas a diferença é que com a inferência fuzzy torna-se mais fácil visualizar quais são as melhores soluções e, por intermédio de um único parâmetro (defuzzificação), obtem-se toda a aptidão do indivíduo. Assim, é possível, após a defuzzificação, trabalhar o AE como se fosse um mono-objetivo, ou seja, a ordenação realizar-se-á em relação a um único valor para cada indivíduo da população. Isto se torna importante, pois não há a necessidade de dividir a população em fronteiras e, para cada fronteira, através da distância da multidão ${ }^{1}$ se obtem seus melhores indivíduos, sendo esta a forma como o NSGA-II trabalha. Tal estratégia, como já citado², pode se tornar inapropriada para problemas com mais de três objetivos.

Assim, a operação do sistema fuzzy formulado pode ser resumido em cinco passos principais conforme explicitado a seguir:

1. Normalização dos fitness dos indivíduos no universo de discurso $\min (0)$ e o $\max (1)$.

2. Geração dos quatro conjuntos fuzzy conforme citado anteriormente.

3. Obtenção do valor do grau de pertinência de cada fitness.

\footnotetext{
${ }^{1}$ Ver seção 3.4.2.

${ }^{2}$ Ver Deb et al. (2006).
} 
4. Aplicação das regras fuzzy (Inferência).

5. Aquisição do valor de defuzzificação.

O Passo 1 é responsável em normalizar os fitness para o domínio [0,1], tendo como propósito converter os mesmos para uma mesma base de comparação.

A Geração dos quatro conjuntos fuzzy (Passo 2) se refere aos procedimentos que visam ajustar as funções de pertinência dos mesmos.

A seguir, no Passo 3, será obtido o grau de pertinência de cada fitness.

O Passo 4 consiste de detectar quais termos das funções fuzzy foram ativados pelos fitness. O fitness que possuir o grau de pertinência diferente de zero implicará na ativação das regras fuzzy. Tendo as funções de ativação de cada fitness, verifica-se então quais das regras Fuzzy foram ativadas.

Após computada a região fuzzy advinda da contribuição de cada regra ativada (Passo 5) ocorrer-se-á então a defuzzificação. Com este valor se tem a "importância" de cada indivíduo perante toda a aplicação, pois, obtem-se o valor de defuzzificação em relação a todos os objetivos do problema investigado. Tal valor será denominado neste trabalho de "Autoridade de Aptidão", tendo como propósito quantificar o nível de dominância de um indivíduo perante os demais.

Visto que a utilização do uso da fronteira de Pareto em problemas multi-objetivo contendo mais que três objetivos pode se tornar inapropriado, será mostrado a seguir, para fins ilustrativos, o uso do algoritmo proposto em um problema hipotético com três objetivos.

O gráfico da Figura 4.1 é uma representação dos quatro conjuntos fuzzy já citados. Cada função triangular do gráfico representa, respectivamente, os conjuntos fuzzy \{ MUITO BOA (1), BOA (2), RUim (3), muito Ruim (4)\}.

Como exemplo demonstrativo, considera-se um fitness (normalizado) sendo representado por $f_{1}=0.6, f_{2}=0.1$ e $f_{3}=0.7$. A Figura 4.2 ilustra os conjuntos fuzzy ativados com os valores de cada fitness.

A inferência dar-se-á utilizando as regras fuzzy conforme o Quadro 4.2 e utilizando 


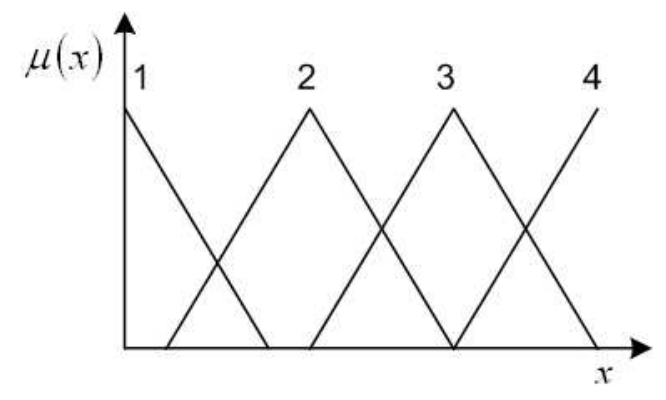

Figura 4.1: Uma representação dos conjuntos fuzzy.
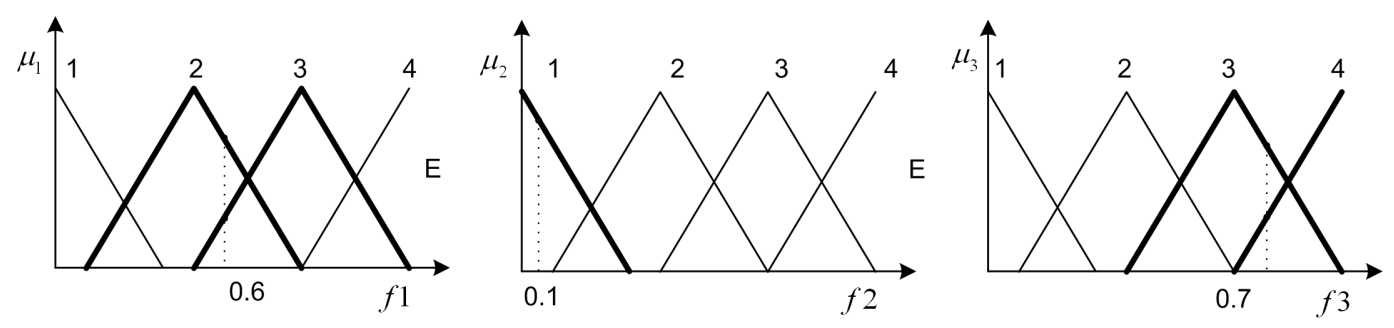

Figura 4.2: Funções fuzzy ativadas pelos fitness.

para tanto o operador de implicação Mandani (Seção 3.5.4). A Figura 4.3 ilustra todo o

Quadro 4.2 Exemplo das regras fuzzy

R1: se $\mathrm{F} 1=3$ e $\mathrm{F} 2=1$ e $\mathrm{F} 3=3$ então $\mathrm{R}=3$

R2: se F1 $=3$ e F2 $=1$ e $F 3=4$ então $R=4$

R3: se $F 1=2$ e $F 2=1$ e $F 3=3$ então $R=3$

R4: se $F 1=2$ e $F 2=1$ e F3 $=4$ então $R=3$

R5: se $\mathrm{F} 1=1$ e $\mathrm{F} 2=1$ e $\mathrm{F} 3=1$ então $\mathrm{R}=1$

R6: se $F 1=1$ e $F 2=2$ e F3 $=1$ então $R=2$

R7: se $F 1=2$ e $F 2=3$ e $F 3=4$ então $R=3$

R8: se $F 1=2$ e $F 2=3$ e $F 3=1$ então $R=3$

R9: se $\mathrm{F} 1=4$ e F2 $=4$ e F3 $=1$ então $\mathrm{R}=4$

processo de inferência fuzzy utilizando o conjunto de regras fuzzy especificados no Quadro 4.2 e tendo como entrada os valores dos fitness já citados. A Figura 4.4 evidencia a região resultante advinda da agregação das regiões fuzzy implicadas a partir das regras ativadas (Figura 4.3).

Para obter a Autoridade de Aptidão, considerando as regras ativadas na Figura 4.3, basta defuzzificar a região fuzzy representada na Figura 4.4 conforme os métodos descritos na Seção 3.5.5. Assim, por intemédio do valor defuzzificado é então possível ordenar os indivíduos por ordem de "autoridade". 

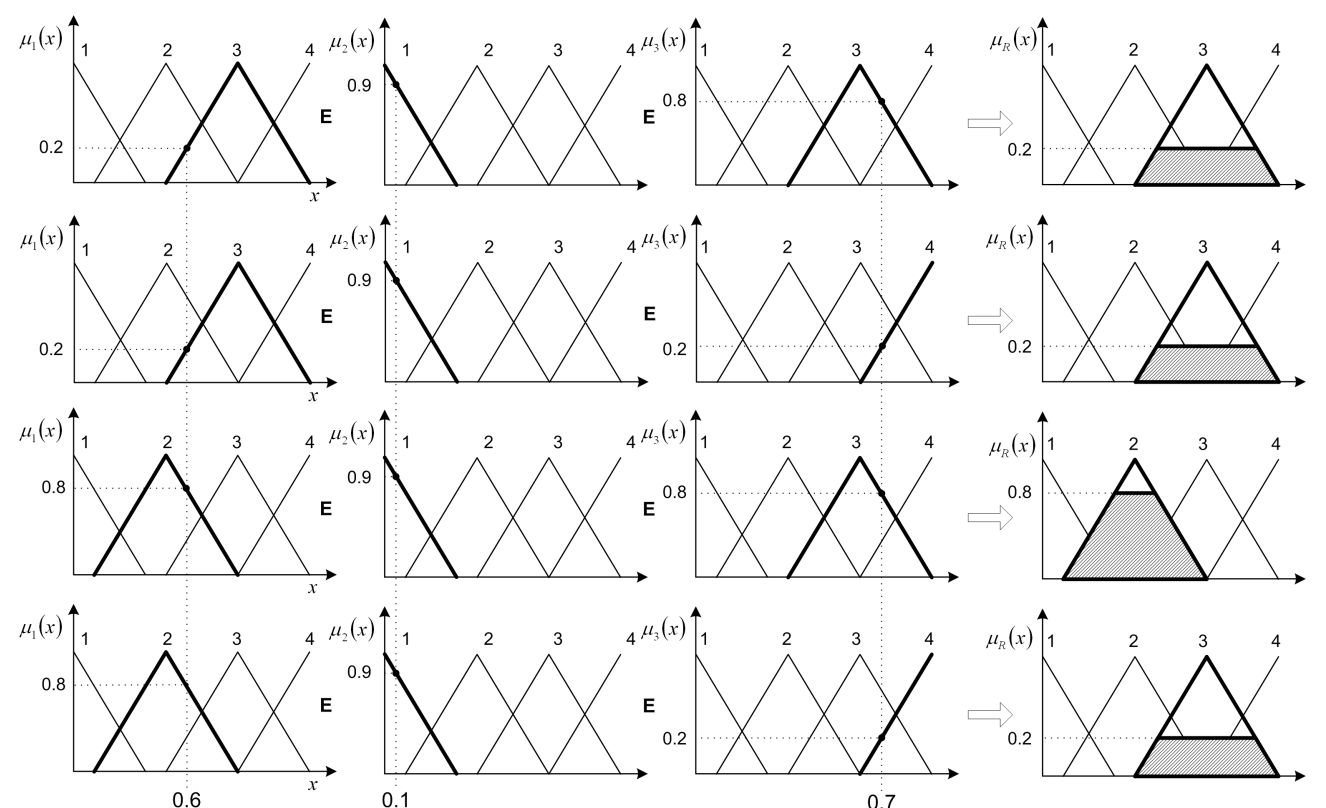

Figura 4.3: Processo da Inferência fuzzy

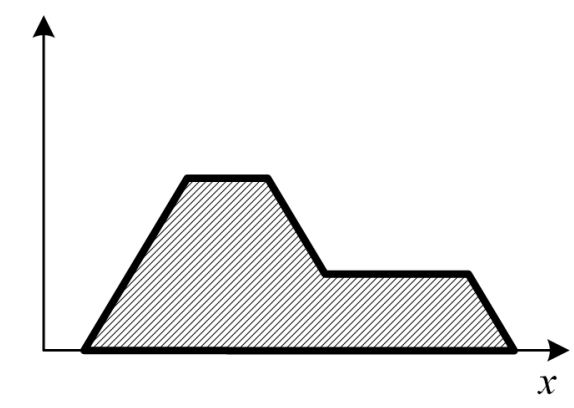

Figura 4.4: Região fuzzy de saída

Em relação à diversidade para os problemas multi-objetivo, a Tabela 4.1 ilustra o comportamento do algoritmo no tratamento da mesma, sendo o valor adotado para $\epsilon$ foi de 0.03. Pode-se concluir que somente serão selecionados os indivíduos que não forem similar. Então, considerando os valores apresentados na Tabela 4.1, conclui-se assim que serão selecionados somente os indivíduos do seguinte conjunto $\{1,4,5,6,8$ e 9$\}$. 
Tabela 4.1: Valores hipotéticos de Autoridade de Aptidão.

\begin{tabular}{||c||c|c|c||}
\hline \hline Indivíduos & Autoridade & Similar & Selecionado \\
\hline \hline $\mathbf{1}$ & 0.555 & & \\
\hline 2 & 0.554 & & \\
\hline 3 & 0.552 & & \\
\hline $\mathbf{4}$ & 0.489 & & \\
\hline $\mathbf{5}$ & 0.455 & & \\
\hline $\mathbf{6}$ & 0.345 & & \\
\hline 7 & 0.342 & & \\
\hline $\mathbf{8}$ & 0.333 & & \\
\hline $\mathbf{9}$ & 0.288 & & \\
\hline
\end{tabular}

\subsection{Considerações Parciais}

Neste capítulo foi possível descrever de forma resumida o método proposto e proporcionar o cenário de aplicação para este algoritmo. Deve ser ressaltado que a aplicabilidade do algoritmo proposto não se resume apenas no problema de predição de estrutura terciária. A escolha de tal problema está em virtude da grande relevância que o mesmo assume na literatura correlata.

Sendo o NSGA-II o AEMO mais utilizado na literatura, observa-se que o mesmo utiliza a fronteira de Pareto, a qual pode se tornar inapropriada para problemas com mais de três objetivos. Neste caso, o sistema fuzzy desenvolvido pode ser uma alternativa promissora à utilização de fronteira de Pareto, substituindo as mesmas em tais situações.

Os resultados da aplicação do algoritmo proposto no problema de predição de estrutura terciária de proteínas será apresentado na próxima seção. 


\section{Capítulo 5}

\section{Resultados da Aplicação do Algoritmo}

\section{Proposto na Predição de Estrutura}

\section{Terciária de Proteínas}

O algoritmo híbrido multi-objetivo proposto no capítulo anterior será utilizado no presente capítulo para predizer a estrutura terciária de proteínas. Neste caso, o algoritmo proposto utiliza a modelagem por homologia, pois para predizer a estrutura terciária da proteína, o mesmo necessita ter um conhecimento prévio (treinamento) de uma proteína similar à proteína que se deseja predizer.

Esta abordagem torna-se relevante uma vez que nos banco de dados de proteínas, tal como o PDB, já há um número considerável de proteínas em que pode ser homóloga (similar) à proteína que se deseja conhecer sua estrutura terciária. Em relação ao sistema fuzzy, o ajuste dos termos das funções de pertinência foi efetuado de forma automática a partir do uso da técnica ANFIS, sendo a mesma baseada no método de Takagi-Sugeno (Seção 3.5.6). Os detalhes envolvidos com a técnica ANFIS são destacados no Apêndice A. Torna-se importante destacar que, em virtude de ser possível obter informações quantitativas sobre o relacionamento entrada/saída do processo, o sistema fuzzy pode então ser sintonizado automaticamente pela aplicação da técnica ANFIS, melhorando assim o desempenho do mesmo. 
Em razão do método proposto ser um evolutivo Fuzzy, a função de avaliação utilizada pelo algoritmo evolutivo será detalhada na Seção 5.1.

A Seção 5.2 elucida o processo de treinamento do sistema fuzzy. Já a Seção 5.3 abordará quais foram as proteínas escolhidas para a comprovação do algoritmo proposto, sendo que os resultados providos pelo mesmo serão apresentados na Seção 5.4.

\subsection{Função de Avaliação}

A função de avaliação consiste das funções de energia que foram discutidas na Seção 2.8.

Em virtude de não haver uma função de avaliação para o DEP se torna possível modelar sua própria função de avaliação. Sendo assim, tais funções de energia foram separadas para dois casos de testes: um para o problema com três objetivos e a outra para o problema com quatro objetivos. Para uma melhor compreensão, a Tabela 5.1 ilustra o relacionamento entre função energia e seu símbolo que a representará a partir deste ponto.

Tabela 5.1: Funções de Energia e seu símbolo para representar na Função de Avaliação.

\begin{tabular}{||c|c||}
\hline \hline Função Energia & Símbolo \\
\hline \hline Comprimento de Ligação & $E_{\text {bonds }}$ \\
\hline Ângulo de Torsão & $E_{\text {tors }}$ \\
\hline Urey-Bradley & $E_{\text {urey }}$ \\
\hline Imprópria & $E_{\text {impro }}$ \\
\hline Van der Waals & $E_{\text {vdw }}$ \\
\hline Eletrostática ou de Carga & $E_{\text {charge }}$ \\
\hline
\end{tabular}

Os três fitness utilizados no AE com três objetivos estão representados a seguir.

A primeira função objetivo do AE com três objetivos denotada por $F_{1} o b j_{3}$, é composta somente pelo potencial de energia de Van der Waals, ou seja:

$$
F_{1} o b j_{3}=E_{v d w}
$$


O somatório das energias, o qual é constituído por Comprimento de Ligação, Ângulo de Torsão, Urey-Bradley e Imprópria se referem à segunda função objetivo do AE com três objetivos, sendo então denotada por $F_{2} O b j_{3}$, ou seja:

$$
F_{2} o b j_{3}=E_{\text {bonds }}+E_{\text {tors }}+E_{\text {urey }}+E_{\text {impro }}
$$

Finalmente, a terceira função objetivo do mesmo AE se caracteriza somente pela energia Eletrostática e sua representação é dada por $F_{3} o b j_{3}$, ou seja:

$$
F_{3} \mathrm{obj}_{3}=E_{\text {charge }}
$$

Tendo a função de avaliação do AE com três objetivos descrita acima, a seguir será apresentado os quatro fitness (objetivos) utilizados no AE com quatro funções objetivos.

É denotado por $F_{1} o b j_{4}$ a primeira função objetivo do AE com quatro objetivos, sendo a mesma composta somente pelo potencial de energia Van der Waals, ou seja:

$$
F_{1} o b j_{4}=E_{v d w}
$$

A segunda função objetivo do AE com quatro objetivos é composta pela energia Comprimento de Ligação e é denotada por $F_{2} o b j_{4}$, ou seja:

$$
F_{2} o b j_{4}=E_{b o n d s}
$$

Já a terceira função objetivo deste mesmo AE é composta pela energia Eletrostática, sendo então denotada por $F_{3} o b j_{4}$, ou seja:

$$
F_{3} \mathrm{obj}_{4}=E_{\text {charge }}
$$

A quarta e última função objetivo do AE com quatro objetivos é composta pelo somatório das energias: Ângulo de Torsão, Urey-Bradley e Imprópria, o qual é denotado 
por $F_{4} o b j_{4}$, ou seja:

$$
F_{4} o b j_{4}=E_{\text {tors }}+E_{\text {urey }}+E_{\text {impro }}
$$

\subsection{Processo de Treinamento do Algoritmo Proposto}

O processo de treinamento do algoritmo fuzzy proposto consiste do ajuste das funções de pertinência e do cálculo do valor de defuzzificação dos quatro conjuntos Fuzzy proposto e consistiu em duas etapas, conforme apresentado a seguir.

\subsubsection{Primeira Etapa}

A primeira etapa consistiu da geração de padrões de treinamento entrada/saída visando o ajuste das quatro funções de pertinência (Muito Boa, Boa, Ruim e Muito Ruim) de forma automática. Neste caso, utilizou-se a técnica $\mathrm{ANFIS}^{1}$ para ajustar de forma automática tais funções de pertinência.

Para calcular a saída desejada do ANFIS, há a necessidade de se conhecer o valor de cada uma das energias apresentadas na Tabela 5.1 advindas de uma proteína determinada no PDB. A representação de suas respectivas energias determinadas no PDB é de forma similar a Tabela 5.1, tendo apenas o acréscimo, ao seu final, da palavara $D^{e t . ~ T o m a-~}$ se como exemplo o potencial de Van der Waals, sendo que de acordo com a Tabela 5.1 sua representação é $E_{v d w}$, então a representação deste potencial determinado no PDB é denotado por $E_{v d w_{D} e t}$.

A saída desejada para a técnica ANFIS foi obtida de duas maneiras, sendo elas uma para o caso com três objetivos e uma outra para o caso com quatro objetivos. A seguir, é apresentada cada uma de tais saídas.

A saída desejada do ANFIS com três objetivos é denotada por $D_{o b j_{3}}$, sendo composta pelos fitness do AE com três funções objetivos apresentadas na Seção 5.1 e os valores de energia (representados na Tabela 5.1) da proteína determinda no PDB. Em relação à segunda função objetivo, sendo constituída de um somatório de energias, houve então a

\footnotetext{
${ }^{1}$ Maiores detalhes sobre a técnica ANFIS é apresentada no Apêndice A.
} 
necessidade de se obter um termo onde também houvesse o somatório das mesmas energias apresentadas neste fitness. Sendo assim, tal somatório é representado por Soma $_{D}$ et e é constituído pelas energias: Comprimento de Ligação, Ângulo de Torsão, Urey-Bradley e Imprópria da protéina determinada no PDB. A seguir, é apresentada a saída desejada para a técnica ANFIS no caso com três funções objetivos, ou seja:

$$
D_{o b j_{3}}=\left(F_{1} o b j_{3}-E_{v d w_{D} e t}\right)+\left(F_{2} o b j_{3}-S o m a 1_{D} e t\right)+\left(F_{3} o b j_{3}-E_{\text {charge }_{D} e t}\right)
$$

É finalidade de tal saída obter o quão distante está a proteína que se deseja predizer em relação à proteína determinada no PDB. Para um melhor entendimento, toma-se a exemplo, o fitness $F_{3} \mathrm{Obj}_{3}$ composto somente pela energia eletrostática. O mesmo será subtraído com a energia eletrostática da proteína determinada no PDB ( $\left.E_{\text {charge }_{D} e t}\right)$ e o valor desta subtração é a sua contribuição para a saída desejada. O mesmo procedimento ocorre com os outros termos desta saída.

Já para a saída desejada da técnica ANFIS com quatro objetivos, denotada por $D_{o b j_{4}}$, a sua composição é a mesma que a saída desejada com três objetivos $\left(D_{o b j_{3}}\right)$. A diferença então é a quantidade de termos, pois uma trata com três e a outra com quatro termos. A saída desejada com quatro fitness é composta pelas funções objetivos do AE com quatro objetivos apresentadas na Seção 5.1 e os valores de energia (representados na Tabela 5.1) da proteína determinada no PDB. Como ocorrido na saída anterior, houve a necessidade de um termo onde representasse o somatório das energias determinadas no PDB. Neste caso, o somatório é denotado por Soma $2_{D}$ et sendo constituído pelas energias: Ângulo de Torsão, Urey-Bradley e Imprópria da protéina determinada. Assim, é apresentada a saída desejada para a técnica ANFIS para o caso com quatro funções objetivos, ou seja:

$$
D_{o b j_{4}}=\left(F_{1} o b j_{4}-E_{v d w_{D} e t}\right)+\left(F_{2} o b j_{4}-E_{b o n d s_{D} e t}\right)+\left(F_{3} o b j_{4}-E_{\text {charge }_{D} e t}\right)+\left(F_{4} o b j_{4}-S_{o m a} 2_{D} e t\right)
$$

A saída com quatro termos possui a mesma finalidade que a saída desejada com três objetivos conforme já foi elucidado.

Para a executar a técnica ANFIS no Matlab, é necessário determinar alguns parâ- 
metros, os quais são detalhados no Apêndice A. Foi possível obter os valores destes parâmetros após a realização de testes e análises com valores empíricos dos referidos parâmetros, assim então, é possível informar quais parâmetros e seus respectivos valores, ou seja: o parâmetro número de épocas teve como valor 8 , já o parâmetro tolerância de erros teve como valor 0.006 e, finalmente, o algoritmo híbrido foi o utilizado no parâmetro método de otimização.

Finalizada a execução da técnica ANFIS para os dois casos, torna-se então possível verificar as informações geradas, tais como o número de regras obtidas em cada um dos conjuntos de teste, além de ilustrar o ajuste das funções de pertinência. O número de regras de cada um dos conjuntos de teste é ilustrado na Tabela 5.2. Já o ajuste das funções de pertinência é apresentado na Figura 5.1.

Tabela 5.2: Quantidade de Regras Fuzzy para cada treinamento.

\begin{tabular}{||c|c||}
\hline \hline Número Objetivos & Quantidade de Regras \\
\hline \hline 3 & 64 \\
\hline 4 & 256 \\
\hline
\end{tabular}

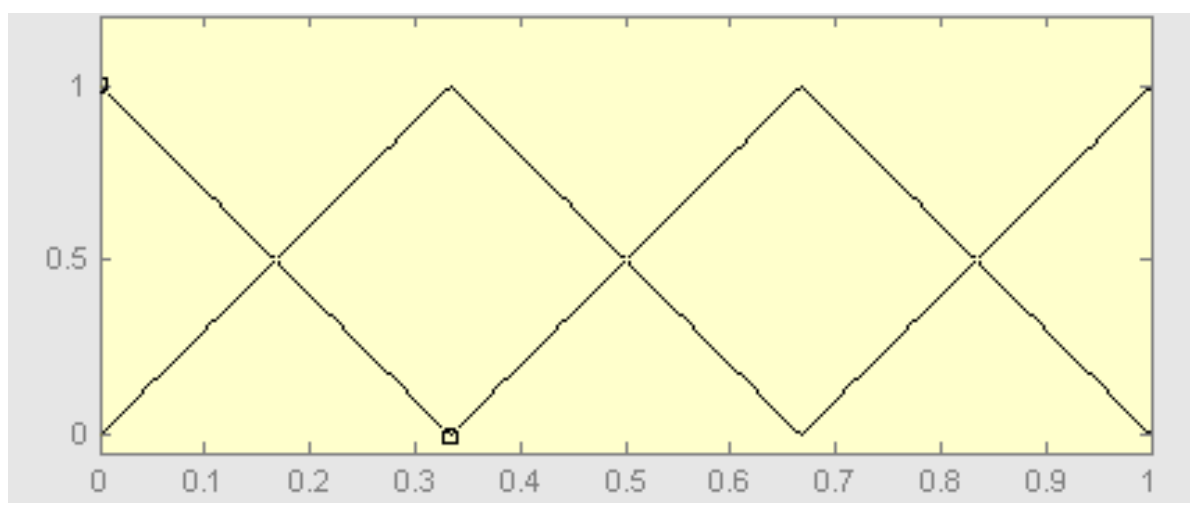

Figura 5.1: Representação dos quatro conjuntos Fuzzy proposto ajustado pelo ANFIS.

É importante ressaltar dois aspectos verificados nas simulações realizadas neste trabalho que são referentes a Figura 5.1, pois se torna importante um bom entendimento da mesma para a compreensão desta dissertação, ou seja:

1. Utilização da função Triangular evidenciou um bom desempenho computacional, 
pois além de se conseguir um bom mapeamento é uma função bem mais simples quando comparada com uma função Gaussiana, por exemplo.

2. Aplicação deste mesmo processo de ajuste das funções de pertinência ocorreu nos dois casos, ou seja, tanto com três quanto com quatro termos. Uma justificativa plausível se deve ao fato da normalização do universo de discurso conforme apresentado na Seção 4.1, ressaltando ainda que a diferença entre os dois casos, em suma, é a decomposição do segundo termo da $D_{o b j_{3}}$ resultando no segundo termo da $D_{o b j_{4}}$, ou seja, não apresenta uma mudança a ponto de justificar um ajuste diferente entre os dois casos.

\subsubsection{Segunda Etapa}

Esta fase se constituiu após o ajuste do ANFIS, pois há a possibilidade de gerar a defuzzificação de forma direta visando obter automaticamente a Autoridade de aptidão, ou seja, a "importância" do indivíduo, possibilitando então uma avaliação do mesmo perante todos os outros indivíduos. Portanto, uma seleção dos indivíduos para a próxima geração.

Por intermédio do toolbox Fuzzy do Matlab, torna-se possível gerar um arquivo texto contendo as entradas do sistema Fuzzy e seu valor defuzzificado. Com tal arquivo, torna-se então, também possível, obter uma matriz que pode ser integrada diretamente ao restante do processo.

Tendo como objetivo uma justicativa plausível ao emprego de um sistema Fuzzy, analisou-se alguns relacionamentos entre as entradas com sua respectiva saída em cada um dos casos.

Para o primeiro caso, ou seja, com três funções objetivos (três entradas) foram analisados dois relacionamentos de entrada com a sua respectiva saída $\left(D_{o b j_{3}}\right)$, os quais são representados, respectivamente, pelas Figuras 5.2 e 5.3, as quais serão discutidas a seguir.

A Figura 5.2 ilustra o relacionamento entre a primeira entrada $\left(F_{1} o b j_{3}\right)$ com a segunda entrada $\left(F_{2} o b j_{3}\right)$ e sua respectiva saída. É notável a visualização de uma superfície não linear, demonstrando então o comportamento não-linear entre as entradas e sua respectiva 
saída.

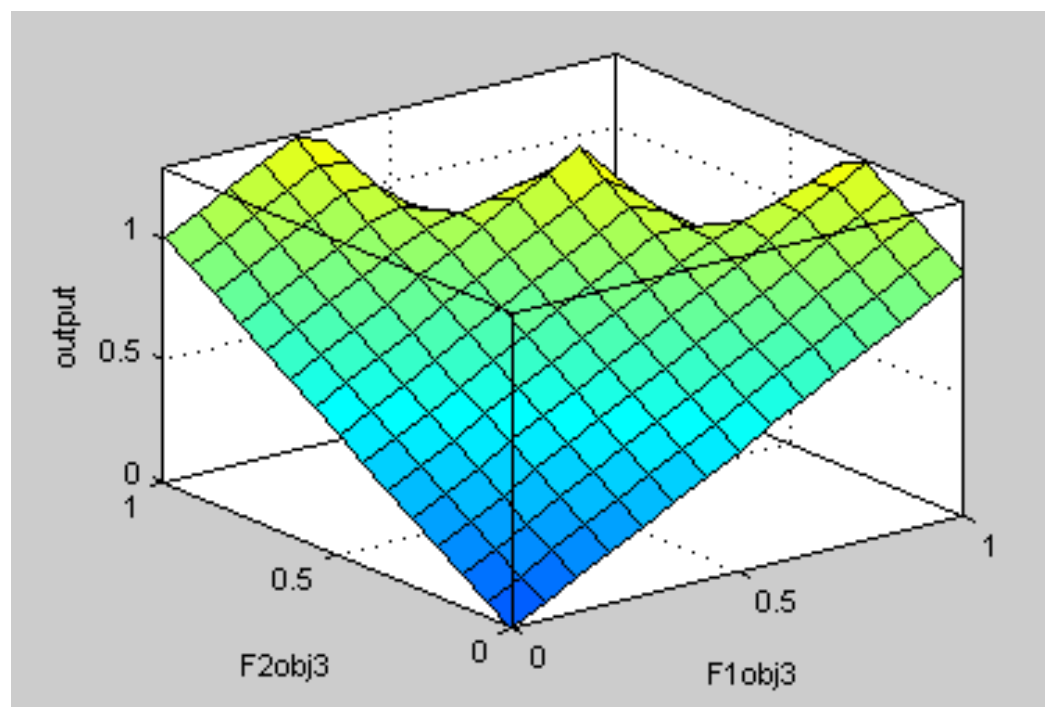

Figura 5.2: Superfície entre os fitness $F_{1} o b j_{3}$ e $F_{3} o b j_{3}$ para o caso com três objetivos.

Já a Figura 5.3 evidencia o interelacionamento entre a segunda e a terceira entrada, ou seja, respectivamente $F_{2} o b j_{3}$ e $F_{3} o b j_{3}$. Como na situação anterior, é também possível visualizar uma superfície não linear.

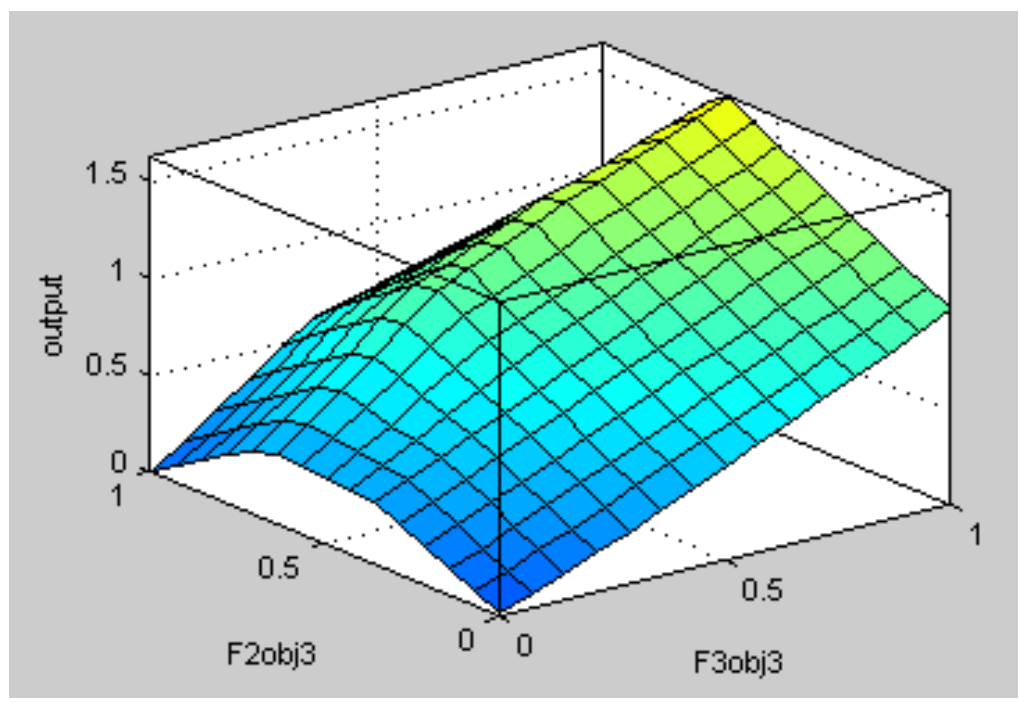

Figura 5.3: Superfície entre os fitness $F_{2} o b j_{3}$ e $F_{3} o b j_{3}$ para o caso com três objetivos.

Para o segundo caso, ou seja, com quatro entradas, foram realizadas três relacionamentos os quais estão apresentados, respectivamente, nas Figuras 5.4, 5.5 e 5.6, e serão detalhadas a seguir. 
O primeiro relacionamento consiste nas entradas: primeira $\left(F_{1} o b j_{2}\right)$ e segunda $\left(F_{2} o b j_{4}\right)$. A saída, neste caso, é a saída desejada já apresentada para o caso contendo quatro objetivos que foi denotada por $D_{o b j_{4}}$. Em tal relacionamento, é também observável uma superfície não linear.

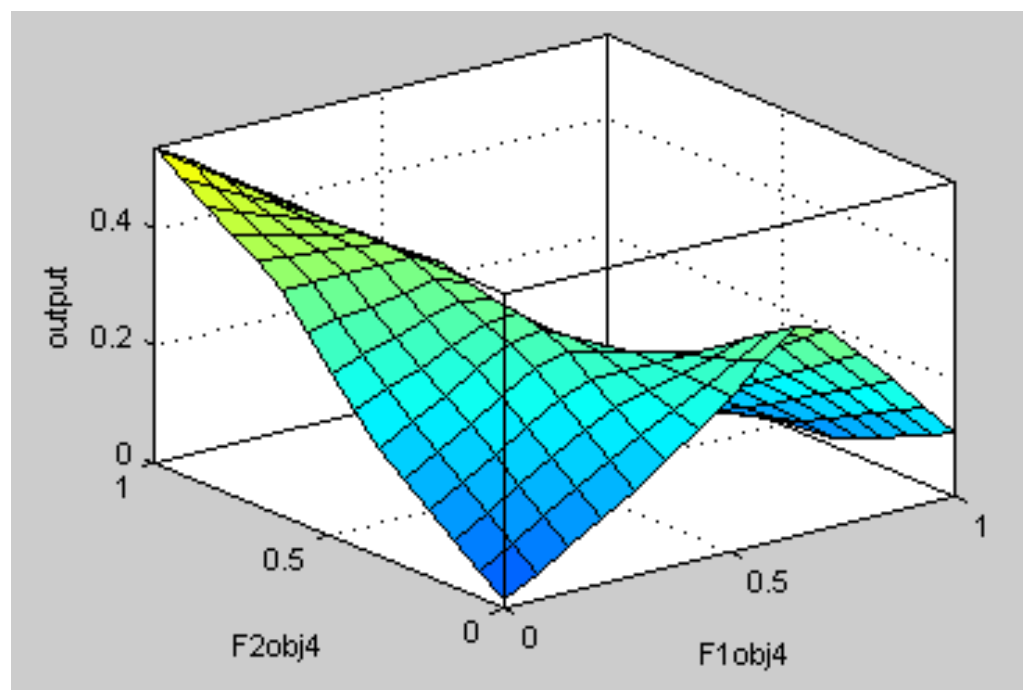

Figura 5.4: Superfície entre os fitness $F_{1} o b j_{4}$ e $F_{2} o b j_{4}$ para o caso com quatro objetivos.

O segundo relacionamento evidencia o comportamento entre as funções objetivos $F_{2} o b j_{4}$ e $F_{3} o b j_{4}$, ou seja, respectivamente segunda e terceira entrada para o caso com quatro entradas. Mais que notável, outra vez, uma superfície não linear é obtida, demonstrando parte da complexidade envolvida no relacionamento entrada/saída.

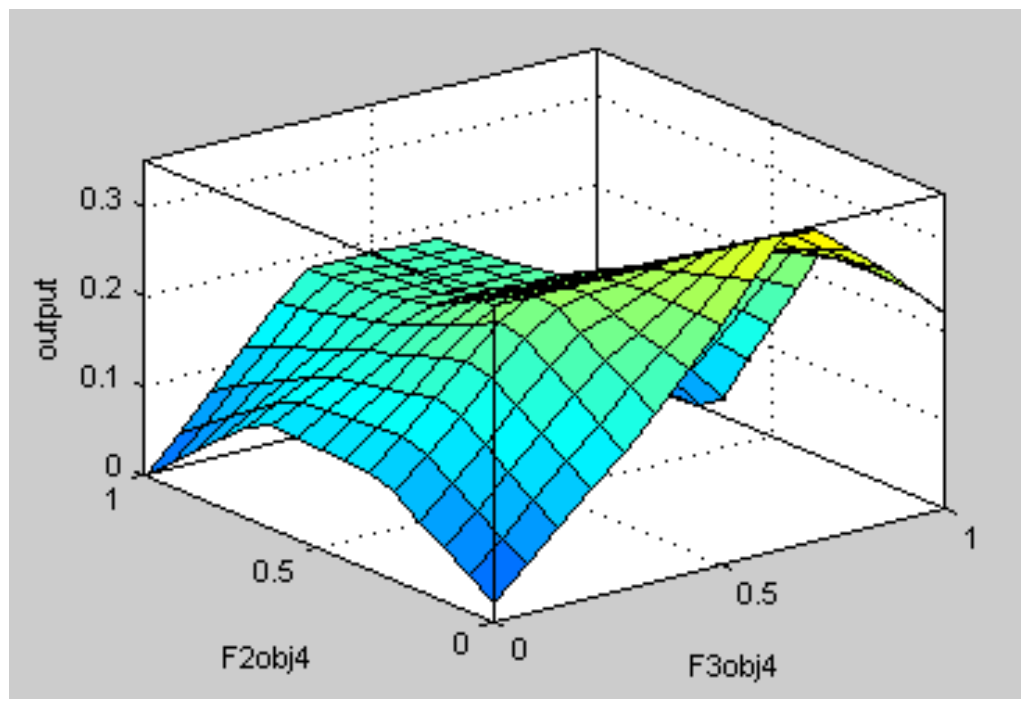

Figura 5.5: Superfície entre os fitness $F_{2} o b j_{4}$ e $F_{3} o b j_{4}$ para o caso com quatro objetivos. 
Por fim, o relacionamento entre as entradas do segundo caso é composto por: terceira $\left(F_{3} o b j_{4}\right)$ e quarta $\left(F_{4} o b j_{4}\right)$ entrada. A superfície de saída é uma superfície não linear.

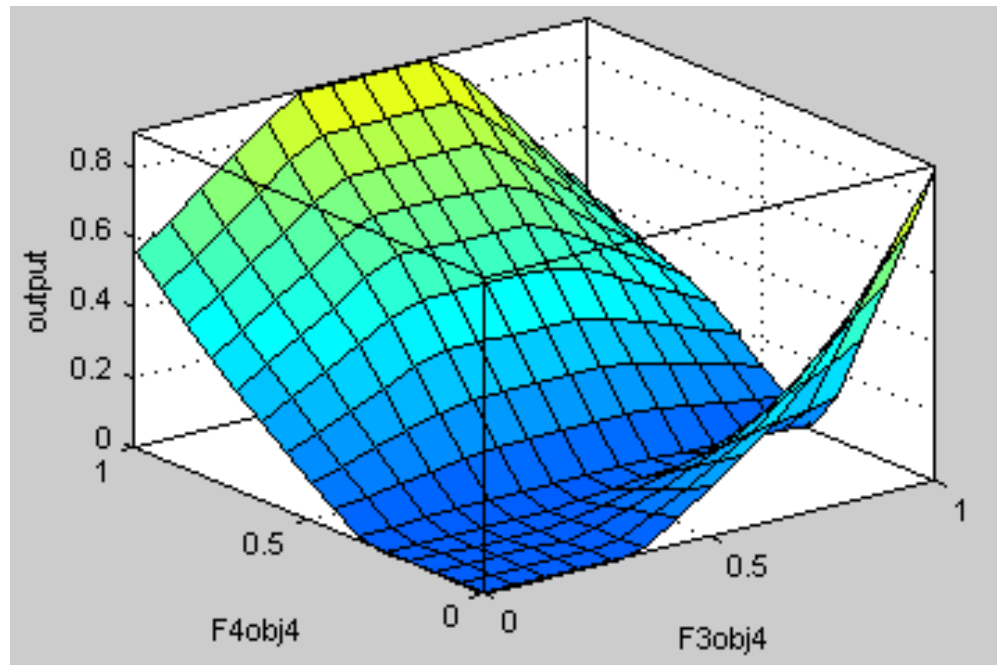

Figura 5.6: Superfície entre os fitness $F_{3} o b j_{4}$ e $F_{4} o b j_{4}$ para o caso com quatro objetivos.

Assim, tendo apresentado alguns dos possíveis relacionamentos entre as entradas e a saída nos dois casos, torna-se notável, em todos os casos de relacionamentos, a evidência de uma superfície bem não linear. Tal evidência corrobora a empregabilidade, então, da lógica Fuzzy, como uma ferramenta especialista no mapeamento de sistemas não-lineares justificando também a sua aplicabilidade neste tipo de problema.

\subsection{Proteínas Alvo}

A proteína utilizada para o processo de treinamento foi a $1 \mathrm{CRN}$. Para o processo de predição (validação), foram utilizadas as proteínas 1JXT e 1AB1. A Tabela 5.3 representa a sequência de aminoácidos de cada uma das proteínas para evidenciar sua similaridade.

Tabela 5.3: Estrutura primária das proteínas preditas e a utilizada no treinamento.

\begin{tabular}{||c|c||}
\hline \hline Proteína & Estrutura Primária \\
\hline \hline 1AB1 & TTCCPSIVARSNFNVCRLPGTSEAICATYTGCIIIPGATCPGDYAN \\
\hline 1JXT & TTCCPSIVARSNFNVCRLPGTPEALCATYTGCIIIPGATCPGDYAN \\
\hline 1CRN & TTCCPSIVARSNFNVCRLPGTPEAICATYTGCIIIPGATCPGDYAN \\
\hline
\end{tabular}


Sendo as proteínas 1AB1 e 1JXT similares a 1CRN, há a necessidade, então, de apresentar quais resíduos se diferem da proteína 1CRN. Estes resíduos estão ilustrados na Tabela 5.3 e foram escritos em negrito com a finalidade de, mesmo que visualmente, diferenciá-los dos demais. Nota-se, então, um alto grau de similaridade entre as proteínas 1AB1 e 1JXT com a proteína 1CRN.

\subsection{Resultados}

Foram executados com as proteínas 1JXT e 1AB1 dois casos de testes: primeiro com três objetivos e um outro com quatro objetivos. Nestes dois casos, foram utilizados o AEMO implementado em de Lima $(2006)^{2}$, sendo o mesmo referenciado a partir daqui somente de AEMO, e o algoritmo proposto nesta dissertação.

Em cada execução, todos realizados na mesma máquina, foram consideradas 100 gerações e 200 indivíduos tanto para o AEMO quanto para o algoritmo proposto. Os resultados representam os melhores indivíduos de cada caso de execução.

Os parâmetros utilizados para o cálculo das energias foram os mesmos utilizados em de Lima (2006), exceto a constante elétrica cujo valor foi modificado para 1.

Para avaliar o resultado do processo de predição da estrutura terciária foi utilizado o critério de matriz de distância $(D M E)^{3}$ entre suas coordenadas, pois $D M E$ verifica a similariade do enovelamento entre as estruturas real e predita. Seja $X$ a matriz das distâncias da estrutura conhecida, onde $X_{i, j}$ é a distância do átomo $i$ ao átomo $j$ na estrutura, e $Y$ a matriz das distâncias da estrutura predita, onde $Y_{i, j}$ é a distância do átomo $i$ ao átomo $j$ na estrutura predita. $D M E$ é definido como a média da diferença das matrizes de distância $X$ e $Y$, ou seja:

$$
D M E=\sqrt{\frac{\sum_{i=1}^{n-1} \sum_{j=i+1}^{n}\left(X_{i, j}-Y_{i, j}\right)^{2}}{\frac{n(n-1)}{2}}}
$$

onde $n$ é o número total de átomos da estrutura. Portanto, quanto mais baixo for o valor

\footnotetext{
${ }^{2}$ Versão em $22 / 01 / 2007$.

${ }^{3} D M E$, do inglês Distance Matrix Error.
} 
do $D M E$ mais exata é a predição da estrutura terciária da proteína.

Os valores do cálculo do $D M E$ para as proteínas $1 \mathrm{AB1}$ e $1 \mathrm{JXT}$ em relação às suas respectivas proteínas reais são apresentadas a seguir.

A Tabela 5.4 ilustra, respectivamente, o valor do $D M E$ do AEMO e do algoritmo proposto para o caso de execução contendo três objetivos. Em tal tabela, nota-se que mesmo no caso com três objetivos o algoritmo proposto conseguiu um bom desempenho. Esta informação torna-se relevante uma vez que com até três objetivos, conforme relata a literatura, as fronteiras de Pareto conseguem obter resultados satisfatórios. Tendo então o algoritmo proposto também obtido bons resultados, evidencia-se portanto uma estratégia alternativa às fronteiras de Pareto.

Tabela 5.4: $D M E$ entre as proteínas no teste com três objetivos.

\begin{tabular}{||c|c|c||}
\hline \hline Algoritmo & 1JXT & 1AB1 \\
\hline \hline AEMO & 6.41 & 15.88 \\
\hline Proposto & 12.25 & 8.03 \\
\hline
\end{tabular}

Já os valores do DME para o segundo caso, ou seja, comparado AEMO e o algoritmo proposto com quatro objetivos, são apresentados na Tabela 5.5. É possível notar em tal tabela que o $D M E$ apresentado pelo algoritmo proposto é menor do que o AEMO, ou seja, conseguiu predizer melhor as proteínas 1JXT e 1AB1. Sendo assim, torna-se possível comprovar o relato da literatura onde se constata que tais fronteiras (acima de três objetivos) pode não conseguir alcançar um bom mapeamento, obtendo portanto, resultados insatisfatórios.

Tabela 5.5: $D M E$ entre as proteínas no teste com quatro objetivos.

\begin{tabular}{||c|c|c||}
\hline \hline Algoritmo & 1JXT & 1AB1 \\
\hline \hline AEMO & 18.65 & 14.68 \\
\hline Proposto & 8.65 & 13.13 \\
\hline
\end{tabular}

Vale ressaltar que o algoritmo proposto conseguiu generalizar o comportamento do processo, pois o sistema Fuzzy desenvolvido, conforme apresentado na Seção 5.2, foi trei- 
nado com as informações da proteína 1CRN e foi capaz de predizer a estrutura terciária de duas outras proteínas: a 1JXT e a 1AB1. Mesmo que as proteínas sejam similares e possuem estruturas bem parecidas, todas elas apresentam características únicas, as quais foram possíveis de se mapear.

Um aspecto importante se deve aos valores do $D M E$ das proteínas 1JXT e 1AB1. Observando as Tabelas 5.4 e 5.5, para o algoritmo proposto, evidencia a situação onde para o caso de teste com a proteína 1JXT foi apresentado um valor de DME maior considerando três objetivos, constratando com o seu caso de quatro objetivos. Entretanto, para a proteína $1 \mathrm{AB} 1$ se verifica o inverso. Este fato, deve-se à primeira fase do processo de treinamento do algoritmo proposto, uma vez que esta etapa consiste da geração de padrões de treinamento, havendo assim um melhor mapeamento de tais padrões em cada uma das proteínas.

Além dos valores do $D M E$, foi também avaliado o custo (esforço) computacional. Torna-se relevante apresentar uma comparação do custo computacional, conforme relatado pela literatura, quando se está investigando a aplicabilidade de diferentes algoritmos, sendo também este um dos objetivos do trabalho proposto. Tal custo evidencia o tempo em que foi utilizado para executar o algoritmo por completo, ou seja, o tempo em que o computador levou para executar (processar) o algoritmo desde o seu início até o seu término. Neste trabalho adotou-se a unidade segundos para medir o custo computacional. Os valores do esforço computacional obtidos pelo AEMO e pelo algoritmo proposto estão apresentados a seguir.

A Tabela 5.6 ilustra o custo computacional com três objetivos do AEMO e do algoritmo proposto.

Tabela 5.6: Custo computacional entre as proteínas no teste com três objetivos.

\begin{tabular}{||c|c|c||}
\hline \hline Algoritmo & 1JXT & 1AB1 \\
\hline \hline AEMO & 907.40 & 855.88 \\
\hline Proposto & 778.69 & 758.24 \\
\hline
\end{tabular}

Já para o caso de teste com quatro objetivos, os valores do custo computacional referentes ao AEMO e ao algoritmo proposto estão apresentados na Tabela 5.7. 
Tabela 5.7: Custo computacional entre as proteínas no teste com quatro objetivos.

\begin{tabular}{||c|c|c||}
\hline \hline Algoritmo & 1JXT & 1AB1 \\
\hline \hline AEMO & 806.32 & 934.20 \\
\hline Proposto & 869.94 & 909.44 \\
\hline
\end{tabular}

Observando as Tabelas 5.6 e 5.7, nota-se, mesmo com três objetivos, o custo computacional do algoritmo proposto foi menor em todos os casos, exceto em um único caso contendo quatro objetivos. Uma justificativa plausível para o bom desempenho do algoritmo proposto se deve ao fato da função de pertinência do sistema Fuzzy ser uma função Triangular, já que tal função possui como característica, a simplicidade de execução quando comparada com o cálculo da distância de multidão, conforme apresentada na Seção 3.4.2, a qual é empregada pelo AEMO para diversificar os indivíduos da tal fronteira. Já uma razão relacionada à única exceção mostrada, pode ser atribuído ao fato de que, neste caso, o algoritmo proposto conseguiu uma "varredura" mais detalhada no espaço de busca. Um fator que contribui para tal justificativa é o fato de ser esse mesmo caso onde conseguiu obter uma melhor predição, considerando somente, a situação com quatro objetivos.

Um aspecto relevante a ser apresentado se deve ao fato onde há o emprego de técnicas na qual se exige um processo de treinamento. Nesta situação, não há necessidade de adicionar ao valor do custo computacional do algoritmo, o esforço (tempo) decorrido do processo de treinamento.

Finalmente, a seguir, torna-se possível uma comparação visual das proteínas já citadas na sua forma nativa e predita em todos os casos de testes realizados.

A Figura 5.7 representa a estrutura predita pelo AEMO e pelo algoritmo proposto, ambos referentes ao caso com três objetivos da proteína 1JXT, juntamente com a estrutura terciária nativa da referida proteína. É possível notar na Figura 5.7(a) uma melhor predição da estrutura terciária quando a mesma é comparada com a predição realizada pelo algoritmo proposto (Figura 5.7(c)), resultado este já esperado conforme a Tabela 5.4, pois o AEMO apresentou um valor de $D M E$ menor. É possível também observar que ambas as estruturas preditas pelos algoritmos apresentam algumas partes similares à 
estrutura nativa da proteína (Figura 5.7(b)), evidenciando assim, que ambos algoritmos apresentaram resultados relevantes.

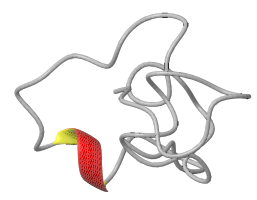

(a) Estrutura Predita pelo AEMO.

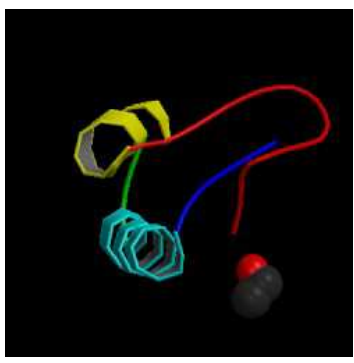

(b) Estrutura Nativa.

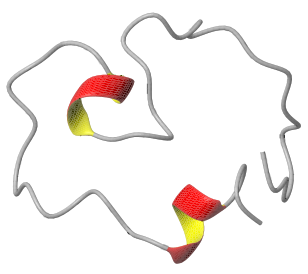

(c) Estrutura Predita pelo algoritmo proposto.

Figura 5.7: Estruturas terciárias da proteína 1JXT com três objetivos.

Já a Figura 5.8 ilustra a estrutura predita pelas abordagens AEMO e pelo algoritmo proposto para o mesmo caso de teste, ou seja, com três objetivos. Mas, neste caso, a estrutura é referente à proteína 1AB1. Assim sendo, a Figura 5.8(a) representa a estrutura terciária da proteína 1AB1 predita pelo AEMO. A estrutura desta mesma proteína predita pelo algoritmo proposto fica evidenciado na Figura $5.8(\mathrm{c})$ e a sua estrutura nativa é apresentado na Figura 5.8(b). É possível observar que a melhor predição da estrutura pertence à quem obteve um valor de $D M E$ menor e, conforme apresentado na Tabela 5.4, o algoritmo proposto apresenta um valor de $D M E$ menor. A mesma relevância atribuída ao resultado da predição da proteína 1 JXT se pode atribuir ao resultado da proteína 1AB1, pois, também, se conseguiu partes similares da proteína 1AB1 preditas por ambos 
algoritmos quando a mesma é comparada à sua estrutura nativa.

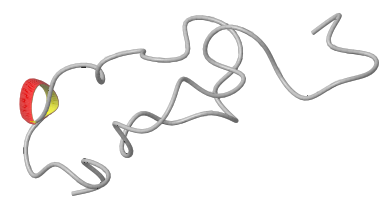

(a) Estrutura Predita pelo AEMO.

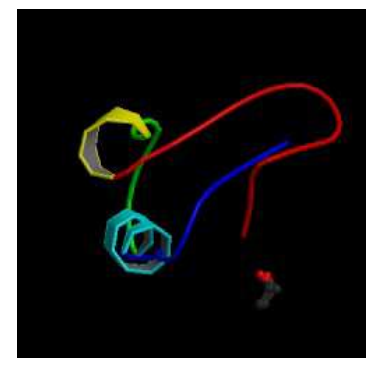

(b) Estrutura Nativa.

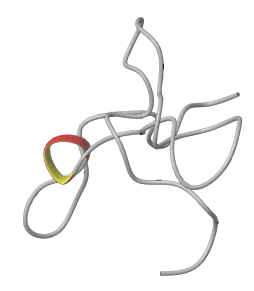

(c) Estrutura Predita pelo algoritmo proposto.

Figura 5.8: Estruturas terciárias da proteína 1AB1 com três objetivos.

Em seguida, a predição realizada no caso de teste com quatro objetivos da proteína 1JXT é apresentada na Figura 5.9. Torna-se, então, possível visualizar a Figura 5.9(a) como sendo a estrutura predita pelo AEMO, a Figura 5.9(c) representando a estrutura predita pelo algoritmo proposto e finalmente sua estrutura nativa na Figura 5.9(b). O algoritmo proposto apresenta uma estrutura mais próxima da estrutura nativa quando a mesma é comparada com a estrutura do AEMO. A justificativa para a predição recorre novamente ao valor do DME (Tabela 5.5).

Por fim, é apresentada na Figura 5.10 a predição realizada pelo AEMO e pelo algoritmo proposto no caso com quatro objetivos para a proteína 1AB1. Observando a Figura 5.10(a) é possível visualizar a predição da estrutura realizada pelo AEMO. Já a Figura 


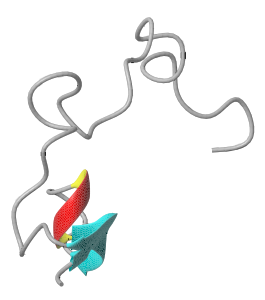

(a) Estrutura Predita pelo AEMO.

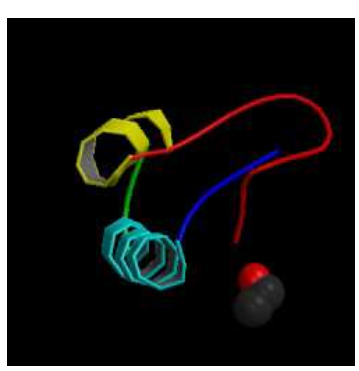

(b) Estrutura Nativa.

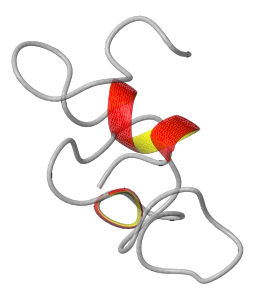

(c) Estrutura Predita pelo algoritmo proposto.

Figura 5.9: Estruturas terciárias da proteína 1JXT com quatro objetivos.

5.10(b) ilustra a estrutura nativa da proteína $1 \mathrm{AB} 1$ e a predição da estrutura realizada pelo algoritmo proposto sendo apresentado na Figura 5.10(c). Assim, observa-se que a estrutura predita pelo algoritmo proposto possui uma maior similaridade com a estrutura nativa em relação à estrutura predita pelo AEMO. 


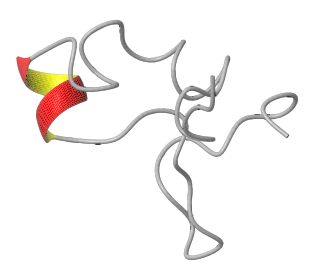

(a) Estrutura Predita pelo AEMO.

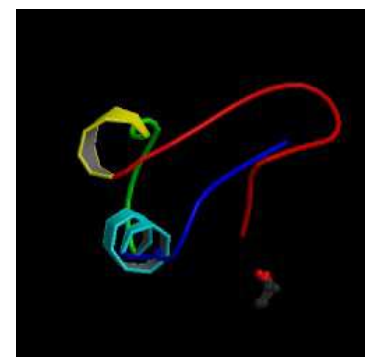

(b) Estrutura Nativa.

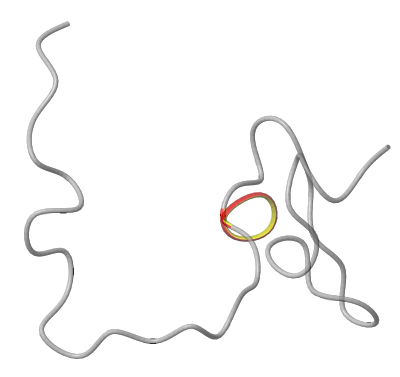

(c) Estrutura Predita pelo algoritmo proposto.

Figura 5.10: Estruturas terciárias da proteína 1AB1 com quatro objetivos. 


\section{Capítulo 6}

\section{Conclusões e Trabalhos Futuros}

Este trabalho investigou o uso da lógica Fuzzy ao invés da fronteira de Pareto nos algoritmos evolutivos aplicados em problemas de otimização multi-objetivo, sem que haja mudanças significativas na estrutura dos algoritmos evolutivos. Na literatura, há investigações onde se evidencia a não utilização da fronteira de Pareto para problemas acima de três objetivos. Muitos desses estudos não usufruem dos algoritmos evolutivos, devido à limitação da tal fronteira tomando como exemplo Farina e Amato (2003).

Torna-se possível tratar a Determinação da Estrutura da Proteína (DEP) como um problema de otimização multi-objetivo com três, quatro ou até mais objetivos, possuindo o mesmo uma elevada relevância, sendo este então o caso escolhido para evidenciar uma comparação entre o algoritmo proposto e um outro algoritmo aplicado ao DEP.

Os Algoritmos Evolutivos aplicados em problemas Multi-Objetivo são conhecidos como AEMO. Dentre os AEMOs, o mais utilizado na literatura é o NSGA-II e este utiliza a fronteira de Pareto. Sendo assim, o NSGA-II vem sendo aplicado ao DEP e de Lima (2006) apresentou resultados satisfatórios ao DEP, tornando-se portanto um relevante caso para teste de desempenho ao algoritmo proposto.

O DEP é um problema de extrema complexidade e por isso existem diversas abordagens (métodos de otimização) para tratá-lo, entre elas: threading, homologia e Ab initio. Para o algoritmo proposto foi elaborado a abordagem por homologia.

Por ser uma abordagem por homologia há, então, a necessidade de obter informações de 
alguma proteína. Como no PDB já existe um número razoável de proteínas determinadas, neste trabalho buscou-se explorar esse contexto. Assim, por intermédio de um sistema Fuzzy ajustado com as informações de uma proteína conhecida do PDB, a finalidade do algoritmo proposto está em predizer a estrutura terciária de uma proteína que tenha similaridade com tal proteína.

Os resultados foram satisfatórios mesmo para os problemas com três objetivos, onde se evidenciou um esforço computacional menor em todos os casos analisados. Já com quatro objetivos, o custo computacional do algoritmo proposto foi maior somente em um dos testes $(\cong 1 \mathrm{~min})$, mas todas as estruturas preditas pelo mesmo apresentaram melhores resultados.

Em se tratando de resultados, torna-se importante observar as duas Tabelas (5.4 e 5.5) referentes aos valores de $D M E$ para os dois casos de testes realizados, onde é possível notar um fato interessante ocorrido com a proteína 1JXT. Esta proteína, no primeiro caso, apresentou para o algoritmo proposto um $D M E$ superior em relação ao AEMO, mas, já no segundo caso ocorreu o inverso. Fica então evidenciado a necessidade em analisar o DEP tendo uma quantidade maior do que três ou até mesmo quatro objetivos, pois tal problema exige um mapeamento mais apropriado, caracterizando então a importância de se investigar técnicas computacionais alternativas à fronteira de Pareto.

Além da possibilidade de substituir a fronteira de Pareto, o algoritmo proposto buscou efetuar a substituição da referida fronteira sem causar mudanças drásticas ao AEMO. Este objetivo fora totalmente atingindo, uma vez que não ocorreu quaisquer mudanças no AEMO apresentado em de Lima (2006), exceto na seleção dos indivíduos para a próxima geração.

Portanto, a abordagem proposta não se esgota a possiblidade de se investigar outras possíveis ou até mesmo melhores soluções para o DEP. Mesmo para as proteínas similares onde houve o treinamento, há ainda a necessidade de propor melhores abordagens para predizer mais precisamente suas proteínas similares.

Em relação aos trabalhos futuros, em primeira instância, realizar-se-á a investigação do algoritmo proposto contendo cinco e seis objetivos, ou seja, cada uma das funções de energia ser um objetivo específico. Após essa análise, pesquisar-se-á quais poderiam 
ser outras informações pertinentes na contribuição da estrutura terciária da proteína. Em seqüência, iniciar-se-á a busca de um modelo computacional que possa representar o processo de folding, permitindo-se obter uma predição mais exata da proteína.

A possibilidade de investigar as regras Fuzzy que tenha maior significância é uma outra possibilidade, pois assim se consegue mapear as informações mais revelantes, como o já citado em Alcalá et al. (2006).

Uma outra investigação será treinar o sistema Fuzzy com duas ou mais proteínas similares e, em seguida, analisar as informações em comum. O objetivo é, além de se encontrar padrões similares entre as proteínas, a tentativa de predizer a estrutura de proteínas que sejam similares àquelas que participaram do processo de treinamento. Com isso, espera-se alavancar um número maior de proteínas para predizer (não necessitando um alto grau de similaridade), além da possibilidade de entender todo o processo de enovelamento das proteínas.

Como o emprego da abordagem proposta não se limita somente ao problema de predição de estrutura terciária de proteínas, a mesma pode ser também investigada para aplicação em outros tipos de problemas que se encontram utilizando a fronteira de Pareto, mas tendo resultados insatisfatórios. 


\section{Referências Bibliográficas}

Aarts, E. e J. Korst (1989). Simulated Annealing and Boltzmann Machines: A Stochastic Approach to Combinatorial Optimization and Neural Computing. John Wiley and Sons.

Alcalá, R., J. Alcalá-Fdez, M. J. Gacto, e F. Herrera (2004). Ten years of genetic fuzzy systems: current framework and new trends. In Fuzzy Sets and Systems Vol. 141, pp. $5-31$.

Alcalá, R., J. Alcalá-Fdez, M. J. Gacto, e F. Herrera (2006). Rule base reduction and genetic tuning of fuzzy systems based on the linguistic 3-tuples representation. In Soft Computing - A Fusion of Foundations, Methodologies and Applications Vol. 11, pp. $401-419$.

Bajic, V. B., V. Brusic, J. Li, S. K. Ng, e L. Wong (2003). From informatics to bioinformatics. In Proceedings of the first Asia-Pacific bioinformatics conference on Bioinformatics Vol. 19, pp. 3-12.

Barton, G., P. Cohen, e D. Bradford (1993). Conservation analysis and structure prediction of the protein serine/threonine phosphatases. Eur. J. Biochem Vol. 220, pp. $225-237$.

Battistella, E. e A. Cechin (2004). The protein folding problem solved by a fuzzy inference system extracted from an artificial neural network. In Ibero-American Conference on Artificial Intelligence (IBERAMIA) Vol. 3315, pp. 474-483.

Baxevanis, A. e B. Ouellette (2001). Bioinformatics - A practical guide to the analysis of genes and proteins. Lawrence Erlbaum Associates Publishers. 
Bäck, T., D. Fogel, e Z. Michalewicz (1997). Handbook of Evolutionary Computation. Institute of Physics Publishing and Oxford University Press.

Bergeron, B. (2003). Bioinformatics computing. Prentice Hall.

Bonissone, P., R. Subbu, e K. Aggour (2002). Evolutionary optimization of fuzzy decision systems for automated insurance underwriting. In Fuzzy Systems Vol.2, pp. 1003-1008.

Branden, C. e J. Tooze (1991). Introduction to Protein Structure. Garland Publishing.

Bryson, K., M. Luck, M. Joy, e D. T. Jones (2000). Applying agents to bioinformatics in geneweaver. In International Workshop on Cooperative Information Agents Vol. 1860, pp. $60-71$.

Cheng-Jian, L. e X. Yong-Ji (2005). A hybrid evolutionary learning algorithm for tsktype fuzzy model design. In Mathematical and Computer Modelling Vol. 43, No. 5, pp. $563-581$.

Chou, S. M., T. S. Lee, Y. E. Shao, e I. F. Chen (2004). Mining the breast cancer pattern using artificial neural networks and multivariate adaptive regression splines. In Expert Systems with Applications Vol. 27, pp. 133-142.

Coello, C. e G. Pulido (2001). Multiobjective optimization using a micro-genetic algorithm. In L. Spector, E. Goodman, A. Wu, W. Langdon, H. Voigt, M. Gen, S. Sen, M. Dorigo, S. Pezeshk, M. Garzon, e E. Burke (Eds.), Proceedings of the Genetic and Evolutionary Computation Conference (GECCO 2001), pp. 274-281. Morgan Kaufmann Publishers.

Cohen, B., S. Presnell, e F. Cohen (1993). Origins of structural diversity within sequentially identical hexapeptides. Protein Science Vol. 2, pp. 2134-2145.

Cohen, J. (2004). Bioinformatics an introduction for computer scientists. ACM Comput. Surv. Vol. 36 (no. 2), pp. 122-158.

Copeland, R. (1993). Methods for Protein Analysis - A pratical guide to laboratory protocols. M. Chapman e Hall. 
Corne, D., N. Jerram, J. Knowles, e M. Oates (2001). Pesa-ii: Region-based selection in evolutionary multiobjective optimization. In L. Spector, E. Goodman, A. Wu, W. Langdon, H. Voigt, M. Gen, S. Sen, M. Dorigo, S. Pezeshk, M. Garzon, e E. Burke (Eds.), Proceedings of the Genetic and Evolutionary Computation Conference (GECCO 2001), pp. 283-290. Morgan Kaufmann Publishers.

Corne, D., J. Knowles, e M. Oates (2000). The pareto envelope-based selection algorithm for multiobjective optimization. In K. Deb, X. Y. G. Rudolph, E. Lutton, J. J. Merelo, e H. P. Schwefel (Eds.), Proceedings of the Parallel Problem Solving from Nature VI Conference, pp. 839-848. Springer. Lecture Notes in Computer Science No. 1917.

Cui, Y., R. Chen, e W. Wong (1998). Protein folding simulation with genetic algorithm and supersecondary structure constraints. Proteins Vol. 31, pp. 247-257.

Cutello, V., G. Narzisi, e G. Nicosia (2005). A multi-objective evolutionary approach to the protein structure predicition problem. J. R. Soc. Interface Vol. 83, pp. 1-13.

Darwin, C. (1859). On the Origin of Species By Means of Natural Selection.

de Lima, T. W. (2006). Algoritmos Evolutivos para Predição de Estruturas de Proteínas. Dissertação de Mestrado, Instituto de Ciências Matemáticas e de Computação - ICMCUSP.

de Moura, L. (2002). Um Algoritmo Genético para Otmização Multi-Objetivo Fuzzy. Dissertação de Mestrado, Universidade Estadual de Campinas - Unicamp.

Deb, K. (2001). Multi-Objective Optimization using Evolutionary Algorithms. John Wiley and Sons.

Deb, K., S. Agrawal, A. Pratab, e T. Meyarivan (2000). A Fast Elitist Non-Dominated Sorting Genetic Algorithm for Multi-Objective Optimization: NSGA-II. KanGAL report 200001, Indian Institute of Technology, Kanpur, India.

Deb, K., S. Chaudhuri, e K. Miettien (2006). Towards estimating nadir objective vector using evolutionary approaches. In GECCO '06: Proceedings of the 8th annual conference on Genetic and evolutionary computation. 
Doolittle, R. (1986). Of URFs and ORFs: A Primer on How to Analyze Derived Amino Acid Sequences. University Science Books.

Doostfatemeh, M. e S. Kremer (2005). Biological sequence prediction using general fuzzy automata. In Proceedings of the 2005 IEEE Symposium on Computational Intelligence in Bioinformatics and Computational Biology, pp. 1-8.

Encyclopédia Britannica, P. S. (2007). Vilfredo pareto.

Eshelman, L. e J. Schaffer (1993). Real-coded genetic algorithms and interval schemata. In Foundations of Genetic Algorithms Vol. 2, pp. 187-202.

Ezziane, Z. (2006). Applications of artificial intelligence in bioinformatics: A review. In Expert System with Applications Vol. 30, pp. 2-10.

Farina, M. e P. Amato (2003). Fuzzy Optimality and Evolutionary Multiobjective Optimization. In Second International Conference, EMO 2003, Proceedings, pp. 58-73. Springer Berlin / Heidelberg.

Fogel, D. (1994). An introduction to simulated evolutionary computation. IEEE Transactions on Neural Networks Vol. 5, pp. 3-14.

Fogel, G. e D. Corne (2003). Evolutionary Computation in Bioinformatics. Morgan Kaufmann Publishers.

Fonseca, C. e P. Fleming (1993). Genetic Algorithms for Multiobjective Optimization: Formulation, Discussion and Generalization. In S. Forrest (Ed.), Proceedings of the Fifth International Conference on Genetic Algorithms, San Mateo, California, pp. 416423. University of Illinois at Urbana-Champaign: Morgan Kauffman Publishers.

Goldberg, D. E. (1989). Genetic Algorithms in Search, Optimization, and Machine Learning. Reading, MA: Addison-Wesley Publishing Company, Inc.

González, J., R. Ignacio, H. Pomares, L. Herrera, A. Guillén, e R. F. (2006). Improving the accuracy while preserving the interpretability of fuzzy function approximators by means of multi-objective evolutionary algorithms. In International Journal of Approximate Reasoning, Vol. 43, pp. 59-75. 
Gusfield, D. (2004). Introduction to the ieee/acm transactions on computational biology and bioinformatics. In IEEE/ACM Transactions on Computational Biology and Bioinformatics Vol. 1, pp. 2-3.

Haiming, L. e G. Gary (2003). Rank-density-based multiobjective genetic algorithm and benchmark test function study. In IEEE Transactions on Evolutionary Computation Vol. 7 , pp. $325-343$.

Hajela, P. e C. Y. Lin (1992). Genetic search strategies in multicriterion optimal design. Structural Optimization Vol. 4, pp. 99-107.

Handl, J., K. Douglas, e K. Joshua (2006). Multiobjective optimization in bioinformatics and computational biology. In IEEE Transaction on Computational Biology and Bioinformatics, pp. 1-28.

Haykin, S. (1999). Neural Networks - A Comprehensive Foundation. Prentice Hall.

Hilbert, M., G. Böhm, e R. Jaenicke (1993). Structural relationships of homologous proteins as a fundamental principle in homology modeling. Proteins Vol. 17, pp. 138151.

Holland, J. (1975). Adaptation in natural and artificial systems. University of Michigan Press.

Holland, J. (1992). Adaptation in natural and artificial systems. MIT Press.

Horn, J., N. Nafpliotis, e D. Goldberg (1994). A Niched Pareto Genetic Algorithm for Multiobjective Optimization. In Proceedings of the First IEEE Conference on Evolutionary Computation, IEEE World Congress on Computational Intelligence, Volume Vol. 1, Piscataway, New Jersey, pp. 82-87. IEEE Service Center.

Inbar, Y., H. Benyamini, R. Nussinov, e H. Wolfson (2003). Protein structure prediction via combinatorial assembly of sub-structural units. Bioinformatics Vol. 19, pp. 158-168.

Inbar, Y., H. Wolfson, e R. Nussinov (2005). Multiple docking for protein structure prediction. The International Journal of Robotics Research Vol. 24, pp. 131-150. 
Jiménez, F., J. Cadenas, G. Sánchez, A. Gómez-Skarmeta, e V. J. (2006). Multi-objective evolutionary computation and fuzzy optimization. In International Journal of Approximate Reasoning Vol., pp. 59-75.

Kabsch, W. e C. Sander (1983). Dictionary of protein secondary structure: pattern recognition of hydrogen bonded and geometrical features. Biopolymers Vol. 22, pp. $2577-2637$.

Karplus, M. e E. Shakhnovich (1992). Protein Folding, Chapter Protein Folding: Theorical Studies of Thermodynamics and Dynamics. W. H. Freeman and Company.

Khimasia, M. e P. Coveney (1997). Protein structure prediction as a hard optimization problem: the genetic algorithm approach. In Molecular Simulation Vol. 19.

Kita, H., Y. Yabumoto, N. Mori, e Y. Nishikawa (1996). Multi-Objective Optimization by Means of the Thermodynamical Genetic Algorithm. In H.-M. Voigt, W. Ebeling, I. Rechenberg, e H.-P. Schwefel (Eds.), Parallel Problem Solving from Nature-PPSN $I V$, Lecture Notes in Computer Science, Berlin, Germany, pp. 504-512. Springer-Verlag.

Kleeman, M. e G. Lamont (2005). Solving the aircraft engine maintenance scheduling problem using a multi-objective evolutionary algorithm. In Evolutionary Multi-Criterion Optimization Lecture Note in Computer Science Vol. 3410, pp. 782-796. Springer-Verlag Berlin, Heidelberg Platz.

Knowles, J. e D. Corne (1999). The Pareto Archived Evolution Strategy: A New Baseline Algorithm for Multiobjective Optimisation. In 1999 Congress on Evolutionary Computation, Washington, D.C., pp. 98-105. IEEE Service Center.

Koppen, M., R. Vicente-Garcia, e N. B. (2005). Fuzzy-pareto-dominance and its application in evolutionary multi-objective optimization. In Evolutionary Multi-Criterion Optimization Vol. 3410, pp. 399-412. Springer-Verlag Berlin Heidelberg.

Laumanns, M., G. Rudolph, e H.-P. Schwefel (1998). A Spatial Predator-Prey Approach to Multi-Objective Optimization: A Preliminary Study. In Parallel Problem Solving From Nature - PPSN V Vol. 1498, Amsterdam, Holland, pp. 241-249. Springer-Verlag. 
Leach, A. R. (2001). Molecular Modelling - Principles and Applications. Perason.

Lodish, H., A. Berk, P. Matsudaira, C. A. Kaiser, M. Krieger, e M. Scott (2004). Biologia Celular e Molecular. Artmed.

Markowetz, F., L. Edler, e M. Vingron (2003). Support vector machines for protein fold class prediction. In Biometrical Journal Vol. 45 no. 3, pp. 377-389.

Michalewicz, Z. (1996). Genetic algorithms + Data Structures = Evolution Programs. Springer-Verlag New York, Inc.

Michalewicz, Z. e M. Schoenauer (1996). Evolutionary algorithms for constrained parameter optimization problems. Evolutionary Computation Vol. 4, pp. 1-32.

Morse, P. M. (1929). Diatomic molecules according to the wave mechanics. ii. vibrational levels. Phys. Rev. Vol. 34 (no. 1), pp. 57-64.

Pedrycz, W. e F. Gomide (1998). An Introduction to Fuzzy Sets - Analysis and Design. MIT Press.

Peitsch, M. (2002). About the use of protein models. Bioinformatics Vol. 18, pp. 934-938.

Pendharkar, P. C., J. A. Rodger, G. J. Yaverbaum, N. Herman, e M. Benner (1999). Association, statistical, mathematical and neural approaches for mining breast cancer patterns. In Expert Systems with Applications, pp. 223-232.

Petsko, G. e D. Ringe (2004). Proteins Structure and Function. New Science Press Ltd.

Ponder, J. (2001). Tinker software tools for molecular design. washington university, saint louis.

Ramachandran, G. e V. Sasiskharan (1968). Conformation of polypeptides and proteins. Protein Chem. Vol. 23, 283-437.

Ripon, K., S. Sam, e K. Man (2007). A real-coding jumping gene genetic algorithm (rjgga) for multiobjective optimization. In Information Sciences Vol. 17 ry no. 2, pp. 632-654. Sciences. 
Rudolph, G. (2001). Evolutionary Search under Partially Ordered Fitness Sets. In Proceedings of the International NAISO Congress on Information Science Innovations (ISI 2001), pp. 818-822. ICSC Academic Press: Millet/Sliedrecht.

Schaffer, J. (1985). Multiple objective optimization with vector evaluated genetic algorithms. In Genetic Algorithms and their Applications: Proceedings of the First International Conference on Genetic Algorithms, pp. 93-100. Lawrence Erlbaum.

Schulz, G. e R. Schirmer (1979). Principles of Protein Structure. Springer-Verlag.

Silva Junior, C. e S. Sasson (2003). Biologia. Saraiva.

Srinivas, N. e K. Deb (1994). Multiobjective Optimization Using Nondominated Sorting in Genetic Algorithms. Evolutionary Computation Vol. 2(no. 3), pp. 221-248.

Takagi, T. e M. Sugeno (1985). Fuzzy identification of systems and its applications to modeling and control. In IEEE Transactions on Systems, Man, and Cybernetics. Vol. $S M C-15$, pp. 116-132.

Tan, A. C. e D. Gilbert (2003). An empirical comparison of supervised machine learning techniques in bioinformatics. In Proceedings of the first Asia-Pacific bioinformatics conference on Bioinformatics, pp. 219-222.

Ticona, W. G. C. (2003). Aplicação de Algoritmos Genéticos Multiobjetivos para Alimento de Seqüências Biológicas. Dissertação de Mestrado, Instituto de Ciências Matemáticas e de Computação - ICMC-USP.

Tsunoda, D. F. (2004). Abordagens Evolucionárias Para a Descoberta de Padrões e Classificação de Proteínas. Tese de Doutorado, Centro Federal de Educação Tecnológica do Paraná.

Veldhuizen, D. (1999). Multiobjective Evolutionary Algorithms: Classifications, Analyses, and New Innovations. Tese de Doutorado, Department of Electrical and Computer Engineering. Graduate School of Engineering. Air Force Institute of Technology, WrightPatterson AFB, Ohio. 
Voget, S. e M. Kolonko (1998). Multidimensional optimization with a fuzzy genetic algorithm. In Journal of Heuristics Vol. 4, pp. 221-244.

Vullo, A. (2002). On the role of machine learning in protein structure determination. AIIA.

Wangshu, Y., S. Chen, e Z. Chen (2006). Sdmoga: A new multi-objective genetic algorithm based on objective space divided. In The 13th International Conference on Neural Information Processing (ICONIP) Vol. 3, pp. 754-762.

Wiebringhaus, T., C. Igel, e J. Gebert (2004). Protein fold class prediction using neural networks with tailored early-stopping. In Proceedings of the 2004 IEEE International Joint Conference on Neural Networks, pp. 1693-1697.

Wilson, I., D. Haft, E. Getzoff, J. Tainer, R. Lerner, e S. Brenner (1985). Identical short peptide sequences in unrelated proteins can have different conformations: A testing ground for theories of immune recognition. Proc. Natl. Acad. Sci. Vol. 82, pp. 52555259.

Zadeh (1973). Outline of a new approach to the analysis of complex systems and decision processes. In IEEE Transactions on Systems Vol. SMC-3, pp. 28-44.

Zadeh (1992). Fuzzy logic, neural networks and soft computing. In Proceedings of the 2nd International Conference on Fuzzy Logic and Neural Networks, pp. 13-14.

Zitzler, E., K. Deb, e L. Thiele (2000). Comparison of Multiobjective Evolutionary Algorithms: Empirical Results. Evolutionary Computation Vol. 8(No. 2), pp. 173-195.

Zitzler, E., M. Laumanns, e L. Thiele (2001). SPEA2: Improving the Strength Pareto Evolutionary Algorithm. Technical Report no. 103, Computer Engineering and Networks Laboratory (TIK), Swiss Federal Institute of Technology (ETH) Zurich, Gloriastrasse 35, CH-8092 Zurich, Switzerland.

Zitzler, E. e L. Thiele (1998). An Evolutionary Algorithm for Multiobjective Optimization: The Strength Pareto Approach. Technical Report no. 43, Computer Engineering and Communication Networks Lab (TIK), Swiss Federal Institute of Technology (ETH), Zurich, Switzerland. 


\section{Apêndice A}

\section{Toolbox Fuzzy Logic}

Esta dissertação utilizou o toolbox Fuzzy Logic do Matlab. Tal toolbox consiste de uma coleção de funções construídas sobre o ambiente do Matlab, permitindo assim uma maneira fácil de criar e editar sistemas de inferêncria Fuzzy dentro do framework do Matlab, além da possibilidade de programas escritos em linguagem $\mathrm{C}$ executar funções construídas dentro do Matlab.

Para se utilizar um sistema de inferência Fuzzy, este não necessita já estar modelado completamente. Mesmo possuindo somente um conjunto de dados quantitativos é possível criar um sistema de inferência Fuzzy. Uma possível abordagem para criar tal sistema de inferência é denominada ANFIS (Adaptive Neuro-Fuzzy Inference System). O ANFIS será detalhado na Seção A.2.

O ambiente do Matlab, além de gerar um sistema Fuzzy, se permite visualizar e, até mesmo, ajustar ("refinar") um sistema Fuzzy. Tendo então esta necessidade, se pode utilizar a ferramenta do Matlab conhecida como toolbox Fuzzy Logic. A Seção A.1 será responsável pela explanação deste toolbox.

É importante ressaltar que a compilação deste apêndice é todo baseado no guia de usuário (user's guide) do Matlab, o mesmo apresenta de forma bem didática todos os principais aspectos envolvidos com o toolbox fuzzy logic. 


\section{A.1 Toolbox Fuzzy Logic do Matlab}

O Toolbox Fuzzy Logic do Matlab consiste de seis componentes. Além do editor ANFIS, o qual será detalhado na Seção A.2, possui ainda os editores: de regras (Rule Editor), o editor das funções de pertinência (Membership Function Editor) e o editor de Sistema de Inferência Fuzzy (FIS) ${ }^{1}$. Acrescenta-se ainda neste Toolbox os visualizadores de regras (Rule Viewer) e superfície (Surface Viewer). A Figura A.1 evidencia a visualização de um esquema para uma melhor compreensão referentes aos componentes constituintes do Toolbox Fuzzy Logic do Matlab. Neste esquema, somente adiciona-se o editor ANFIS. A seguir será discutido, brevemente, cada um destes componentes.

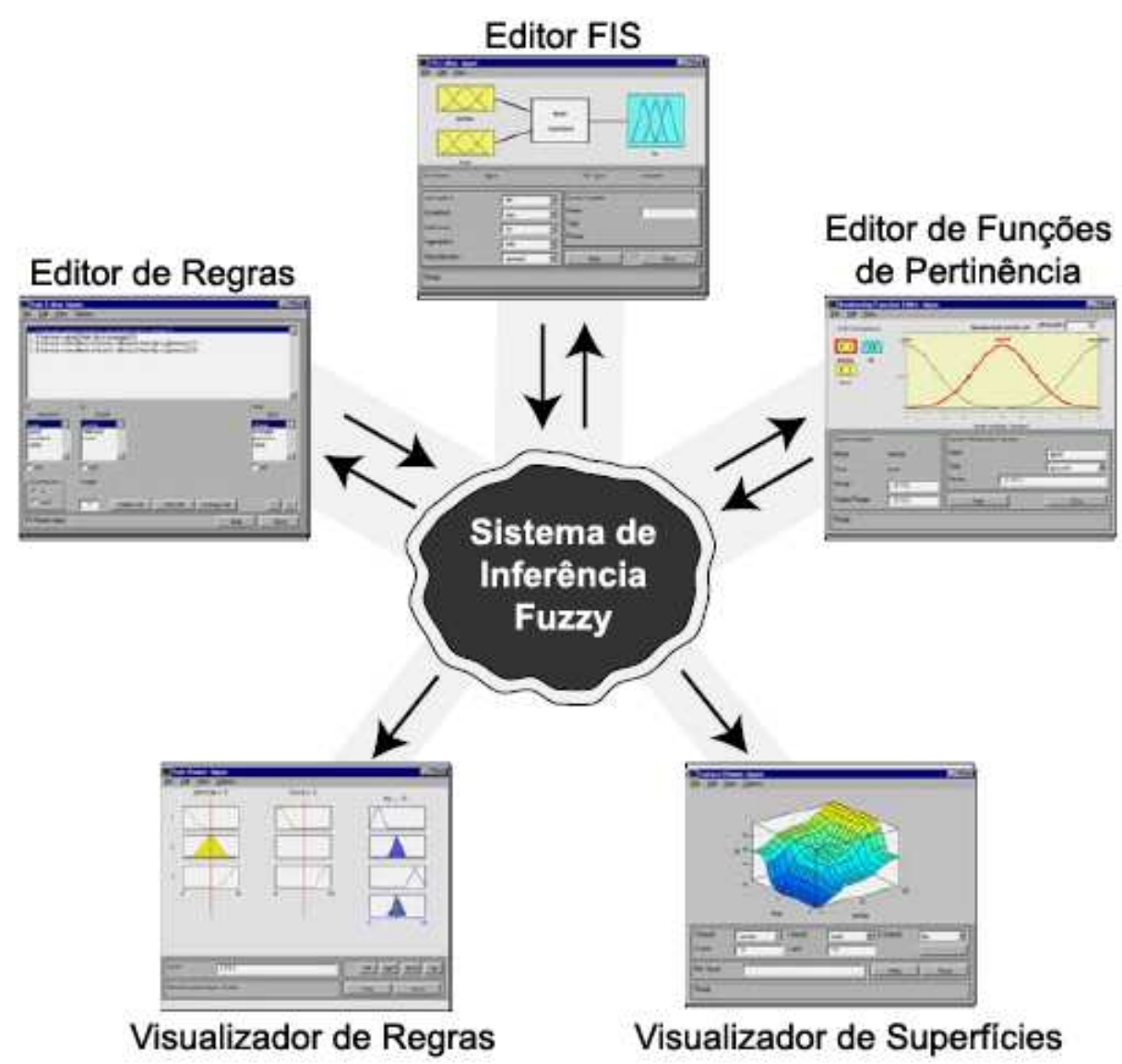

Figura A.1: Esquema dos componentes constituíntes do Toolbox Fuzzy Logic do Matlab.

O primeiro componente a ser abordado é o editor FIS. É finalidade deste editor ilustrar as informações, de forma resumida, referente a um sitema de inferência Fuzzy, por exem-

\footnotetext{
${ }^{1}$ do inglês, Fuzzy Inference System.
} 
plo, um sistema Fuzzy construído a partir da técnica ANFIS. Ou seja, o ANFIS ajusta as funções de pertinência e, também, cria as regras de tal sistema e, então, utilizando este editor se consegue visualizar o sistema gerado a partir da técnica ANFIS. Para se obter a tela do editor FIS, basta digitar o comando "fuzzy" na janela de comando no Matlab. Após a execução deste comando, torna-se possível visualizar a ilustração da Figura A.2, a qual consiste na tela inicial deste editor.

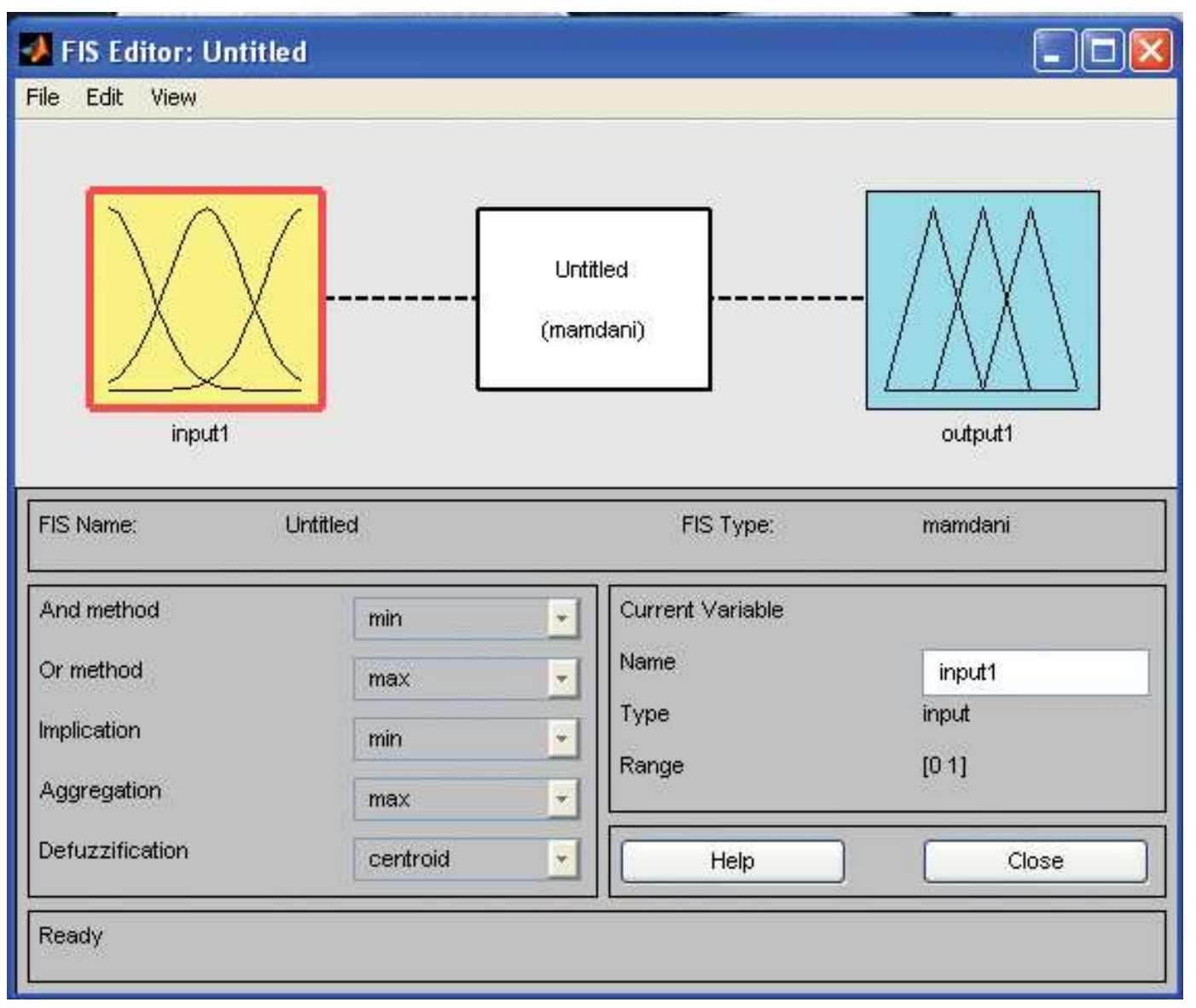

Figura A.2: Tela inicial do editor FIS.

Para se obter a visualização de um sistema de inferência Fuzzy, basta abrir o arquivo FIS do sistema Fuzzy. O arquivo FIS contém todas as informações de um sistema Fuzzy, sendo que o editor FIS apenas mostra o conteúdo deste arquivo de uma maneira mais interativa.

Torna-se possível, através do editor de funções de pertinência, gerenciar as funções de pertinência do sitema Fuzzy, ou seja, permite editar e visualizar todas as funções de pertinência. A Figura A.3 exibe a tela inicial deste editor. 


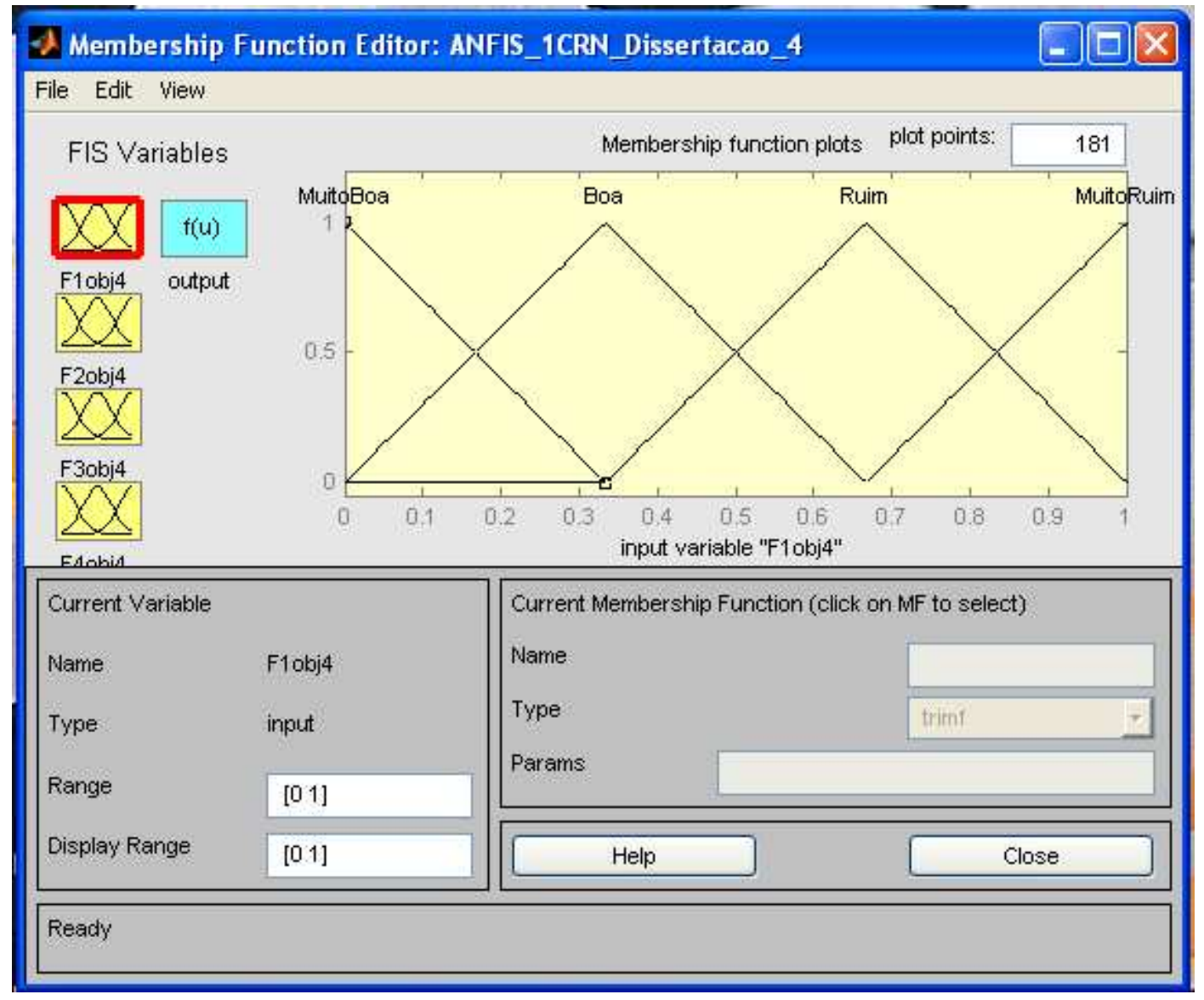

Figura A.3: Tela inicial do editor das funções de pertinência.

Já o editor de regras tem como finalidade proporcionar um fácil ambiente para trabalhar com as regras do sistema Fuzzy, permitindo construir, modificar, deletar e ignorar regras. Assim sendo, a Figura A.4 ilustra a tela do editor contendo as regras do sistema Fuzzy proposto com quatro entradas.

Para visualizar as regras do sistema Fuzzy, recorre-se ao componente do toolbox Fuzzy Logic conhecido como visualizador de regras. Assim sendo, a Figura A.5 permite visualizar as regras, as quais foram determinadas no editor de regras Fuzzy descrito anteriormente.

Por fim, o toolbox Fuzzy Logic do Matlab possui o componente para visualizar as superfícies. Este visualizador tem como objetivo criar uma curva tridimensional para representar o mapeamento das entradas do sistema Fuzzy. Para os sistemas com mais de três entradas e uma saída, como apresentado nesta dissertação, por exemplo, o visualizador consegue gerar uma superfície de saída tridimensional, pois os monitores dos computadores são incapazes de plotar uma superfície com cinco dimensões. Portanto, o visualizador 


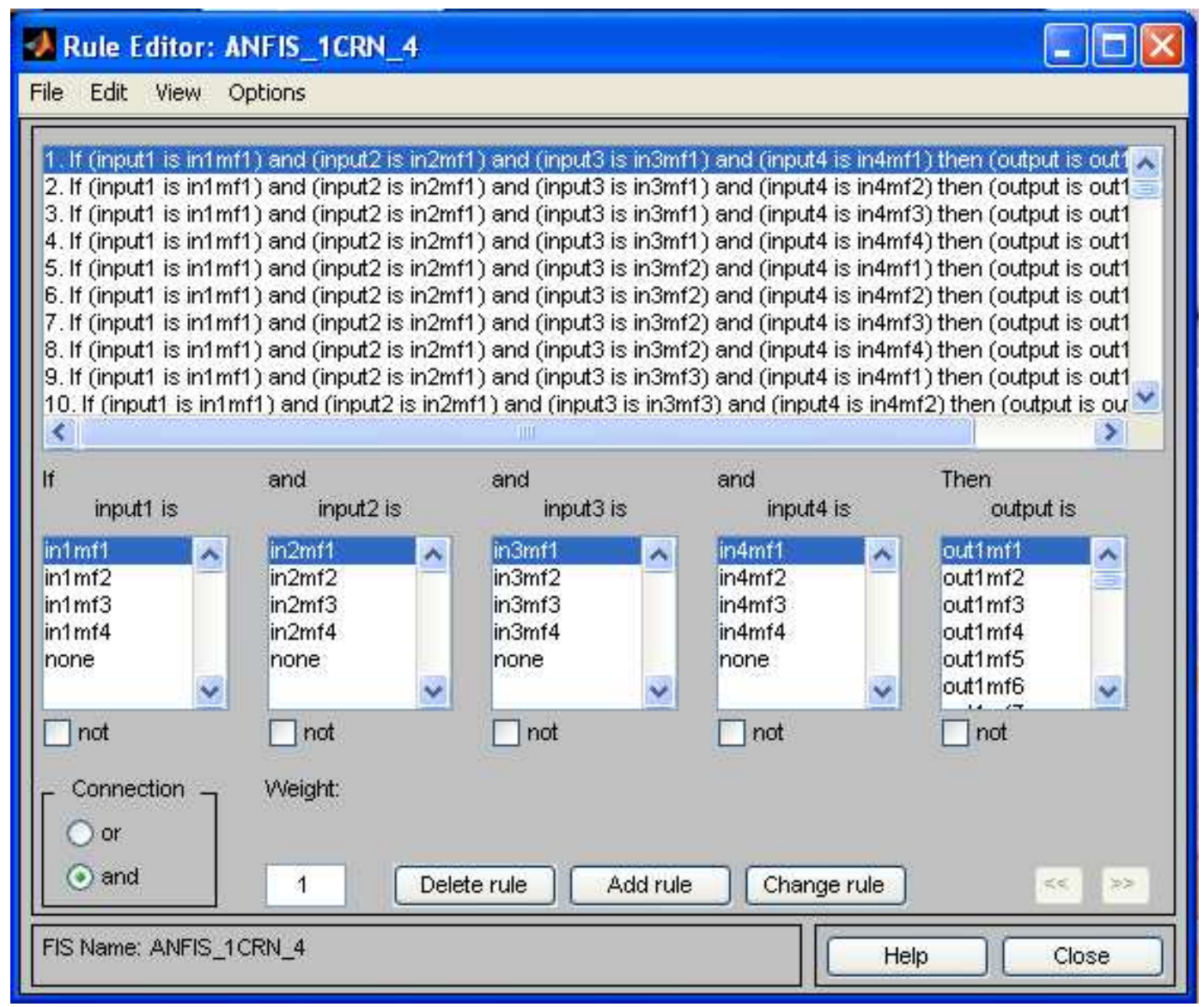

Figura A.4: Editor de regras ilustrando regras do sistema proposto com quatro entradas.

permite que selecione duas das entradas e as demais serão consideradas como constante. Para ilustrar a tela desse visualizador, esta será apresentada juntamente com uma das superfícies já demonstratada neste trabalho. Assim, a Figura A.6 evidencia o referido visualizador.

\section{A.2 Técnica ANFIS}

Torna-se possível, mesmo contendo somente dados quantitativos, modelar um sistema de inferência Fuzzy. O ANFIS consiste de uma das possíveis técnicas para tal procedimento, além de que é bem simples sua utilização. Assim sendo, investigar sua aplicabilidade evidencia uma tarefa extremamente relevante quando seus dados são disponibilizados da forma quantitativa e houver a necessidade de se gerar um sistema de inferência Fuzzy.

Com um conjunto de dados quantitativos contendo as entradas e sua respectiva saída 


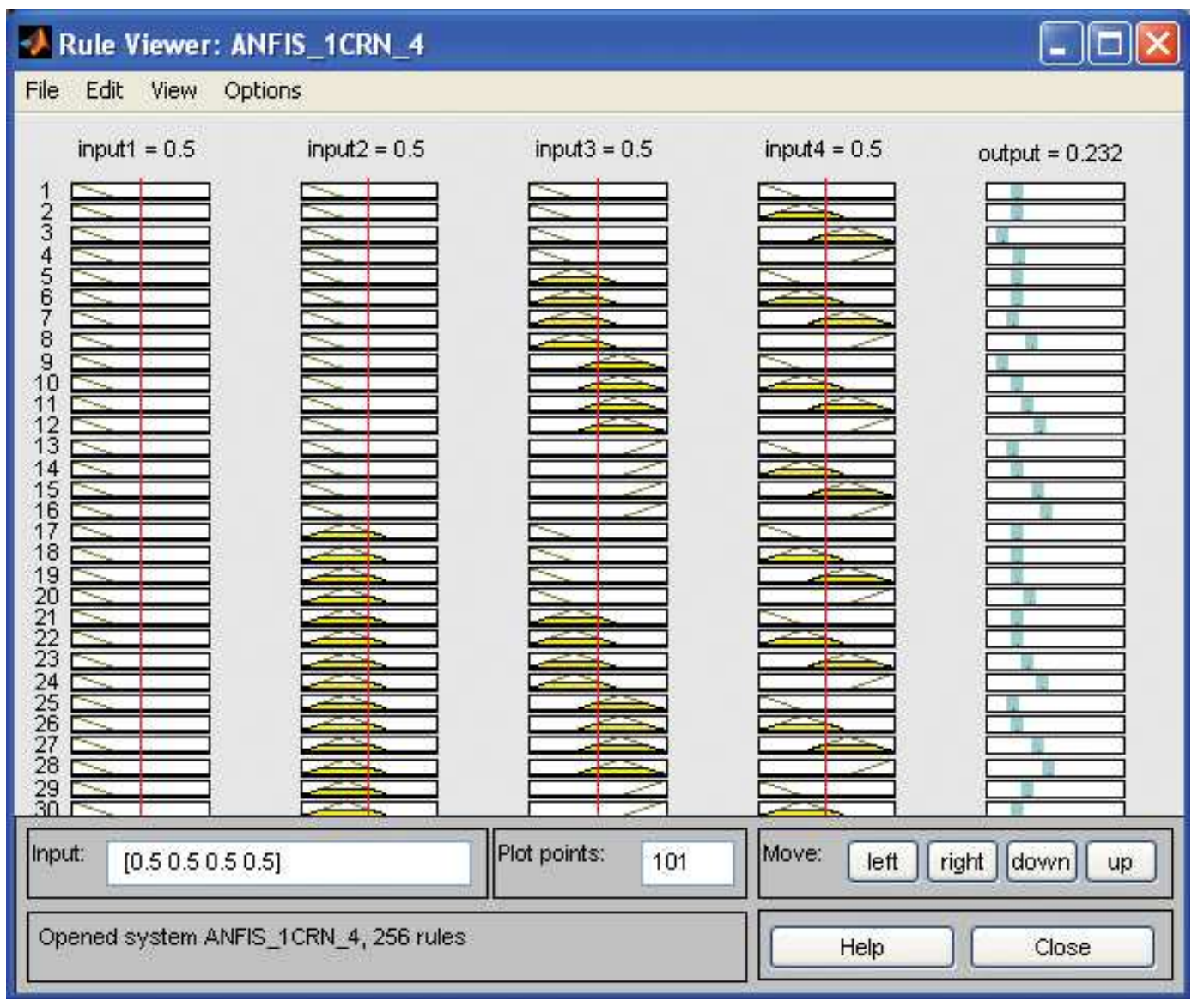

Figura A.5: Visualização das regras do sistema proposto com quatro entradas.

desejada, é possível obter um sistema de inferência Fuzzy já ajustado com suas funções de pertinência e regras. Sendo assim, pode-se afirmar que as regras e as funções de pertinência foram geradas de forma automática.

Para se utilizar a técnica ANFIS no Matlab há duas maneiras: Primeira, através de uma interface gráfica conhecida como editor $\mathrm{GUI}^{2}$ e, a segunda, através de linha de comando. Ressalta-se que a primeira possibilidade é uma maneira interativa, porém para se conseguir flexibilidade há a necessidade de utilizar o ANFIS por linha de comando. Portanto, decidir qual das abordagens utilizar dependerá, antes de tudo, da experiência e necessidade do usuário.

A seguir, será detalhada tais possibilidades para se trabalhar com o ANFIS. A Seção A.2.1 ilustra o editor GUI do ANFIS e, conseqüentemente, a Seção A.2.2 abordará o ANFIS por linha de comando.

\footnotetext{
${ }^{2}$ do inglês, Graphical User Interface
} 


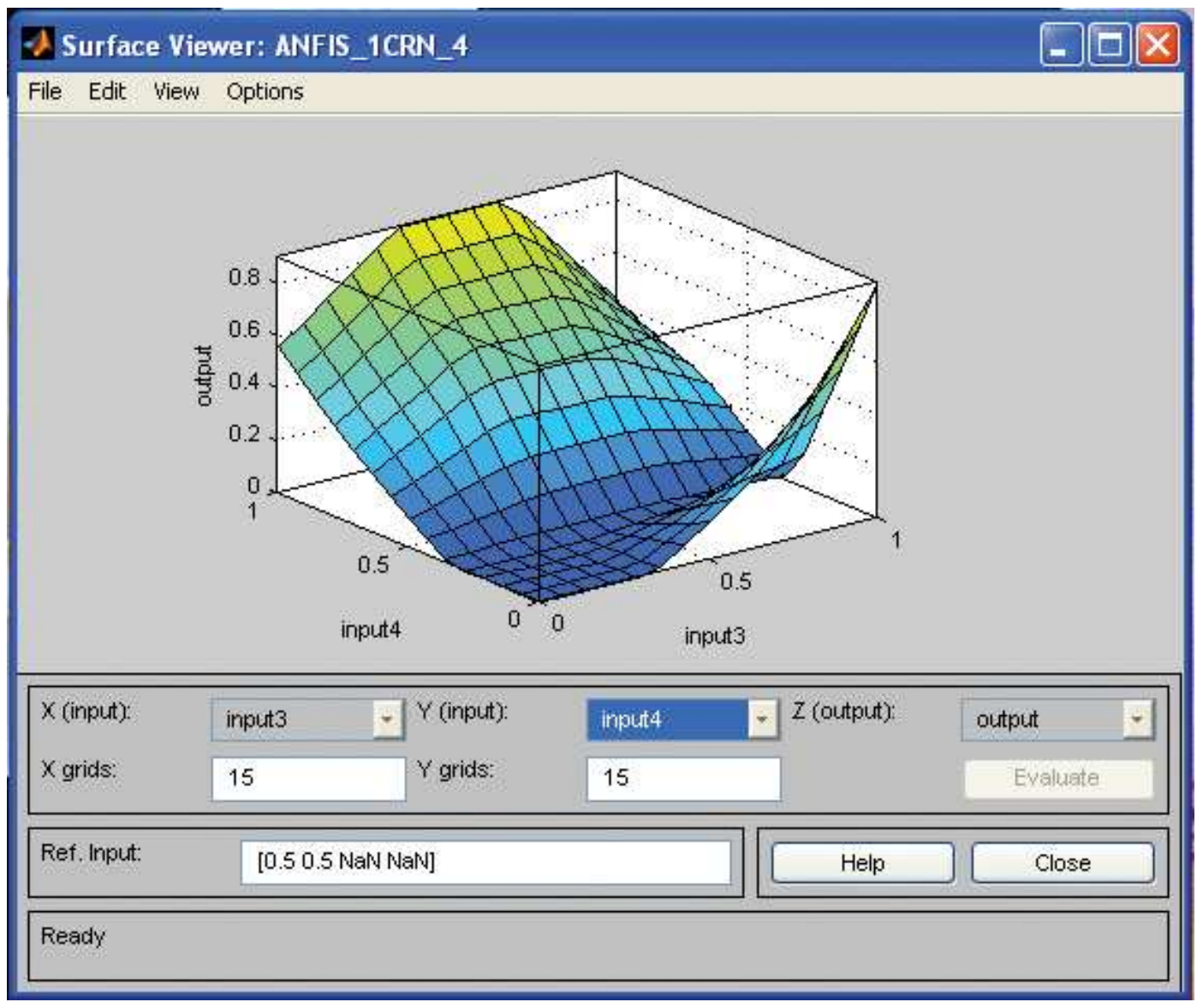

Figura A.6: Visualizador de superfícies.

\section{A.2.1 Editor GUI ANFIS}

Para iniciar o editor GUI do ANFIS basta digitar "anfisedit" na janela de comandos do Matlab. A Figura A.7 ilustra a tela inicial do referido editor.

Nota-se a partir da Figura A.7, a interatividade obtida pelo editor GUI. As etapas de todo o processo da técnica ANFIS estão agrupadas de maneira cronológica de execução. Visualmente, nota-se uma separação decorrida de agrupamento de campos limitados entre retângulos.

O primeiro retângulo consiste no carregamento (Load) dos dados (Data). Os dados podem ser então: Treinamento (Training), Teste (Testing) e Checagem (Checking). Estes tipos de dados podem ser carregados a partir do disco ou até mesmo da Workspace.

O segundo retângulo, denotado por Generate FIS, consiste na etapa de geração do sistema de inferência. Sendo assim, é possível nesta etapa informar dois parâmetros es- 


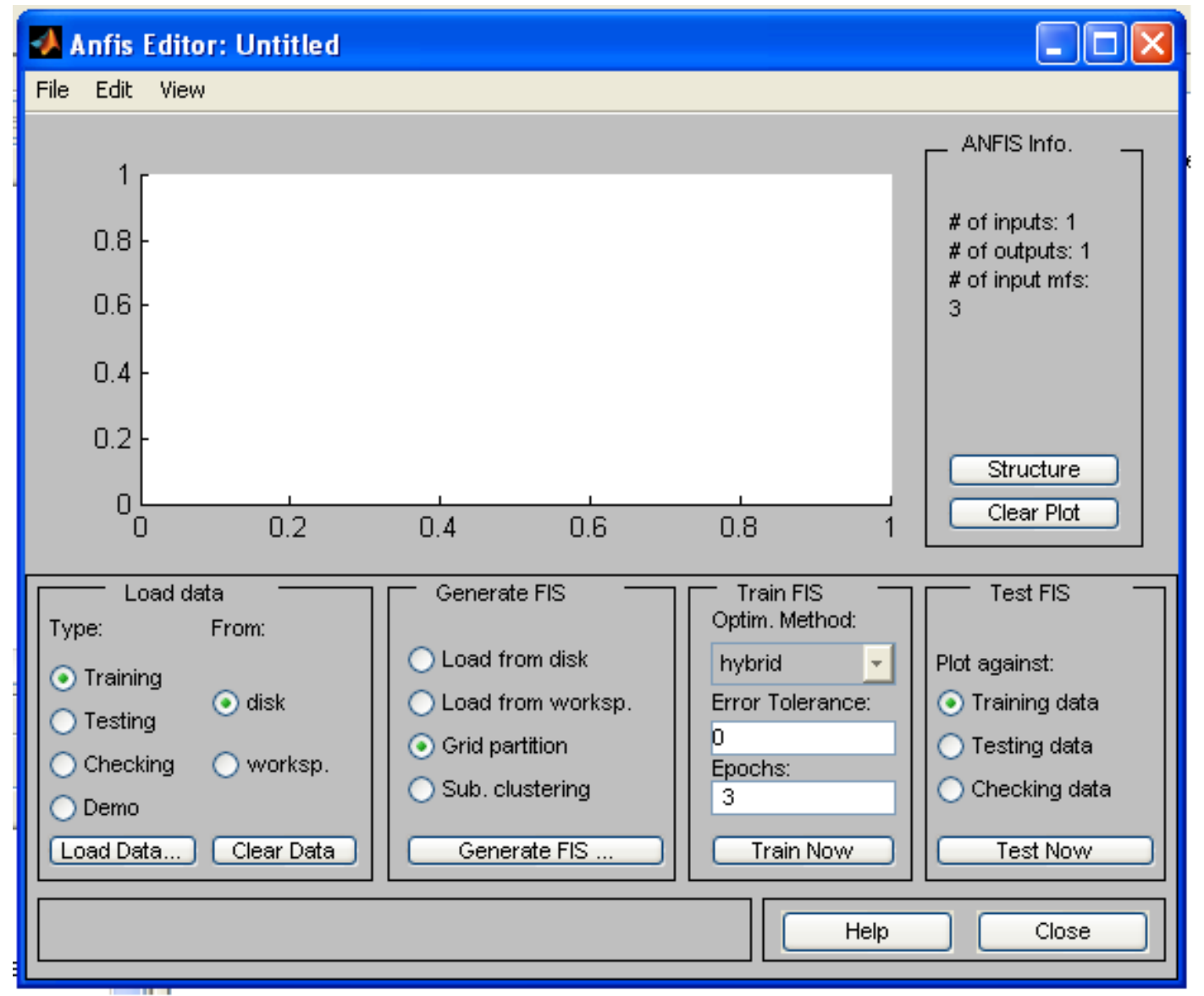

Figura A.7: Tela inicial do editor GUI ANFIS.

senciais para o decorrer da técnica, sendo eles: função de pertinência e o tipo de saída. Para a função de pertinência torna-se possível selecionar qual função utilizar, tendo como algumas possibilidade escolher, por exemplo, se será função Triangular (trimf) ou Gaussiana (gaussmf). Já o tipo de saída, uma vez que a técnica ANFIS baseia na metodologia Takagi-Sugeno, apresenta duas opções: a primeira denotada por constante (constant) e a segunda por linear. A Figura A.8 ilustra a tela onde se pode determinar esses dois parâmetros.

Para efetuar a geração do sistema de inferência Fuzzy há a necessidade, ainda, de informar qual será o método de otimização (Optim. Method), tolerância de erros (Error Tolerance) e o número de épocas (Epochs). A determinação desses parâmetros fica na responsabilidade do terceiro retângulo (Train FIS). Com relação ao método de otimização, tem-se como opção para o treinamento o algoritmo Backpropagation e um misto (combinação) entre estimação de mínimos quadrados com o Backpropagation, também 


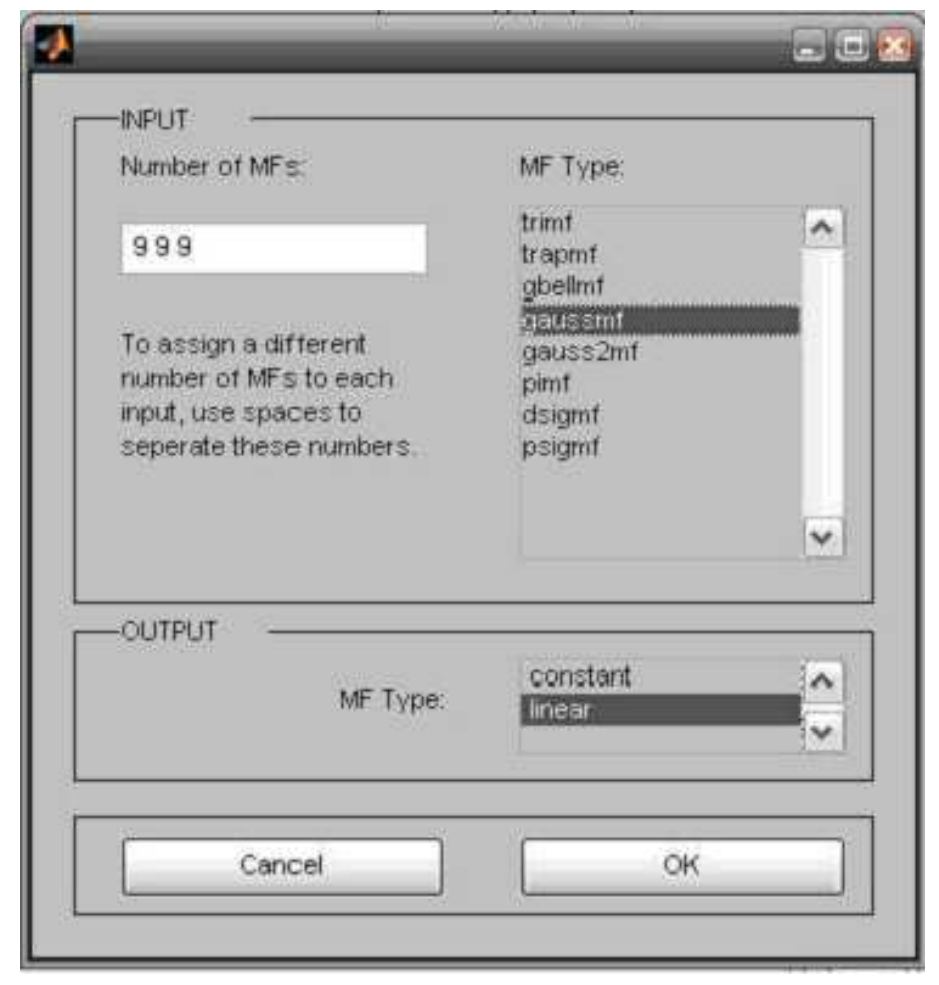

Figura A.8: Editor para determinar parâmetros essenciais.

conhecido como método híbrido (hybrid). Já informando a tolerância de erros e o número de épocas, consegue-se determinar os critérios de parada para o treinamento.

Finalmente, no quarto retângulo (Test FIS), consegue-se executar o procedimento de validação do sistema de inferência Fuzzy.

A estrutura e os parâmetros de ajuste do toolbox ANFIS baseia em uma estrutura similar a de uma rede neural utilizada para associar as entradas/saídas mapeando assim as funções de pertinência. Durante o processo de aprendizagem, tais parâmetros podem ser alterados (ajustados) através do vetor gradiente, sendo esta a medida para avaliar o quão bem está sendo o mapeamento das entradas/saídas do conjunto de parâmetros. A Figura A.9 evidencia um caso de exemplo da estrutura utilizada pelo ANFIS.

Observa-se na Figura A.9 a similaridade da estrutura do ANFIS com uma rede neural. É ilustrado nesta figura uma estrutura ANFIS contendo três entradas e uma saída. 


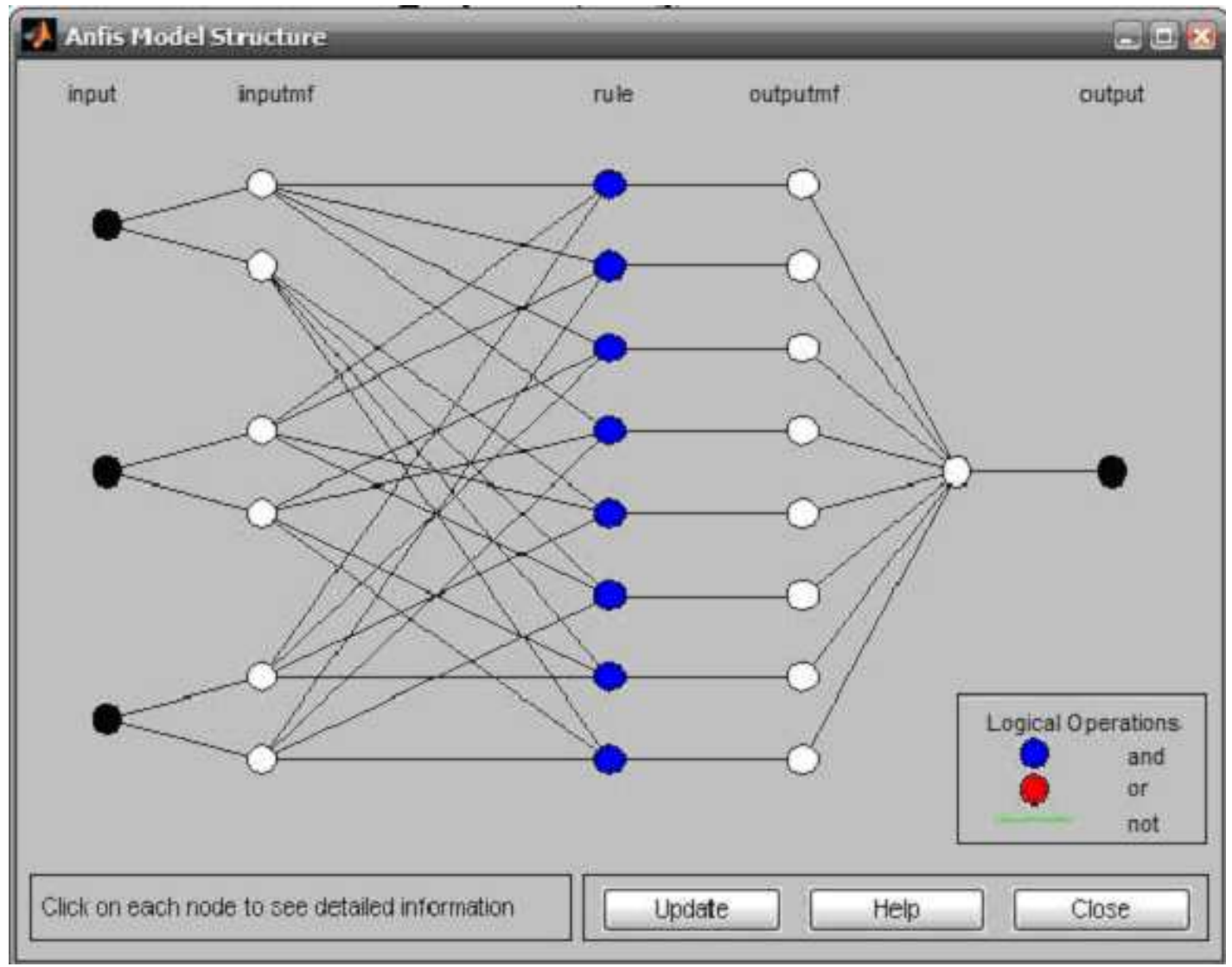

Figura A.9: Estrutura utilizada pelo ANFIS.

\section{A.2.2 ANFIS por Linha de Comando}

Entende-se ANFIS por linha de Comando a possibilidade de executar e parametrizar a sua estruturab da mesma forma que o editor GUI permite. Contudo, tem-se aqui a flexibilidade de trabalhar diretamente com os comandos que são executados pelo editor.

A técnica ANFIS tendo sido já detalhada na Seção A.2.1, torna-se relevante nesta seção apenas abordar os comandos, os quais serão ilustrados a seguir. É importante ressaltar que tais comandos abordados serão somente os comandos da técnica ANFIS.

O primeiro comando, o genfis1, inicia o processo de treinamento gerando as funções de pertinência iniciais cobrindo todo o espaço de busca. Este comando recebe como parâmetro de entrada três valores, sendo respectivamente: o arquivo com os dados quantitativos de entrada e sua saída, o número de funções de pertinência e, por último, o tipo de função de pertinência.

Já o comando anfis tem a finalidade de ajustar as funções de pertinência geradas 
inicialmente pelo comando genfis1. A quantidade de parâmetros constitui em seis e são, respectivamente: os dados de entrada, a saída gerada pelo comando genfis1, as opções de treinamento (épocas, tolerância, etc), tratamento das mensagens durante e após o processo de treinamento (este parâmetro só existe por linha de comando) e finalmente, determinar qual método (algoritmo) de treinamento será utilizado. 
